\title{
WestVirginiaUniversity
}

THE RESEARCH REPOSITORY @ WVU

Graduate Theses, Dissertations, and Problem Reports

2021

\section{Shutting the Door on Voting: The Effects of "The Great Poll Closure"}

Joshua Matthew Squires

West Virginia University, jsquire2@mix.wvu.edu

Follow this and additional works at: https://researchrepository.wvu.edu/etd

Part of the American Politics Commons

\section{Recommended Citation}

Squires, Joshua Matthew, "Shutting the Door on Voting: The Effects of "The Great Poll Closure"'" (2021). Graduate Theses, Dissertations, and Problem Reports. 8294.

https://researchrepository.wvu.edu/etd/8294

This Dissertation is protected by copyright and/or related rights. It has been brought to you by the The Research Repository @ WVU with permission from the rights-holder(s). You are free to use this Dissertation in any way that is permitted by the copyright and related rights legislation that applies to your use. For other uses you must obtain permission from the rights-holder(s) directly, unless additional rights are indicated by a Creative Commons license in the record and/ or on the work itself. This Dissertation has been accepted for inclusion in WVU Graduate Theses, Dissertations, and Problem Reports collection by an authorized administrator of The Research Repository @ WVU.

For more information, please contact researchrepository@mail.wvu.edu. 
Shutting the Door on Voting: The Effects of "The Great Poll Closure"

Joshua Matthew Squires

Dissertation submitted

to the Eberly College of Arts and Science

at West Virginia University

in partial fulfillment of the requirements for the degree of

a Ph.D. in Political Science

Matthew L. Jacobsmeier, Ph.D., Chair

John C. Kilwein, Ph.D.

Erik S. Herron, Ph.D.

Rachael A. Woldoff, Ph.D.

Department of Political Science

Morgantown, West Virginia

2021

Keywords: election administration, voter turnout

Copyright 2021 Joshua Matthew Squires 


\begin{abstract}
Shutting the Door on Voting:

The Effects of "The Great Poll Closure"
\end{abstract}

Joshua Matthew Squires

The 2016 election was the first presidential election following the landmark Shelby County $v$. Holder (2013) case that invalidated Section 4(b) of the Voting Rights Act of 1965. The decision in Shelby meant that certain jurisdictions with histories of racial discrimination no longer needed permission or "preclearance" from the federal government before making changes to election administration procedures. Perhaps not coincidentally, voting jurisdictions across the United States also saw a record number of polling place closures - especially in formerly preclearance areas. Past research has studied the effects of precinct closures on voter turnout in individual counties and at the state level, but never nation-wide - which is where this research differs. Using precinct data from over 2,270 voting jurisdictions across the United States, I answer the following questions: (1) who determines the location of polling places?; (2) which jurisdictions are more likely to close polling places?; (3) what types of citizens are most affected by the location and relocation of polling places? The goal of this project is to better our understanding of the causes of precinct closures, the types of jurisdictions that close precincts most frequently, and the characteristics of citizens who are most affected by precinct closures. I expect my work to make significant contributions to the study of electoral administration, constitutional law, voting behavior, and racial and ethnic politics. 


\section{Dedication}

I dedicate this work to my wife, Danielle Squires, my parents, Matt and Jodi Squires, and my sister, Hannah Squires. 


\section{Acknowledgment}

I would like to acknowledge my dissertation advisor, Dr. Matthew Jacobsmeier, for helping me through this process. Your willingness to never give up on me these past six years is one of the main reasons I was able to complete this project. I also want to acknowledge the rest of my dissertation committee: Dr. John C. Kilwein, Dr. Erik S. Herron, and Dr. Rachael A. Woldoff. Thank you for giving me feedback and guidance along the way. I would also like to thank my wife, my parents, family, and friends for supporting me through this whole process. 


\section{Table of Contents}

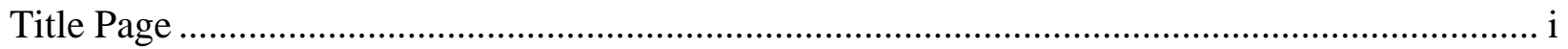

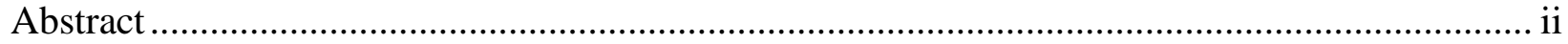

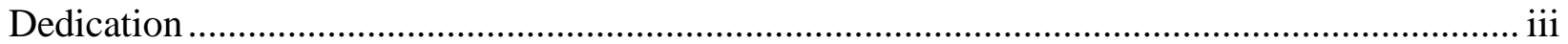

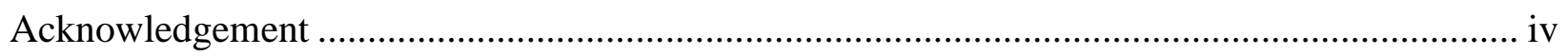

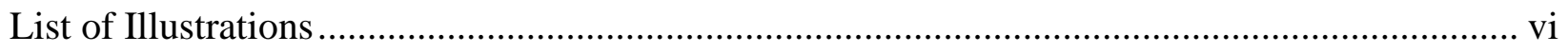

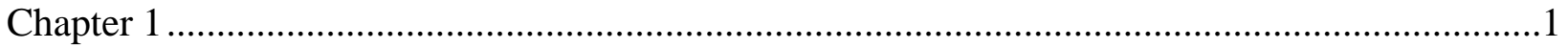

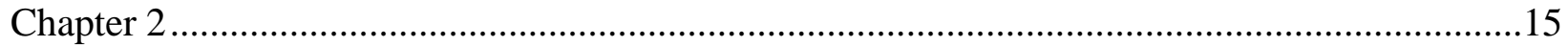

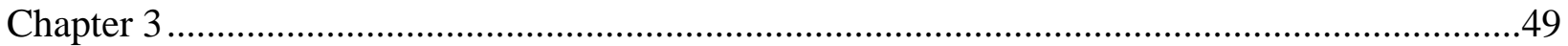

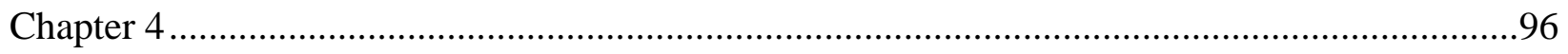

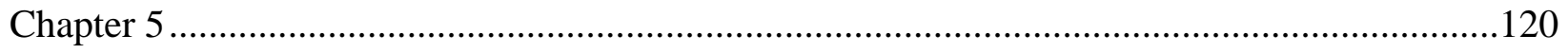

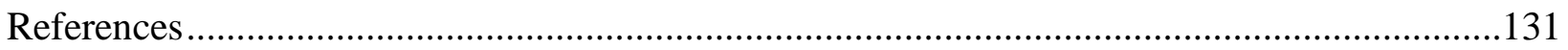

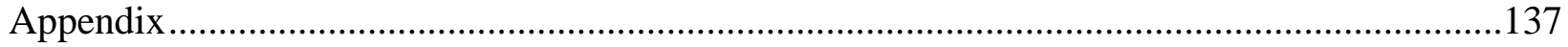




\section{List of Tables and Figures}

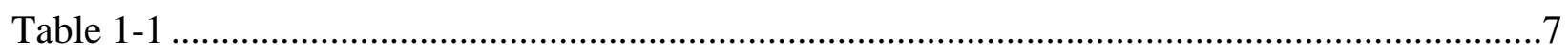

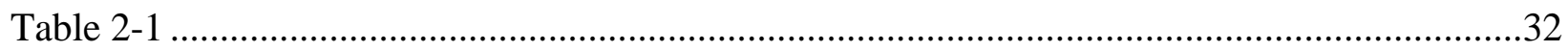

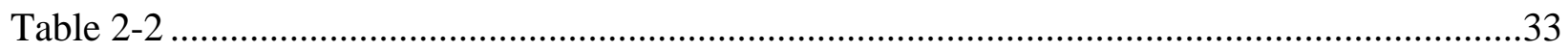

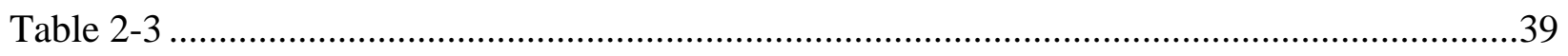

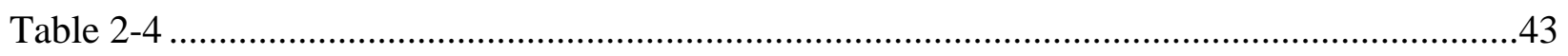

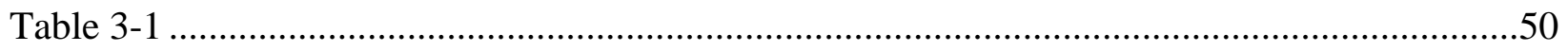

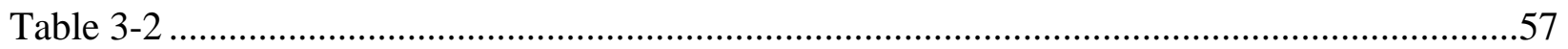

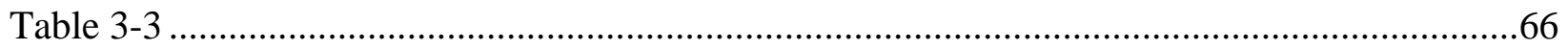

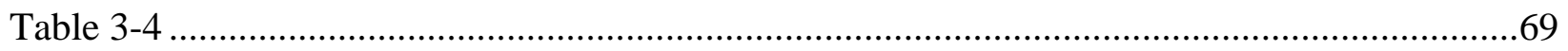

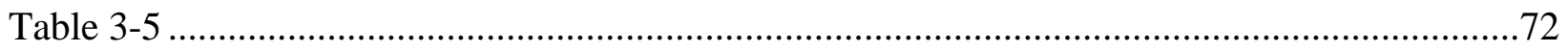

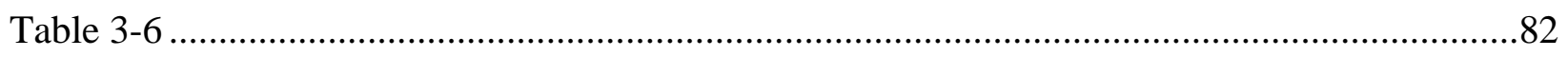

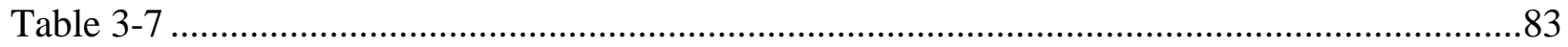

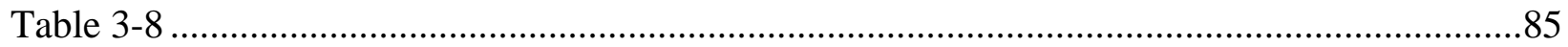

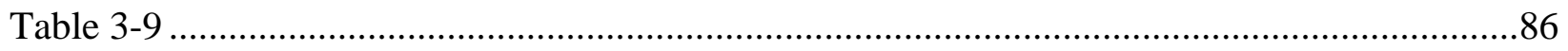

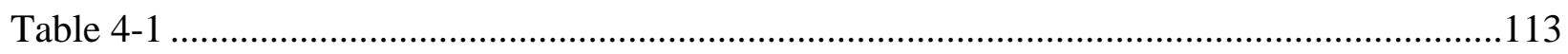

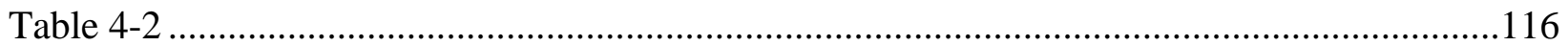

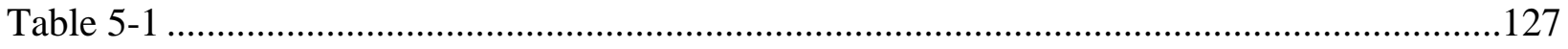

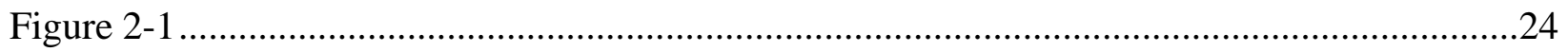

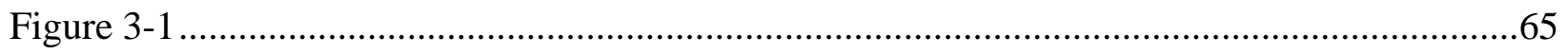

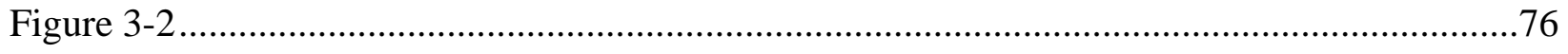

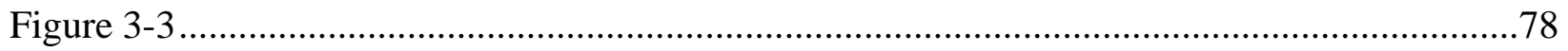

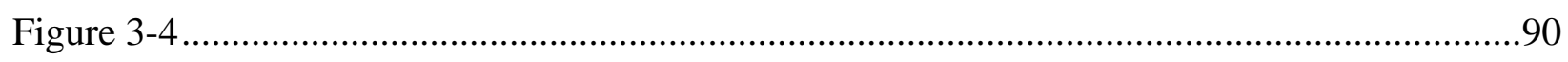

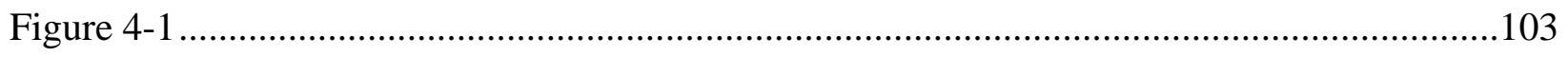

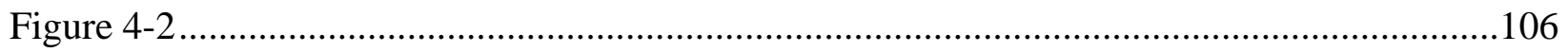

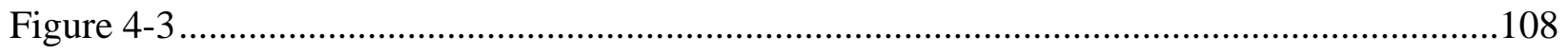




\section{CHAPTER 1: Introduction}

The 2016 presidential election was the first general election following the landmark Shelby County v. Holder (2013) case that invalidated the 4th section of Voting Rights Act (VRA) of 1965. For the first time since 1964, the United States held elections without the full protection of the VRA. Perhaps not coincidentally, 2016 also saw a record number of polling place closures across the United States. The Leadership Conference Education Fund (LCEF) named this phenomenon "The Great Poll Closure". ${ }^{1}$ Of the large number of closures, the LCEF found that roughly 800 belonged to counties that were formerly under preclearance. To analyze The Great Poll Closure, I draw from three different areas of study within political science: constitutional law, political institutions, and political behavior. My first research chapter outlines the processes of closing precincts according to each states' election statutes. My second chapter determines which factors contributed to voting jurisdictions' closing polling places following Shelby. My third (and final substantive chapter) looks at the effects of poll closures on county-level turnout.

\section{Shelby County v. Holder}

In terms of ensuring the voting rights for non-white ${ }^{2}$ citizens, many scholars have argued that the 4th and 5th sections of the VRA were the act's most important sections (MacCoon 1979; Motomura 1982); they were also the sections that were up for debate in Shelby. Both sections worked in tandem to ensure that certain states and counties with histories of voter discrimination would uphold the standards of the Voting Rights Act. Section 5 (also known as preclearance)

\footnotetext{
1 The Leadership Conference Education Fund. 2016. "The Great Poll Closure”. http://civilrightsdocs.info/pdf/reports/2016/poll-closure-report-web.pdf

${ }^{2}$ According to the most recent American Political Science Association style guide, names of ethnic and national groups are capitalized. Black and Indigenous, when referring to race, are also capitalized. With that, I will be capitalizing Hispanic and Black in this dissertation. White will be lowercased which is also stated in the updated APSA style guide. Please see this link for other questions: https://mk0apsaconnectbvy6p6.kinstacdn.com/wp-content/uploads/sites/43/2020/07/Style-Manualfor-Political-Science-July-2020-Revision.pdf.
} 
required that areas with histories of discrimination receive federal approval by either the U.S. Department of Justice- Civil Rights Office or the District Court for the District of Columbia for all election administration changes, whereas Section 4(b) (also known as the coverage formula) created a "coverage" formula to determine which states/counties would need to receive preclearance. If a state/county met the criteria set forth by the coverage formula, that jurisdiction would be referred to as a preclearance jurisdiction.

To provide some context as to how preclearance and the coverage formula of the VRA were challenged in front of the Supreme Court in 2013, I believe it is necessary to first understand why Shelby County became the plaintiff and the poster-county for the unraveling of the nation's most important piece of voter discrimination legislation. In the next chapter, I provide a summary on the history of voting rights in the United States that describes several important pieces of legislation and the major players in election administration. I provide a much briefer summary here for the purposes of this introductory chapter.

The coverage formula of the VRA required that states and/counties receive federal preclearance on all election changes if, as of November $1^{\text {st }} 1964$, it used voting tests such as a poll tax or literacy test and exhibited low voter registration rates or low voter turnout in the 1964 presidential election. The VRA banned the use of voting tests, and over time, voter registration and turnout in many jurisdictions identified by the coverage formula increased substantially. As such, especially in more recent years leading up to Shelby, voter registration and turnout rates had surpassed the thresholds that the VRA set forth for quite some time. Anticipating changes in 
conditions related to voting rights over time, legislators had built a "bailout" option, ${ }^{3}$ into the VRA through which states and counties that showed strong records meeting the requirements of the VRA, could have the opportunity to "bailout" of the coverage formula. However, one issue with bailouts that they are difficult to secure. For example, the burden of proof was on state governments, not the county jurisdictions, which made it difficult to convince judges to allow statewide bailouts, especially when a state had a history of discriminatory practices. In the 1982 revision of the VRA, Congress relaxed the qualifications for bailout which then allowed county and city jurisdictions the opportunity to prove that they no longer needed preclearance. Even with the relaxed bailout options, counties were still not able to be granted bailouts in practice. There were several attempts by counties in the deep South to escape preclearance, ${ }^{4}$ but always came up short - with Shelby County, Alabama - being one of the counties that requested but was denied a bailout.

Shelby County is located in Appalachian Alabama. Because of its location in the mountains, it is not known for the old slave plantations found in counties located in the southern part of the state. However, its geographical location did not exempt the county from a history of voter discrimination. Like it's southern county neighbors, voter discrimination laws such as the poll tax or the literacy test were frequently used in Shelby County specifically to keep the Black vote down. Because of this, the Black population in Shelby County began to dwindle each decade following the rise of Jim Crow. In 1960, the Black population was roughly $18 \%$, and by 2010, it had dropped to $11 \%$. In addition to becoming whiter, Shelby also became relatively

\footnotetext{
${ }^{3}$ Under Section 4(a), a covered jurisdiction may seek exemption from coverage through a process called "bailout." To achieve an exemption, a covered jurisdiction must obtain a declaratory judgment from a three-judge panel of the District Court for D.C. that the jurisdiction is eligible to bail out - https://www.justice.gov/crt/section-4-voting-rights-act.

${ }^{4}$ Here is an example of a Texas School District: Northwest Austin Municipal Utility District No. 1 v. Holder, 557 U.S. 193 (2009)
} 
wealthy, suburban, and modern. In 2012, it ranked among the hundred most affluent counties in the United States with $90 \%$ of the residents having at least a high school degree. The average household also ranks relatively highly compared to other counties across the United States.

In terms of its history with the VRA and preclearance, Shelby County has generally complied. In its time under preclearance, its proposed elections administration changes have been objected a total of 5 times- three of which involved the city of Alabaster in the 1970's (Bullock, Gaddie, and Wert 2016). Because of Shelby's economic success since the 1960s and its near perfect record with the Department of Justice regarding submissions for election procedure changes, the county election officials felt that in more recent years, it had the right to be bailed out of the coverage formula (and preclearance). In 2011, the county sued the U.S. Attorney General in the U.S. District Court for the District of Columbia on the grounds that the coverage formula and preclearance provision were unconstitutional. The District Court upheld the provisions, stating that they were still necessary to secure voting rights. A few years earlier in 2006, the VRA had been up for renewal. The District Court used the evidence presented during those Congressional hearings to provide evidence that the coverage formula and preclearance were still constitutionally valid.

In 2012, Shelby County appealed the ruling to the Court of Appeals in the D.C. Circuit. As with the ruling in the District Court, the appellate court also ruled that Section 4(b) and Section 5 were still valid. Finally, the Supreme Court granted certiorari to question whether Congress' decision on the 2006 renewal of the VRA may have exceeded its power under the $14^{\text {th }}$ and $15^{\text {th }}$ amendments and thus violated the $10^{\text {th }}$ amendment, which states that powers not delegated to the federal government by the Constitution are reserved to the states. 
On June $25^{\text {th }}, 2013$, the Supreme Court ruled in favor of Shelby County, stating that the coverage formula was no longer necessary, "making it no longer responsive to current needs" (Department of Justice 2015). The decision was controversial and fell along ideological lines in a five to four vote. The Court's conservative bloc made up the majority opinion and, the liberal bloc constituted the minority. The ruling received mixed reaction from parties on opposite sides of the political aisle. Most Republican states were in favor of the ruling, while most Democratic states were not. For example, within hours of the Shelby ruling, Texas and North Carolina passed election laws with more stringent voter identification laws. ${ }^{5}$ In closing, as scholars Bullock, Gaddie, and Wert (2016) stated the Shelby ruling was "the last act in the play of the second Reconstruction, and of the Voting Rights Act" (xiii).

\section{Polling Place Closures}

Another popular election law change that states enacted following Shelby involved the closing, relocating, or changing of precincts and polling places. For background purposes, it is important to understand the difference between a precinct and a polling place and how they can relate to one another. A precinct is the smallest geographic unit of the electoral system. Local governments divide up their jurisdictions into these precincts to administer elections and collect votes. Within a precinct, election officials normally place at least one polling place. By definition, a polling place is a building where voting takes place during an election. These polling places are usually in churches, gymnasiums, firehalls, or other widely recognized buildings in the communities.

${ }^{5}$ This link provides more information on this: https://www.brennancenter.org/our-work/policy-solutions/effects-shelby-county-v-holder. 
The act of changing, closing, and/or consolidating precincts takes place at the local level. In the beginning of most election years, a local government official or election official will determine whether changes in a precinct would benefit the voters. In local governments, it is often the local election official's (or LEOs) or the county commissioner's job to determine precinct boundaries. However, in most cases, it is LEOs set precinct boundaries with county commissioners granting them unquestioned approval.

As stated in the last section, the first presidential election following Shelby saw a record number of polling place closures, especially in locations that were formerly under preclearance. The Leadership Conference Education Fund (LCEF) coined this closure phenomena "The Great Poll Closure." In their 2016 report, the LCEF finds that jurisdictions in formerly preclearance areas tend to share socioeconomic characteristics such as large non-white populations, low income levels, and low average levels of formal education. As extant voting literature has shown, socioeconomic factors are often associated with citizens not casting votes because they lack the resources to do so (Leighley and Nagler 2014; Verba et al. 1995). Closing polling places further reduces the likelihood that citizens with low socioeconomic status will turn out to vote.

The LCEF used a variety of different sources to gather the data on poll closures. For the 2012 baseline data, it used the Election Assistance Commission's Election Administration and Voting Survey (EACS). The EAVS asks three questions about the total number of polling places in a jurisdiction: (1) physical polling places other than election offices; (2) election offices; and (3) other. The LCEF tallied up the three answers and used that as the total number of election day polling places for jurisdictions in 2012. In 2016 it asked each local government for the total number of polling places. As shown in Table 1.1, of the 874 total preclearance jurisdictions, the 
sample included 425 , which is roughly half. It found a total of 868 polling place closures between 2012 and 2016.

\begin{tabular}{|c|c|c|c|c|c|}
\hline \multicolumn{3}{|c|}{$\begin{array}{c}\text { Table 1-1. Comparison of Polling Place Closure I } \\
\text { LCEF Data }\end{array}$} & \multicolumn{3}{|c|}{$\frac{\text { rance Couı }}{\text { My Data }}$} \\
\hline State & $\begin{array}{l}\text { PC Counties in } \\
\text { Sample by } \\
\text { Actual Number } \\
\text { of PC Counties }\end{array}$ & $\begin{array}{l}\text { Number of } \\
\text { Closures } \\
\text { Between } \\
2012 \& 2016\end{array}$ & State & $\begin{array}{l}\text { PC Counties } \\
\text { in Sample } \\
\text { by Actual } \\
\text { Number of } \\
\text { PC Counties }\end{array}$ & $\begin{array}{l}\text { Number of } \\
\text { Closures } \\
\text { Between } 2012 \\
\& 2016\end{array}$ \\
\hline Alabama & 18 of 67 & 66 & Alabama & 67 of 67 & 144 \\
\hline Alaska & 0 of 1 & ------- & Alaska & 0 of 1 & |----- \\
\hline Arizona & 15 of 15 & 212 & Arizona & 15 of 15 & 182 \\
\hline California & 0 of 3 & ------- & California & 3 of 3 & 1 \\
\hline Florida & 0 of 5 & ------- & Florida & 5 of 5 & 2 \\
\hline Georgia & 0 of 159 & ------- & Georgia & 159 of 159 & 422 \\
\hline Louisiana & 64 of 64 & 103 & Louisiana & 64 of 64 & 107 \\
\hline Mississippi & 59 of 82 & 44 & Mississippi & 29 of 82 & 9 \\
\hline New York & 0 of 3 & ------- & New York & 0 of 3 & ------- \\
\hline North Carolina & 40 of 40 & 27 & North Carolina & 40 of 40 & 27 \\
\hline South Carolina* & 46 of 46 & 12 & South Carolina & 46 of 46 & 103 \\
\hline South Dakota & 0 of 2 & $\begin{array}{l}------ \\
\end{array}$ & South Dakota & 2 of 2 & ------- \\
\hline Texas & 134 of 254 & 403 & Texas & 185 of 254 & 318 \\
\hline Virginia & 0 of 133 & ------- & Virginia & 0 of 133 & ------- \\
\hline Totals & $\begin{array}{l}425 \text { of } 874 \\
(49 \%)\end{array}$ & 868 & Totals & $\begin{array}{l}615 \text { of } 874 \\
(\mathbf{7 0 \%})\end{array}$ & 1,315 \\
\hline
\end{tabular}

In terms of my sample, I followed the same procedure as the LCEF in 2012, utilizing the EAVS. However, our data differed in 2016. I was able to gain access to the 2016 EAVS dataset, so I followed the same procedure as in 2012 and summed the three questions regarding election day polling places. Because of this, I was able to find data in about 200 more preclearance jurisdictions, 615 in all and about $70 \%$ of the total number of preclearance jurisdictions. I also identified roughly 1,315 poll closures, roughly 500 more than in the LCEF sample. I believe the differences in the number of closures between the two datasets is due to the data I was able to use for the 2016 election, which was not readily available to the LCEF. Also, the LCEF was 
requesting polling place data from local jurisdictions, so there may be some biased answers caused by that, as well. Regardless of where the data's origins, the results from both datasets suggest that many poll closures occurred in formerly preclearance areas following Shelby.

In addition to the descriptive data in table 1-1, I believe a "real-world" example may also provide a better understanding of how detrimental The Great Poll Closure was to voting rights following Shelby. One of the four Arizona counties that border Mexico, Cochise County, has continually been under siege by the Department of Justice over VRA Section 5 violations. As recently as 2006, the county government violated Section 5 by not providing election materials to Spanish and Spanish-speaking poll workers at local precincts. In preparation for the 2016 presidential election, the election officials of Cochise County decided on a new polling place plan such that the traditional election day precincts would turn into county-wide voting centers. Based on my data, the number of traditional polling places went from 49 to 20 between 2012 and 2016. Local election officials stated that the switch to county-wide voting centers involved identifying locations based on "easy public accessibility, Internet connectivity, and the proximity to former polling places. ${ }^{\prime 6}$ One reason that was not mentioned: ensuring access for Hispanic voters (LCEF 2016).

I believe the Cochise County case is useful for two reasons. First, it shows that the closure of polling places can be a valid legal process. In other words, based on state laws (which will be described in chapter 2), the law allows the changing of precinct locations and polling places. Closures are normally caused by factors such as population change, lack of traditional election day voters, or lack of funds for poll workers and voting locations. In the case of Cochise,

\footnotetext{
${ }^{6}$ County Adopts 18 Voting Centers," Cochise County Herald/Review Media, August 26, 2015. https://www.myheraldreview.com/county-adoptsvoting-centers/article 2c8f2594-4c02-11e5-822f-1f313c861e8a.html.
} 
local officials' arguments were valid in terms of making the change from polling places to voting centers, but the effects on non-whites were not discussed. This is where the coverage formula and preclearance provision of the Voting Rights Act would come into play. For example, when a formerly preclearance jurisdiction election official wanted to make a change in the pre-Shelby era, they would submit the proposal to the Department of Justice. The Department of Justice would then determine if the change would harm the voting opportunities for non-whites. Normally, the DOJ would consider factors such as population size and turnout in previous elections when making its determination. However, with preclearance no longer required, cases like Cochise are starting to become more frequent.

Second, the Cochise County example also shows how socioeconomic status plays a role in the closing of former preclearance jurisdictions with large non-white populations. As I will show in the chapters to follow, polling place closures can be burdensome on voters with lower socioeconomic status. For example, citizens affected by a polling place change are often notified via mail, or the change will be posted at the local county courthouse; but if a citizen does not have a permanent mailing address or is unaware of the posting, it is more difficult for a citizen to cast a vote. Another issue is distance. Non-white citizens are less likely to have access to a personal vehicle or even public transportation than white citizens, making arrangements to get to the new polling place and one that may be further away is a burden; this was a major complaint in Cochise County example.

One important problem, however, with the accounts of polling place closures described thus far is that they are no accompanied by statistical analyses that establish whether former preclearance jurisdictions were closing precincts more frequently in areas with large non-white 
populations, all else equal. This is where the research described in this dissertation is important. In the next section, I discuss the inconsistencies in some of the major studies conducted on polling places, and then conclude by explaining how my work fills those gaps.

\section{Poll Closures in Political Science}

In terms of political science research, precinct relocation and closure has been studied but not as exhaustively as other election administration processes like voter ID laws and redistricting. There have been four major studies on the effects of polling place closures. In 2005, Haspel and Knotts looked at two elections in the city of Atlanta. They found that poll changes increased voter turnout throughout Atlanta. However, the authors attribute their surprising results to two factors. First, local election officials sent out reminder postcard to all voters roughly 30 days prior to the election so voters would not forget about the changes. Second, the city of Atlanta added eight precincts from the first to the second election, giving more voters places to vote. Essentially, Haspel and Knotts showed that adding more precincts (which changes where people vote) had a positive influence on voter turnout.

One of the first studies to find that polling place closures can cause a decrease in turnout was Brady and McNulty (2011). These scholars looked at the effect of poll closures in the 2003 Los Angeles gubernatorial recall election. They found that citizens who had their polling place moved were 1.85 percent less likely to vote than those whose polling place remained the same. Originally, Brady and McNulty found this 1.85 percent to be much higher, but part of the original figure was offset by accounting for absentee and early voting. In other words, they concluded that moving or closing a precinct does result in people not turning out to vote, but it 
also increases the chances in non-traditional forms of voting (i.e. absentee ballots and early voting).

Brady and McNulty also found that the effect of closures was different for Democratic and Republican voters. Democrats were more sensitive to the poll changes compared to Republicans. While these effects did not determine the outcomes of the election, they are worrisome enough "to make it possible for someone to affect outcomes by more extensive manipulation of polling place locations" (Brady and McNulty 2011 115). Amos, Smith and Ste. Claire (2017) takes this partisan concern to the next level by studying reprecincting as a partisan act. In their experiment, they looked at a 2014 midterm election in Manatee County, Florida. They chose this location because the local election official prior to the election was a Democrat, and the one during the election was a Republican. They found that when the Republican LEO was in office, precincts in Manatee County that were predominately non-white, younger, and Democratic were the most likely to be consolidated or closed. When looking at voter turnout, citizens with those demographic characteristics were also the least likely to cast a ballot. In short, Amos, Smith, and Ste. Claire (2017) provides evidence that polling change can be a partisan act that are detrimental to democracy in America.

One limitation of the literature I have discussed to this point is that each individual study has only dealt with one specific jurisdiction or one election. However, Clinton et al. (2020) changed the political science landscape by looking at the effect of poll closures throughout the whole state of North Carolina across three general elections (2008, 2012, and 2016). They find that voters who had their polling place shut down or relocated were less likely to vote than those whose polling places remained the same, but this finding is completely offset when they 
accounted for early voting. In other words, when a person's polling place changes, it discourages them from turning out on election day but not from voting entirely; they just vote earlier.

\section{Goals of the Dissertation}

The contributions made by the scholars I have referenced so far had significant effects on the election administration literature, but there are still some gaps that need to be filled, and my dissertation will attempt to fill those gaps. First, my research will be the first to study polling place closures from a nation-wide standpoint. Using county election data, I compile polling place data from roughly 2,270 voting jurisdictions across the United States for each of my analyses. Second, my research will also provide rigorous statistical analysis in attempt to determine the causes (and effects) of The Great Poll Closure. As I mentioned in an earlier section, journalistic reports have noted that poll closures were especially prominent in areas with large non-white populations that were formerly subject to preclearance. While the importance of those descriptive findings should not be downplayed, they were not accompanied by statistical analyses that accounted for legally valid reasons for closing polling places. Third, I also provide a unique measure of polling place closures called the percentage change in voters per precinct (or PCVPP). PCVPP allows for scholars to compare the effects of poll closures across voting jurisdictions of differing population sizes. My hope is that this measure will be used in future research when studying the impacts of polling place closures specifically at the state or national level.

The discussion above has provided a brief introduction to the central issues addressed by this dissertation. I now provide a brief description of what is to follow. 
Chapter 2 discusses the laws regarding the establishment, modification, and consolidation of precincts in each state. This chapter was created to lay the groundwork for my quantitative chapters to follow. I believe it is important to understand the basics of polling place closures before empirically analyzing the factors associated with such closures.

Chapter 3 examines polling place closures from an institutional point of view. This chapter seeks to determine the main factors that play a role in jurisdictions' decisions to close polling places. As chapter 2 will explain, there are several constitutionally valid, if perhaps unfortunate, reasons for jurisdictions to close precincts such as reduction in the number of voters and fiscal constraints. Controlling for factors that legitimately influence decisions to close precincts is necessary when determining whether precincts are closed for reasons that are potentially problematic in terms of voting rights, and the voting rights of members of racial and ethnic groups. I attempt to determine what the main causes of The Great Poll Closure were. Did the Shelby decision result in a rash of polling places closures that disadvantaged non-white voters, or did jurisdictions close polling places mainly for constitutionally allowable reasons?

Chapter 4 takes a more behavioral approach in studying The Great Poll Closure. My goal in this chapter is to answer one important question: does closing precincts deter citizens, and especially citizens who are members of non-white populations, from voting? Using aggregate data from the 2008, 2012 and 2016 presidential elections, I implement difference-in-difference analyses to explore the effects of changes in polling places on the change in county-level voter turnout between 2008-12 and 2012-16. The findings of this chapter have important implications for the current literature on nonwhite voter turnout and election administration. 
Chapter 5 concludes the dissertation and summarizes each chapter's main findings. It also discusses the important real-world implications of the research described in the dissertation and suggests avenues for future research.

While political scientists have examined the effect of poll closures at the precinct, county, and state level, my work addresses this issue at the national level by identifying patterns in each state law, looking at a large sample of voting jurisdictions over a period of three elections, and then testing the effects of precinct changes on voter turnout. I believe that through my analyses, the discipline will better understand how the process of changing polling places works, which jurisdictions conduct this process most frequently, and who is most affected by it. I expect my work to make significant contributions to the study of electoral administration, voter turnout, and racial and ethnic politics. 


\section{CHAPTER 2: The Legal Aspects of Closing Polls}

This chapter discusses the laws regarding the establishment, modification, and consolidation of precincts in each state. I believe that this is an important aspect of my dissertation because precinct formation tends to be one of the more overlooked procedures of election administration. One other reason for the importance of these laws is that "reprecincting" is often conflated with "redistricting." Although both processes involve drawing boundaries, precincts and districts are established in much different ways. In this chapter, I am going to summarize the "reprecincting" laws of each state. I am also going to compare the states' laws while also identifying patterns in that legislation. For example, most states from the South make it harder for people to vote early and use absentee ballots while Pacific states such as Washington and Oregon do not even have traditional election day voting and require their citizens to vote by mail. In short, I expect to see patterns in precinct laws like those we see in early voting laws and laws related to other voting procedures.

This chapter is divided into three parts. First, I provide a "legal primer" of non-white voting rights in the U.S. I begin with the period of Reconstruction and conclude with the Shelby v. Holder case. I believe it is necessary to understand the progression of voting rights for members of non-white populations before discussing the process of reprecincting and other election administration processes. Second, I will discuss how election administration works and how local, state, and federal governments are connected in the process. This section also analyzes the differences between reapportionment, redistricting, and reprecincting. Last, I compare each state's laws regarding reprecincting using the criteria I created. The goals of this chapter are to not only provide the reader with background on reprecincting but also to help 
make sense of the findings of my final two quantitative chapters regarding the large number of polling place closures since Shelby.

\section{Voting Rights Legislation: From Reconstruction to the VRA}

Prior to the passage of the Voting Rights Act of 1965, there were few specific laws regarding federal oversight of elections. ${ }^{7}$ State and local governments essentially had free reign in terms of election administration. Article 1, Section 4 of the constitution gives Congress "broad power over federal elections while the $14^{\text {th }}$ and $15^{\text {th }}$ Amendments give it power to legislate for any elections where relevant rights are affected" (Hale, Montjoy, and Brown 2015). The $14^{\text {th }}$ amendment (passed in 1868) clarified that every person naturalized or born in the U.S. is a citizen and the $15^{\text {th }}$ (passed in 1970) guaranteed all U.S. citizens the right to vote regardless of race, color, or previous condition of servitude (U.S. Commission of Civil Rights 2018). These amendments were initially successful in "expanding access to the ballot box for recently freed slaves, and in providing voter protections for African-American citizens by outlawing any action taken to suppress their vote" (U.S. Commission of Civil Rights 2018 16). In the election of 1868, 700,000 Blacks voted for the first time. In Louisiana, Mississippi, and South Carolina, Black registration rates exceeded that of white registration. By 1869, over 20 Black citizens were elected to the U.S. Congress. During the period of Reconstruction (1865-1877), Black turnout in elections increased significantly, but this revolution in political participation among Black Americans did not last long.

\footnotetext{
${ }^{7}$ Once example was the Enforcement Act of 1870; It was the first comprehensive federal statute that dealt with elections. Acts such as bribery, interference, false voting, etc. were made federal offenses. Federal judges would visit voting locations to see whether the voting actions warranted federal offenses. However, most parts of the Enforcement act were overturned by a Democratic Congress following the period of Reconstruction. To see a comprehensive breakdown of pre-1965 voting rights legislation, please visit: https://constitution.congress.gov/browse/essay/artI_S4_C1_1_1_1_2/.
} 
In spite of the $14^{\text {th }}$ and $15^{\text {th }}$ amendments, southern states quickly began to find ways to slow the progression of Black political power. In the election of 1876 (often referred to as the Second Corrupt Bargain), Rutherford B. Hayes was elected President through what became known as the Compromise of 1877. This compromise officially ended the period of Reconstruction by leaving the South to govern itself for the first time since the conclusion of the Civil War. In Hayes' first act as commander-and-chief, he withdrew the Northern troops from all Southern capital cities. This move almost single-handedly halted any progression Blacks had made in terms of political power at that time. The Northern troops had been in the South to make sure that local and state governments below the Mason-Dixon line followed the laws put forth by the 14th and $15^{\text {th }}$ amendments. With the removal of Northern Troops, the Compromise of 1877 ended the Reconstruction period and ushered in the era of Jim Crow.

Jim Crow typically refers to the period of time between the collapse of Reconstruction and the start of the Civil Rights Era in the 1950s. During this period, racial segregation under the law prevailed in the Southern part of the United States. Jim Crow laws mandated that separate public facilities (e.g., parks, bathrooms, swimming pools, schools) must be maintained for Blacks and whites. Ten of the eleven former confederate states created new constitutions or amendments that mandated "separate, but equal" guidelines. As expected, Jim Crow also had a large effect on voter registration and turnout among Blacks.

In the late 1800 s, many former confederate states began to implement certain types of voter suppression methods such as poll taxes, literacy tests, and grandfather clauses. For example, a poll tax could cost a citizen in some places $\$ 1.50$ to $\$ 1.75$ to vote, which was a large amount of money for sharecropper in the nineteenth century (Texas Politics 2012). In 
Mississippi, the literacy test required citizens to read and explain parts of the state constitution to the local county clerk. County clerks would pick difficult passages for Blacks to interpret while picking simple sentences for whites to explain (U.S. Commission for Civil Rights 2018).

If poll taxes and literacy tests were not enough to disenfranchise Blacks, election officials (specifically in the South) found other unique ways to stop Blacks from voting. In South Carolina, election officials created an indirect literacy test called the "eight box law" (Holt 1979). Under this requirement, voters had to cast a vote in separate ballot boxes for the eight types of offices. If a ballot was put in the wrong box, that ballot would not count. The only way to identify which ballot box represented which office was by the labels placed on them. Election officials would read the correct names to illiterate whites but the wrong ones to illiterate Blacks. Although the $14^{\text {th }}$ and $15^{\text {th }}$ Amendments to the U.S. Constitution were created to alleviate the barriers Black Americans had to overcome to participate in politics, these amendments, did not address racial discriminatory practices such as the use of literacy tests and poll taxes.

Another way whites' discouraged Blacks from voting during the Era of Jim Crow was by creating "sundown towns" throughout the United States. Sundown towns had very few Black households' decade after decade, with a sharp drop in Black populations between two censuses. In these sundown towns, white residents and lawmakers would force the Black population to leave by enforcing laws that made living conditions unbearable. For example, some sundown towns made Blacks pay a fee to send their kids to public school. Some made it a crime for a Black person to be out "after sundown". This would not only encourage Black residents to leave, but also Black motorists as well. One common misunderstanding made by filmmakers, the media, and the public is that these sundown towns took place s only, or at least largely, in the South. According to Loewen (2009), sundown towns were more likely to be found in the North 
and Midwest. The South seldomly designated towns as sundown towns this because they needed Blacks for cheap labor on plantations. "Among the 204 towns known to have displayed sundown signs, only 9 were in the plantation South" (Loewen 2009 27).

Another way in which Blacks and other non-white populations were disenfranchised was through felon voting restrictions. In their event-history analysis from 1850 to 2002, Manza and Uggen (2004) found that while controlling for factors such as time, region, and economic competition between Blacks and whites, states with larger proportions of non-whites in their prison populations were more likely to pass restrictive laws such as prohibiting ex-felons from voting. This was especially relevant in the deep South following the Civil War, especially regarding types of crimes that Blacks were more likely to be found of committing.

The early $20^{\text {th }}$ century was not entirely discouraging for non-white political power. In 1944, Smith v. Allwright was one of the first Supreme Court cases that challenged the legality of Jim Crow election administration laws. As mentioned earlier in this chapter, there were few guidelines in place that allowed the federal government to intervene when election practices (such as poll taxes) were becoming more separate than equal. However, Texas' "all-white primary" elections created one of the first opportunities for the Supreme Court to intervene. The Court ruled in Smith v. Allwright that these "all-white" primaries restricted access to only white voters. The Court also stated that all primary elections must be open to citizens of all races. The federal court concluded that these all-white primaries were unconstitutional and violated the $14^{\text {th }}$ and $15^{\text {th }}$ amendments.

Following Smith v. Allwright, Black registration rates increased by 6\% percent from 1947 to 1950 across the South (U.S. Commission for Civil Rights 2018 19). However, despite the Court's decisions in cases successfully litigated by parties aiming to advance voting rights, there 
were still no permanent guidelines put in place and racially discriminatory practices continued. By the mid-fifties, the voting registration rates of Blacks in the South was only 15\%. States like Mississippi and Alabama had Black registration rates under 5\%. It was not until 1957 that federal legislation was enacted which to prohibit state governments from implementing racially discriminatory election laws.

Finally, in 1957, Congress passed the first Civil Rights Act (CRA) which gave the Attorney General the authority to stop local election officials from implementing discriminatory practices that would hinder minorities voting. The CRA of 1957 also created the U.S.

Commission on Civil Rights, which conducted studies of discriminatory electoral practices in the South. The Commission would send officials to observe the election practices of areas that have had reports of voter discrimination. However, those observers received backlash from the counties, specifically from the local election officials themselves. For example, some states even created legislation to require the local registrars to burn registration lists so that, members of the commission could not access them. Another obstacle the U.S. Commission on Civil Rights faced was that lower courts (specifically in the South) ruled that the Civil Rights Act was unconstitutional, in that it violated a state's individual right to rule.

Congress attempted to plug the holes of the Civil Rights Act of 1957 by creating amendments with the Civil Rights Act of 1960. The new legislation required that local election officials keep a record of election activity up to 22 months after an election and that they make it available to federal officials. The CRA of 1960 also assigned federal officials to register Blacks in a county if a judge found a local jurisdiction to be using discriminatory registration practices. 
Despite the efforts of the Civil Rights Act of 1957 and 1960, both pieces of legislation proved to be largely ineffective. One of the biggest issues was that both versions of the CRA did not provide "specific authority for the Attorney General to enforce its own provisions" (U.S. Commission for Civil Rights 2018). Because of this, racially discriminatory practices continued into the 1960's. In the Spring of 1963, the Southern Christian Leadership Conference (SCLC), led by Dr. Martin Luther King, Jr., began to bring attention to the integration campaign through several non-violent protests in Birmingham, Alabama. Dr. King and his followers organized sitins and marches that brought media attention from across the country. On live television, American citizens witnessed Black teenagers and young adults get mauled by large police attack dogs and sprayed with giant firehoses. The Birmingham Campaign (as it is often referred to) acted as a lightning rod for the Civil Rights Movement prompting President John F. Kennedy to propose an updated version of the Civil Rights Act to Congress. Kennedy stated there needed to be legislation "giving all Americans the right to be served in facilities which are open to the public as well as the greater protection to vote" (Kennedy 1963). Unfortunately for Kennedy, Congress did not share his enthusiasm on a new Civil Rights Act. Most members of Congress could get on board with most aspects of Kennedy's proposal, but many would not accept the provisions guaranteeing equal access to public facilities. In October of 1963, there looked to be no hope for the new Civil Rights Act.

However, following Kennedy's assassination in November of 1963, the political climate began to change in favor of Kennedy's civil rights proposal. In his first address to a joint session of Congress on November 27th, 1963, Lyndon Johnson, Kennedy's successor, urged Congress to pass the new Civil Rights Act as a tribute to Kennedy's legacy. As Johnson (1963) put it, "No memorial oration or eulogy could more eloquently honor President Kennedy's memory than the 
earliest possible passage of the civil rights bill for which he fought so long." After a series of filibusters by the "Southern Bloc" $"$ which resulted in a substitute version of the bill ${ }^{9}$, the Civil Rights Act of 1964 was finally approved by both houses of Congress and signed into law by President Johnson on July 2nd.

The Civil Rights Act of 1964 has a total of six provisions. In terms of voting rights, the first provision (Title I) was the most important. It made sure that voting rules and procedures would be equally applied to all races. However, Title I did not discuss the idea of voter qualification. In other words, states could still deny people the right to vote if they did not meet the appropriate qualifications (i.e. poll taxes and literacy tests). As one Congressman stated, "While it can be truly said that present laws [Civil Rights Act] have proved to be effective tools to deal with discrimination in voting, the tools are limited in scope; there is no widespread remedy to meet what is still widespread discrimination" (U.S. Commission for Civil Rights 2018 21). In short, despite the momentous efforts by the Johnson administration, Blacks in the South were still being discouraged from voting through the use of discriminatory practices such as the poll tax and the literacy test.

Following the 1964 presidential election year, during which the Democrats won the presidency an overwhelming majority in both houses of Congress, President Johnson began to question the strength of the Civil Rights Act. Although the act made sure that voting rules were administrated equally to all races, voting jurisdictions were still using discriminatory voting practices such as poll tax and the literacy test. Johnson was not alone on this observation, Dr. Martin Luther King and the SCLC also believed that more legislation needed to be passed to

\footnotetext{
${ }^{8} 19$ Senators from the South created a 54-day filibuster that resulted in a substitute version of the bill.

${ }^{9}$ The bill was weaker than the original proposal especially dealing with government enforcement within private businesses.
} 
achieve voting equality for all races. A few months after the 1964 election, King and the SCLC took part in several protests in Southern cities where voting discrimination was most prominent. On March 7, while protesting in Selma, Alabama, King and Congressman John Lewis were both beaten at the foot of Edmund Pettis Bridge. One significant element of this was that it was seen on national television. People from all over the United States witnessed the horrifying event, which immediately caused an outcry to Congress that additional action needed to be taken regarding civil rights. Roughly five months later, on August $6^{\text {th }}$, 1965, President Lyndon B. Johnson signed the Voter Rights Act (VRA) into law. The VRA is a general prohibition of all state and local election laws that have discriminatory intent. It made it illegal for state and local election officials to deny anybody the right to vote because of the color of their skin. Essentially, the VRA was a much stronger version of the voting rights provision contained in the Civil Rights Act of 1957, 1960, and 1964.

One important facet of the VRA was that required federal oversight of election law changes in certain regions of the United States. Section 5 of the VRA required certain states and counties to receive permission for any type of election procedure change. There were two ways to receive preclearance: (1) a jurisdiction could submit their election change to the Department of Justice and have the Voting Rights division determines whether the election change had discriminatory intent, and (2) a jurisdiction could submit their proposal to the U.S. District Court for D.C., and which determined whether the electoral change qualified for preclearance. The counties and/or states required to receive preclearance were determined by the "coverage formula" created in Section 4(b) of the VRA. "Covered" jurisdictions were identified by the following: (1) the use of voting "tests" such as the poll tax and literacy test and (2) low voter registration or voter turnout among minorities. 
The original requirements resulted in coverage of the entire states of Alabama, Alaska, Georgia, Louisiana, Mississippi, South Carolina, and Virginia; and some subdivisions (usually counties) in Arizona, Hawaii, Idaho, and North Carolina. It also created partial coverage of Alaska, Arizona, California, Connecticut, Idaho, Maine, Massachusetts, New Hampshire, New York, and Wyoming. By 1975, the coverage formula covered the whole of Alaska, Arizona, and Texas, and parts of California, Florida, Michigan, New York, North Carolina, and South Dakota (Department of Justice 2015). Figure 2-1 shows a representation of preclearance distribution. As one can tell, covered jurisdictions (except for some county/township jurisdictions) were highly concentrated in the South.

Figure 2-1. Section 5 Covered Jurisdictions (From the Department of Justice) ${ }^{10}$

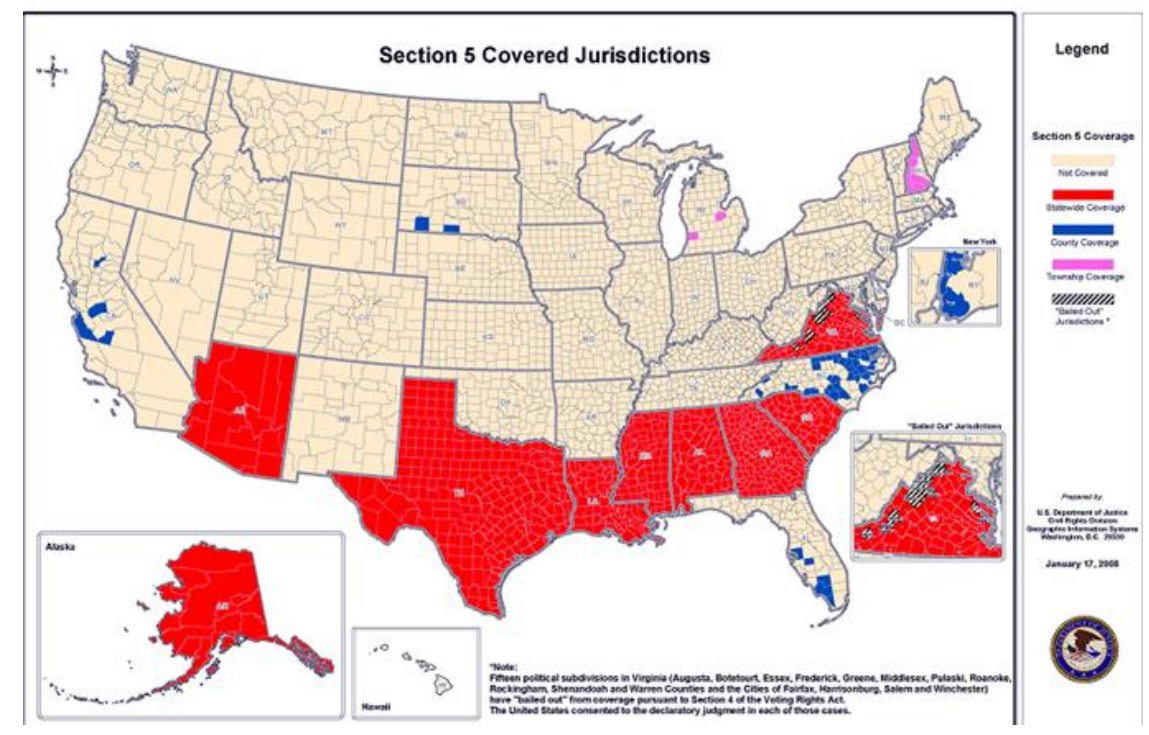

As expected, the VRA and the preclearance provision were highly successful through the first years following its conception. By the late 1960's, federal examiners (granted permission by 
the VRA) "registered more than 150,000 Black southerners to vote in 58 counties covered by Section 5" (U.S. Commission for Civil Rights 2018 23-24). For example, in states that were still segregated (i.e. Mississippi and Alabama), the Black registration rates were more than eight times the pre-VRA average. Even white voting registration rates even increased by almost 20 percent in some covered states. In short, the Voting Rights Act of 1965 was a tremendous success at the onset. However, as time progressed, litigation surrounding the language of the Voting Rights Act began to increase while the influence of its special provisions (i.e. coverage formula and preclearance) began to decrease.

\section{The Rise and Fall of Sections 4 \& 5}

Because Section 2 of the VRA outlawed the use of blatant discriminatory practices such as the poll tax and literacy test, the coverage formula and preclearance provision were relatively dormant in the first couple years of the VRA's existence. In other words, covered jurisdictions did not have to send their electoral changes to the Department of Justice (DOJ) or the United States District Court for the District of Columbia (DC) because those changes were not blatantly discriminatory changes to electoral procedures such as the implementation of a poll tax, there was no reason to submit them for preclearance. This changed, however, following the Allen $v$. State Board of Elections Supreme Court case in 1969. In this case, the Court held that any changes, even if minor, must be submitted for approval. The number of covered jurisdictions' submissions to either the DOJ or DC increased significantly following the Allen case. According to the Justice department, there were roughly 130 preclearance submissions in 1969 and by 1971, that number rose to over 1,000 (Department of Justice 2015). One problem with the DOJ increasing its voting law scope, was pushback by jurisdictions' election officials, specifically 
regarding the language of the purpose and effect prongs of Section 5. In other words, because of the ambiguity surrounding these terms, jurisdictions began challenging how the Courts could reject their election law proposals on the grounds that the VRA itself was not clear.

For a jurisdiction to receive preclearance, the DOJ and/or DC must find that the jurisdiction's proposed election law changes do not have discriminatory "effect" and/or “purpose." Discriminatory effect means that any voting change "cannot result in more discrimination than before the change was made" and discriminatory purpose means that any voting change "cannot have been intended to increase existing discrimination when implemented" (Department of Justice 2015). Because of the vagueness of these two terms, "effect" and "purpose," jurisdictions began challenging how the courts can reject their election law proposals. The existence and ambiguity of the discriminatory effect and purpose prongs has resulted in several Supreme Court cases, with perhaps none more significant than Beer v. United States (1976) and Reno v. Bossier Parrish (2000).

In Beer v. United States, the city of New Orleans sought out preclearance for their redistricting plan in the early 1970s. The District Court for the District of Columbia refused to preclear the plan on the grounds that the redistricting would seriously abridge the right to vote on account of race or color. Following an appeal, the Supreme Court heard the case and reversed the outcome in favor of the City of New Orleans. The Court ruled that the proposed electoral change did not make minorities worse off than they were before the electoral change. The Court referred to this as a "retrogression standard." In other words, "changes that do not make matters worse for minority voters are entitled to preclearance, even where the new method of election appears likely to dilute minority voting strength" (McCrary et al 2006 283-4). This court case seriously weakened the effect of the preclearance provision. Following the Beer case in 1976, preclearance 
objections based on discriminatory effect or "retrogression" were becoming fewer and fewer. According to the Department of Justice, $40 \%$ of preclearance objections in the 1970s belonged to "retrogression", but as time progressed into the 80 's and 90 's, retrogression objections were reduced to less than 10\% (McCrary et al. 2016).

Despite the precedent set by the Beer case, Section 5 of the VRA remained effective through the "discriminatory purpose" prong. Discriminatory purpose is defined as the administering of any election process "with any purpose of denying or abridging the right to vote on account of race, color, or membership in a language minority group" (Department of Justice 2015). According to the Department of Justice, only $11 \%$ of objections in the 70 's belonged to the purpose prong, but that number quadrupled by the 1990s with over half of the objections having to do with discriminatory purpose (2015). Despite this success, the purpose prong, like the effect prong, was also rejected by the Supreme Court.

In the early 1990's, a Louisianan parish (Bossier Parish) proposed a redistricting plan that created no majority Black districts, even though Blacks made up 20 percent of the parish's population. Because of the history of discrimination in Bossier, it was a covered jurisdiction (under the formula in Section 4(b) of the VRA). When Bossier parish proposed their redistricting plans to the Attorney General, they were denied preclearance on the grounds of discriminatory purpose. The parish then filed the preclearance action in the District Court for D.C. The District Court granted Bossier Parish preclearance for their redistricting plan because the proposed plan did not have the intent of making things worse or "did not have a retrogressive purpose" for minorities in that parish. This District Court ruling was heard by the Supreme Court, but the high court remanded the case back to the District Court for a retrial, where they ruled, yet again, in favor of the "retrogression standard". Because of the decisions in the Beer and Bossier cases, the 
discriminatory "effect" and "purpose" prongs of Section 5 were now difficult to enforce. They both required evidence that election procedure changes were "designed not merely to discriminate against minority voters but to make matters worse for them" (McCrary et al. 2006 $302)$.

The number of preclearance objections declined drastically following Bossier. According to the Yale Law Review, there have been a total of 92 objections from 1996 to 2006, that is an objection rate of roughly $0.02 \%$ (2007). It appeared the pre-clearance provision was destined for irrelevance, but in 2006, new life was granted to Section 5 of the VRA.

On May $2^{\text {nd }}, 2006$, President George W. Bush signed into law the Fannie Lou Hamer, Rosa Parks, and the Coretta Scott King Voting Rights Act Reauthorization and Amendments Act (or the VRARA). The VRARA extended the special provisions that had been set to expire in 2007 for another 25 years (U.S. Congress 2006). This included the coverage formula as well as the preclearance provision. The VRARA also addressed the Bossier ruling, making preclearance easier to deny. The language of the VRARA specifically states "that any voting qualification or prerequisite to voting, or standard, practice, or procedure with respect to voting denies or abridges the right to vote if its purpose is or its effect will be the diminishment of the ability of any U.S. citizens on account of race or color, or in contravention of certain guarantees, to elect their preferred candidates of choice" (U.S. Congress 2006). In other words, the retrogression standard was no longer needed for the Attorney General or District Court to deny preclearance. If a covered jurisdiction changes an election process with "any discriminatory purpose or effect", that jurisdiction will be denied preclearance and those changes will not happen. 
The passage of the VRARA helped clear up the confusion surrounding the purpose and effect prongs of Section 5 of the VRA, but it did not deal with any uncertainty surrounding Section 4, especially the bailout provision. Bailout is a clause that allows jurisdictions the opportunity to prove in front of a three-judge panel (the District Court for D.C.) that they no longer needed to receive federal preclearance on any voting procedure changes. The bailout procedure was provided for in the original Voting Rights Act in 1965 but was rarely implemented due to the criteria for a bailout being difficult to meet. The burden was on state governments to prove a that the criteria for bailout were met in the entire state, and it was difficult to convince judges of this, especially when the state had a history of discriminatory practices. In the 1982 revision of the VRA, Congress relaxed the qualifications for bailout and allowed county and city jurisdictions, rather than only states, the opportunity to prove that they no longer needed preclearance. Even with this change, however, jurisdictions were still not "bailing out" of the coverage formula. According to Herbert (2007), following the 1982 amendment, only 12 jurisdictions bailed out. All of them belong to the state of Virginia. Scholars argued that even with the relaxed qualifications, the Department of Justice still made it difficult for jurisdictions to bail out.

Shortly after the passage of the VRARA in 2006, a Texas utility district sought to bail out from Sections 4 and 5 of the VRA. The district argued that because they did not register voters that they did not need to seek preclearance for any election changes. Their case was heard in front of the Supreme Court in Northwest Austin Municipal Utility District No. 1 v. Holder in 2009. In 9-0 decision, the Court ruled that covered jurisdictions shall be allowed to receive bailout if they met the specific criteria set forth by the Attorney General's office (the bailout requirements set by the 1982 amendment). For example, the jurisdiction must eliminate those 
election procedures that "dilute or inhibit equal access to the electoral process" as well as providing evidence of minority electoral participation (Department of Justice 2015). Due to the verdict in the Northwest court case, jurisdictions began challenging the constitutionality of the $4^{\text {th }}$ and $5^{\text {th }}$ sections of the VRA, which eventually led to the official downfall of preclearance.

In September of 2011, Shelby County, Alabama sued the U.S. Attorney General for denying the county preclearance on an election law change. Shelby County argued that sections 4 and 5 of the VRA - and specifically the coverage formula defined by Section 4 - were "facially unconstitutional." The District Court for D.C. ruled to uphold the two provisions, ruling that the VRARA of 2006 was enough evidence to prove that the coverage formula and the preclearance provision were not unconstitutional. Unhappy with that decision, Shelby County took their case to the U.S. Courts of Appeals the following year. On May $12^{\text {th }}, 2012$, the Appellate court upheld the District Courts' ruling that Congresses reauthorization of the VRA in 2006 was enough to justify the constitutionality of Sections 4 and 5.

The Supreme Court granted certiorari on the case to question Congress's decision to reauthorize Section 4(b) and 5 of the VRA in 2006. In the landmark case, Shelby County v. Holder, the Court argued that Congress may have exceeded its power under the $14^{\text {th }}$ and $15^{\text {th }}$ amendments and thus violated the $10^{\text {th }}$ amendment, which states that power not delegated to the federal government by the Constitution is reserved to the states. On June $25^{\text {th }}, 2013$, the Court declared Section 4(b) of the VRA to be unconstitutional because the coverage formula was based on 40-year-old data, "making it no longer responsive to current needs" (Department of Justice 2015). The Court did not rule Section 5 (the preclearance provision) unconstitutional because no jurisdiction can be subject to preclearance without a coverage formula. Members of the majority opinion stated that the coverage formula was "based on 40 -year-old facts with no logical 
relationship to the present day" (Shelby v. Holder 2013). In the 2006 VRARA, Congress did reauthorize the Voting Rights Act for another 25 years but did not update the coverage formula, which had not been changed since 1975 (McCrary et al. 2006). Because of Shelby, voting jurisdictions that were previously covered by Section 4(b) of the VRA were now allowed to make changes to their voting procedures without receiving the federal government's approval.

It is important to note that other sections of the VRA are meant to prevent drastic discriminatory procedural changes from being made. Section 2 of the VRA, allows to the federal government to file lawsuits against voting jurisdictions alleging that voting changes would reduce non-white turnout. This process, however, is expensive, fraught with uncertainty, and often takes years. Section 2 also does not prevent elections from occurring under procedures later found to be discriminatory (U.S. Commission for Civil Rights 2018).

In conclusion, the Shelby decision limited the tools that the federal government has in terms of addressing potentially discriminatory voting procedures. The next section will examine the effects of the Shelby decision and how it has opened the door for jurisdictions to create new ways to slow or even reverse the progression of non-white voting rights.

\section{The Major Effects of Shelby}

Before discussing the major effects of Shelby, I believe it is important to understand how Sections 4 and 5 operated and how effective (or ineffective) they prior to the invalidation of Section 4 by the Court. As explained in the previous sections, Section 4(b) is the coverage formula provision of the Voting Rights Act. It established which jurisdictions would have to receive preclearance from the federal government on proposed voting procedure changes. Section 5 added the preclearance provision, which set the guidelines to how that process was 
conducted. There were two ways in which a jurisdiction could receive preclearance: (1)

administrative preclearance and (2) judicial preclearance. Administrative preclearance was the most common practice. Local jurisdictions would submit their voting changes to the Department of Justice (DOJ) who would then have 60 days to determine the legality of the voting change under the VRA. Through judicial preclearance, a local jurisdiction would submit their voting change to the District Court for the District of Columbia (DC), and a three-judge panel would determine if the local jurisdiction would receive preclearance.

\begin{tabular}{|l|l|l|l|}
\hline \multicolumn{4}{|c|}{ Table 2-1. Section 5 Submissions and Objections, 2000-2012 } \\
\hline Change Type $^{\mathbf{1 1}}$ & Submissions & Objections & \% \\
\hline Annexations & 49,221 & 3 & $0.00 \%$ \\
\hline Elections & 27,436 & 25 & $0.00 \%$ \\
\hline Redistricting & 4,132 & 39 & $0.94 \%$ \\
\hline Ballot Access & 72,218 & 9 & $0.00 \%$ \\
\hline Other & 55,040 & 0 & $0.00 \%$ \\
\hline Totals & 208,047 & 76 & $0.04 \%$ \\
\hline Source: Pildes, Rick and Dan Tokaji. 2013. “What Did VRA Preclearance Actually Do?" \\
\hline
\end{tabular}

Pildes and Tokaji (2013) examined the number of submissions and objections to the DOJ and DC between 2000 and 2012 (see table 2-1 above). Of the 208,047 submissions, only 76 were objected to, which equated to a $0.04 \%$ objection rate. In recent years, scholars have debated the causes of Sections 4 and 5's apparent irrelevancy. Some scholars argue that the small number of objections is a result of "voluntary compliance" with the preclearance provision on the part of jurisdictions (Fraga and Ocampo 2016; Ball et al. 1982). Once the DOJ or the DC objected a voting change, the local jurisdiction must comply with the result; however, there is no way for DOJ or DC to enforce it other than the hope that the local jurisdiction will support the objection (Fraga and Ocampo 2016; Ball et al. 1982). Whether they actually want to protect the voting

\footnotetext{
11 The Change Types are different than the ones presented in Pidles and Tokaji (2013). They had 15 categories which I condensed into 5: Annexations (dealing with any type of land consolidation), Elections (election methods, special elections, selection type, \& bilingual procedures), Redistricting (reapportioning \& redrawing of congressional districts), Ballot Access (voter registration, qualification, \& voting venue), and Other (miscellaneous procedures).
} 
rights or all citizens or they anticipate that proposed changes that are discriminatory in nature will be objected to, state and local election officials may avoid proposing chances that they anticipate will have discriminatory results.

Other scholars believe that Court cases such as Beer and Bossier made it difficult for the DOJ and the DC to object to even the most obviously discriminatory voting change (McCrary et al. 2006). As shown in in table 2-2 below, there were nearly six times as many objections in the 1970 's as there were in the 2000s. McCrary et al. (2006) attribute this decline to the litigation surrounding the discriminatory purpose and effect prongs in Beer and Bossier. Following Beer in 1976, it became harder for the DOJ or the DC to prove that a jurisdiction's proposed changes were discriminatory under the "effect" prong, which explains the decline in objections from the 1970 's to the 1990's. Comparing the 1990s to the 2000s, the number of objections decreased from 402 to 76 . McCrary et al. blame this decline in objections on the "purpose" prong restrictions set forth by the Bossier case.

\begin{tabular}{|l|l|l|l|l|l|l|l|l|l|}
\hline \multicolumn{10}{|c|}{ Table 2-2. Type of Objections by Decade } \\
\hline Change Type & $\mathbf{1 9 7 0 s}$ & $\mathbf{\%}$ & $\mathbf{1 9 8 0 s}$ & $\mathbf{\%}$ & $\mathbf{1 9 9 0 s}$ & $\mathbf{\%}$ & $\mathbf{2 0 0 0 s}$ & $\mathbf{\%}$ & Totals \\
\hline Annexations & 34 & $7 \%$ & 47 & $11 \%$ & 24 & $6 \%$ & 5 & $4 \%$ & 108 \\
\hline Elections & 292 & $59 \%$ & 150 & $35 \%$ & 104 & $26 \%$ & 23 & $29 \%$ & 569 \\
\hline Redistricting & 86 & $17 \%$ & 165 & $38 \%$ & 209 & $52 \%$ & 35 & $51 \%$ & 499 \\
\hline Ballot Access & 77 & $15 \%$ & 64 & $15 \%$ & 56 & $14 \%$ & 12 & $16 \%$ & 209 \\
\hline Other & 9 & $2 \%$ & 5 & $1 \%$ & 9 & $2 \%$ & 1 & $0 \%$ & 23 \\
\hline Totals & 498 & $100 \%$ & 431 & $100 \%$ & 402 & $100 \%$ & 76 & $100 \%$ & 1407 \\
\hline $\begin{array}{l}\text { Source: McCrary, Patrick, Christopher Seaman, and Richard Valelly. 2006. “The End of Preclearance as We Know It" \& About Section 5 from the } \\
\text { Department of Justice }\end{array}$ \\
\hline
\end{tabular}

${ }^{12}$ The decades of $1970 \& 2000$ have additional years that do not belong to their respective categories: 1970 includes $1965-1969 \& 2000$ includes 2010-2013. 
Scholars also observed that when the DOJ or DC objected a local jurisdiction's submission, that objection normally dealt with redistricting, and not ballot access (Bullock et al. 2016; Pildes and Tokaji 2013). Redistricting is any voting change that has to do with the redrawing of congressional district lines, whereas ballot access deals with voter registration, voter qualification, and changes in precincts. As can be seen in table 2-2, redistricting generated more objections than any other type of change in every decade except for the 1970's. At its conception, the Voting Rights Act was created to ensure equal opportunities at the voting booth for all races. Based on table 2-2 and the work of other researchers (Bullock et al. 2016; Pildes and Tokaji 2013), however, it is evident that Section 5 was used primarily in cases for redistricting and other matters of vote dilution than protecting the right of eligible citizens to cast a vote (Bullock et al. 2016 35).

In short, the merits of the Shelby ruling have been extremely contentious. Some scholars believe the Court made the right decision because Sections 4 and 5 have been irrelevant in recent years (Bullock et al. 2016; Pildes and Tokaji 2013), whereas scholars on the "anti-Shelby" side believe that Sections 4 and 5 should have been upheld, as although they were rarely used, they did prevent many discriminatory practices from being implemented (McCrary et al. 2006). In my opinion, the wisdom of the Court's decision in Shelby depends on whether formerly covered jurisdictions implement discriminatory voting practices in the future. Based on events that transpired immediately after the Shelby ruling, I argue that if presented with an opportunity to do so, the Supreme Court should reconsider its position on the constitutionality of the coverage formula established by the Voting Rights Act. Moreover, those events suggest that if Congress wishes to protect the voting rights of citizens of all races and ethnicities, it may need to pass 
legislation that revises the coverage formula in a way that is likely to pass constitutional muster according to federal courts.

In the years following Shelby $v$. Holder, states began implementing voting changes that otherwise would have been blocked by the preclearance provision if it were still in effect. According to the Brennan Center, within 24 hours after the Shelby case concluded, Texas announced that it would implement a strict photo ID law. This was the same strict photo ID law that was declined preclearance several years earlier on the grounds that it "imposed strict unforgiving burdens on the poor, and racial minorities in Texas' who disproportionally live in poverty" (U.S. Commission for Civil Rights 2018 76). As stated in the previous section, voting changes by jurisdictions (that seem to be discriminatory like this one) can be challenged by the federal government or by the private sector in a court of law. For instance, those who are challenging the legitimacy of a voting change often argue the jurisdiction violated Section 2 of the Voting Rights Act, a provision that was not affected by the Shelby decision. In the Texas case under consideration here, the NAACP filed a complaint over the Texas voter ID law. In NAACP v. Steen, the District Court ruled that the law did, in fact, violate both Section 2 of the VRA and the $14^{\text {th }}$ and $15^{\text {th }}$ Amendments of the Constitution. However, litigation can only go so far, and shortly after that, Texas passed on another law regarding strict voter ID that was upheld as constitutionally valid in the Veasey v. Abbot (2016) case (Brennan Center 2018).

Another example of Shelby's immediate impact could be seen in North Carolina. Less than two months after the landmark case ended, the Tar Heel State instituted several voting changes, including a strict photo ID requirement, a shortening of the early voting period, and the elimination of same-day registration. As it did in the Texas case, the NAACP filed a complaint against the state of North Carolina on the grounds that their voting change bill violated Section 2 
of the VRA. In July of 2016, the Court of Appeals ruled in favor of the NAACP, saying that the North Carolina’s House Bill 589 “targeted African Americans with almost surgical precision” (Brennan Center 2018). Even though the voting change was not implemented, legislation like that enacted in Texas and North Carolina continues to appear across the United States, especially in former covered jurisdictions.

Other voting procedure changes that occurred more frequently following Shelby v. Holder were polling place closures. More specifically, voting jurisdictions were closed and consolidated polling places in areas with substantial non-white populations. Between the 2014 midterm election and the 2016 general election, there were over 800 polling place closures in areas formerly under preclearance that has particularly large non-white populations. According to the LCEF, the 2016 general election took place in the wake of the largest number of closures in United States history. ${ }^{13}$

The determination of the location of polling places is done through the process of reprecincting, which is the process of closing, moving, or reconsolidating precincts. Reprecincting is often overlooked by scholars and commentators because it happens at the county level (or at the city level, depending on how elections districts are divided). In the following section, I discuss how the reprecincting process works as well as how it differs from other election processes like reapportionment and redistricting. I believe that it is important to understand how reprecincting works, because doing so allows one to better understand the causes and effects of The Great Poll Closure.

\footnotetext{
${ }^{13}$ The Leadership Conference Education Fund. 2016. “The Great Poll Closure”. http://civilrightsdocs.info/pdf/reports/2016/poll-closure-report-web.pdf
} 


\section{Understanding Reprecincting}

Reprecincting is the act of moving, consolidating, or changing a precinct within a voting jurisdiction (Amos, Smith, and Ste. Claire 2017). A precinct is the smallest geographical unit of an electoral system (Hale, Montjoy, and Brown 2015). Within each precinct, there is at least one polling place which the voters within the precinct boundaries can place their ballot. Maintaining this standard requires those in charge to choose polling locations that are easily accessible to all voters in the precinct. As explained in the last section, political considerations have led to the violation of this principle especially following Shelby. Reprecincting is one of many election administration processes in the United States, and it is important to understand its relationship with other processes.

The first step in understanding reprecincting is to understand that election administration operates on two levels: state and local. At the state level, election administration starts with each states' Chief Election Officer (or CEO). Some states combine the duties of the CEO with those of some other high-ranking position such as the Secretary of State or Lieutenant Governor. States also vary when it comes to selection method; some states directly elect their CEOs, while others appoint them. In terms of duties, States' CEOs tend to have similar responsibilities: implementing uniform election laws, maintaining a central registration file, and approving voting equipment used by the local jurisdictions.

In terms of the elections themselves, the CEO's have little to no authority. That power is wielded by Local Election Officials (LEOs). In fact, most states assign the primary responsibility for the conduct of elections to LEOs. States vary in terms of how these LEOs are selected. For example, in Florida, local election officials are elected on a partisan ballot. In other states, 
however, LEOs are appointed and non-partisan. Like the CEOs, the duties assigned to LEOs may also be part of the job description of a more prominent position. According to Hale, Montjoy, and Brown (2015), LEOs are most commonly county clerks, recorders, and/or registrars. In California's 58 counties, $60 \%$ of the LEOs have duties beyond that of election administration. In terms of selection method, roughly half the states elect their LEOs, while in the other half of states, LEOs are appointed by the mayor or the local governing body (i.e. city council or county commission).

Each LEO has authority over his or her own voting jurisdiction. Jurisdiction boundaries are created based on the boundaries of counties, cities, and/or townships (mainly in New England states). There are other localities that conduct elections such as school districts and city council districts, but these elections are for district-specific positions such as city-council representative and mayor and not for state and local offices ${ }^{14}$. Each jurisdiction varies in size. For example, Rhode Island has a town with roughly 300 registered voters, whereas a Los Angeles County has over 4 million registered voters. Within these jurisdictions, LEOs determine the rules and regulations of elections such as creating or changing the boundaries of the voting precincts (or reprecincting). In some states, the local governing office has the final say regarding precinct design, but the LEO provides significant input. Either way, the LEOs play a key role in the way the precincts are designed in voting jurisdictions. LEOs determine precinct boundaries after the process of reapportionment and redistricting following the decennial census. Before I describe the legal landscape of reprecincting, it is important to understand the relationships that it has with

\footnotetext{
${ }^{14}$ For the purposes of this dissertation, when I refer to voting jurisdictions, I am referring to jurisdictions that elect state and local office positions.
} 
reapportionment and redistricting as well as the roles federal and state governments have in these matters.

\begin{tabular}{|l|l|l|}
\hline Table 2-3. The Differences between Reapportionment, Redistricting, \& Reprecincting \\
\hline Jurisdiction & Process & Frequency \\
\hline Federal & $\begin{array}{l}\text { Reapportionment - Determines } \\
\text { the number of Congressional } \\
\text { seats each state is entitled too }\end{array}$ & $\begin{array}{l}\text { Every 10 years (following } \\
\text { census) }\end{array}$ \\
\hline State & $\begin{array}{l}\text { Redistricting - Sets up the new } \\
\text { district lines following } \\
\text { reapportionment }\end{array}$ & $\begin{array}{l}\text { Every 10 years (following } \\
\text { census) }\end{array}$ \\
\hline Local & $\begin{array}{l}\text { Reprecincting - Boundaries } \\
\text { are determined by the lines } \\
\text { drawn by the state; most often } \\
\text { reflect voter turnout in } \\
\text { previous elections }\end{array}$ & $\begin{array}{l}\text { Every 10 years, but; also, the } \\
\text { beginning of every election } \\
\text { year if deemed necessary by } \\
\text { county or city governments }\end{array}$ \\
\hline
\end{tabular}

Reapportionment takes place every ten years following the census. The federal government oversees this process. With the data gathered from the census, members of Congress determine the total number of representatives each state should receive in the House as well as the total number of electoral college votes that each state will have. Based on each census, some states may gain seats while others may lose seats, depending on relative population growth (or decline). Once the reapportionment process is complete, each state legislature is notified of the number of seats they are entitled too, and then redistricting begins.

Redistricting is the (re-)drawing of electoral district boundaries in each state. This process takes place every ten years following the congressional reapportionment process mentioned in the last paragraph. According to the Constitution (Article I, Section 4), "The Times, Places and Manner of holding Elections for Senators and Representatives, shall be prescribed in each State by the Legislature thereof." In 37 states, redistricting is conducted by the state legislature, whereas four states use independent commissions, and two use political 
commissions. Alaska, North Dakota, Wyoming, South Dakota, Vermont, and Delaware do not currently redistrict because they each have only one congressional district. Despite what the constitution says, the states do not have complete free reign over the drawing of districts. In fact, the federal government can (and will) intervene if it is deemed necessary. In the case Baker v. Carr (1962), the Court ruled that the federal courts now had jurisdiction to hear challenges (from citizens) to state redistricting plans. Federal courts can also intervene when state redistricting plans are redrawn to disadvantage a racial group or, in some cases, a certain political party (a process known as gerrymandering). Regardless, redistricting takes place at the state level with federal oversight if need be.

So, where and when does reprecincting fit in? First off, a precinct is the smallest geographic unit of the electoral system. Local governments (counties and cities) divide up their jurisdiction into precincts in order to administer elections and collect votes. Election officials normally place at least one polling place within each precinct. In most states, this process takes place at the beginning of each election year when a local government official or election official feels that it would benefit the voters if a precinct were opened, closed, etc. However, when county or city governments re-draw precinct lines, they are required by state law to stay within the boundaries already set up by the states in the redistricting process. As shown in table 2-3 (above), all three processes (reapportionment, redistricting, and reprecincting) are connected. With the ruling in Shelby, now, more than ever, those in charge of drawing electoral districts and voting precincts have the freedom and ability to move them in almost any way they wish. In this next section, I am going to discuss how precinct laws vary across states and discuss the implications of reprecincting for the chapters that follow. 


\section{Reprecincting Laws in the States}

Reprecincting takes place immediately following the federal decennial census as well as in the early months of primary and general election year. After careful examination of each state law, I found other patterns that states share regarding reprecincting. In total, I identified four criteria that each state requires their local jurisdictions to follow in terms of reprecincting: authorization of the process, time restrictions, size limitations, and state regulation (see table A in Appendix II for a full breakdown by state).

Authorization. Each state is responsible for identifying the official(s) who will be responsible for overseeing the establishing, creating, and/or changing of the boundaries of precincts. In most states, those who authorize the changes in precincts are either local election officials or local governing authorities. Thirty-one states (plus D.C.) require voting jurisdictions' local governing authorities to make any the precinct changes. Local governing authorities range from town councils, to city council, to county commissioner's board. Seventeen states require the voting jurisdiction's local election officials (LEOs) to make the changes regarding precincts. A LEO can be a single official or multiple officials serving on a board. Two other states, Hawaii and Delaware, have their chief election officer (CEO) conduct the alteration of precinct boundaries because of the limited number of counties in both states.

Time Restrictions. Each state's government requires their local government to follow a specific timeline when reprecincting. As noted in the previous section, reprecincting takes place every ten years following the federal census. However, reprecincting can also be conducted in other years as well. For non-census years, the timelines for most local governments to conduct reprecincting varies by state. For example, some states require their local governments to have 
the precinct process completed 2-3 months before an election, whereas other states set specific dates, normally at the beginning of the general or primary election year (e.g. January $15^{\text {th }}$ or $\left.\operatorname{March} 15^{\text {th }}\right)$.

Size Limitations. Each state requires local governments to place precincts within the boundaries of the legislative district created by the state legislatures (or commissions). States also recommend that their local governments provide "clearly observable boundaries using visible ground features which meet the requirements of the federal bureau of the census and which coincide with census block boundaries as established by the federal bureau of the census" (Kansas Code 25-26a02). In short, the boundaries must adhere to the guidelines established by the Federal Census Bureau. Most states also recommend that local governments take the number of voters per precinct into consideration when changing or closing precincts. Some states were more specific than others when defining their population parameters. For example, Georgia requires that there be a minimum of 100 voters per precinct whereas Iowa provides both a minimum and a maximum. Another option that states consider in to determining precinct size is turnout in previous elections. For example, if the voter list was smaller than it was in previous years, the local governing body can change or consolidate the precincts. In short, states provide local governments with population criteria to follow when determining precincts.

Regulation. The states require their local governments to send their proposed precinct boundaries to the Secretary of State's (SOS) office (or to the State Board of Elections if it is not a part of the state's SOS) for approval or notification. Most states require a written description of changes made to precincts as well as a detailed map illustrating those changes. In Table 2-4, there are two copies of state laws on reprecincting. Example 1 is from a large state from the Northeast (New York) and example 2 is from a small state from the West (Idaho). 
Table 2-4. Examples of Reprecincting State Laws

\author{
Example of State Statute 1: New York \\ 1. The State of New York shall be divided into election districts which shall be the \\ basic political subdivision for purposes of registration and voting as provided in \\ this chapter.
}

2. General Information: [The creation, consolidation, division or alteration of election districts shall be done by the board of elections.]

3. Boundary and Size Guidelines: [a. Each election district shall be in compact form and may not be partly within and partly without a ward, town, city, a village which has five thousand or more inhabitants and is wholly within one town, or a county legislative, assembly, senatorial or congressional district. Except as provided in paragraph $b$ of this subdivision, election district boundaries, other than those boundaries which are coterminous with the boundaries of those political subdivisions mentioned in this paragraph, must be streets, rivers, railroad lines or other permanent characteristics of the landscape which are clearly visible to any person without the need to use any technical or mechanical device. An election district shall contain not more than nine hundred fifty registrants (excluding registrants in inactive status) or, with the approval of the county board of elections, not more than eleven hundred fifty registrants (excluding registrants in inactive status), but any election district may be divided for the convenience of the voters.] b. An election district in a city or town may divide a block, provided that the board of elections prepares an alphabetical list of all the streets in such city or town with the election district for each such street. If any such street is divided between two or more election districts, then such list must contain the lowest and highest street numbers in each such district and if the odd and even numbers on a street are in different districts, such list must contain separate listings for such odd and even numbers and if there are both odd and even numbers in such different election districts, such list must contain separate listings for such numbers. Copies of such lists shall be filed and kept open to public inspection in the offices of such board. Regulation: [One copy of each such list shall be delivered, upon request, to the state board of elections and to a person or officer designated jointly by the speaker of the assembly and the temporary president of the senate.l surplus copies shall be sold at cost.

4. Any election district must be realigned when the total number of registrants, excluding registrants in inactive status, at the time of the preceding general election, exceeds the maximum number permitted by this section by at least fifty registered voters.

5. Time Restrictions: [Any creation, consolidation, division or alteration of election districts in any calendar year shall be made on or before February fifteenth, and shall take effect on April first, except that when required by the creation or alteration of a political subdivision, other than an election district, in which candidates are to be voted for at the next election, such creation, consolidation, division or alteration shall be made and shall take effect immediately upon creation or alteration of such political subdivision. No such creation, consolidation, division or alteration shall be made between February twentieth of a calendar year ending in seven and December first of a calendar year ending in zero unless required by the creation or alteration of a political subdivision.]

Example of State Statute 2: Idaho 


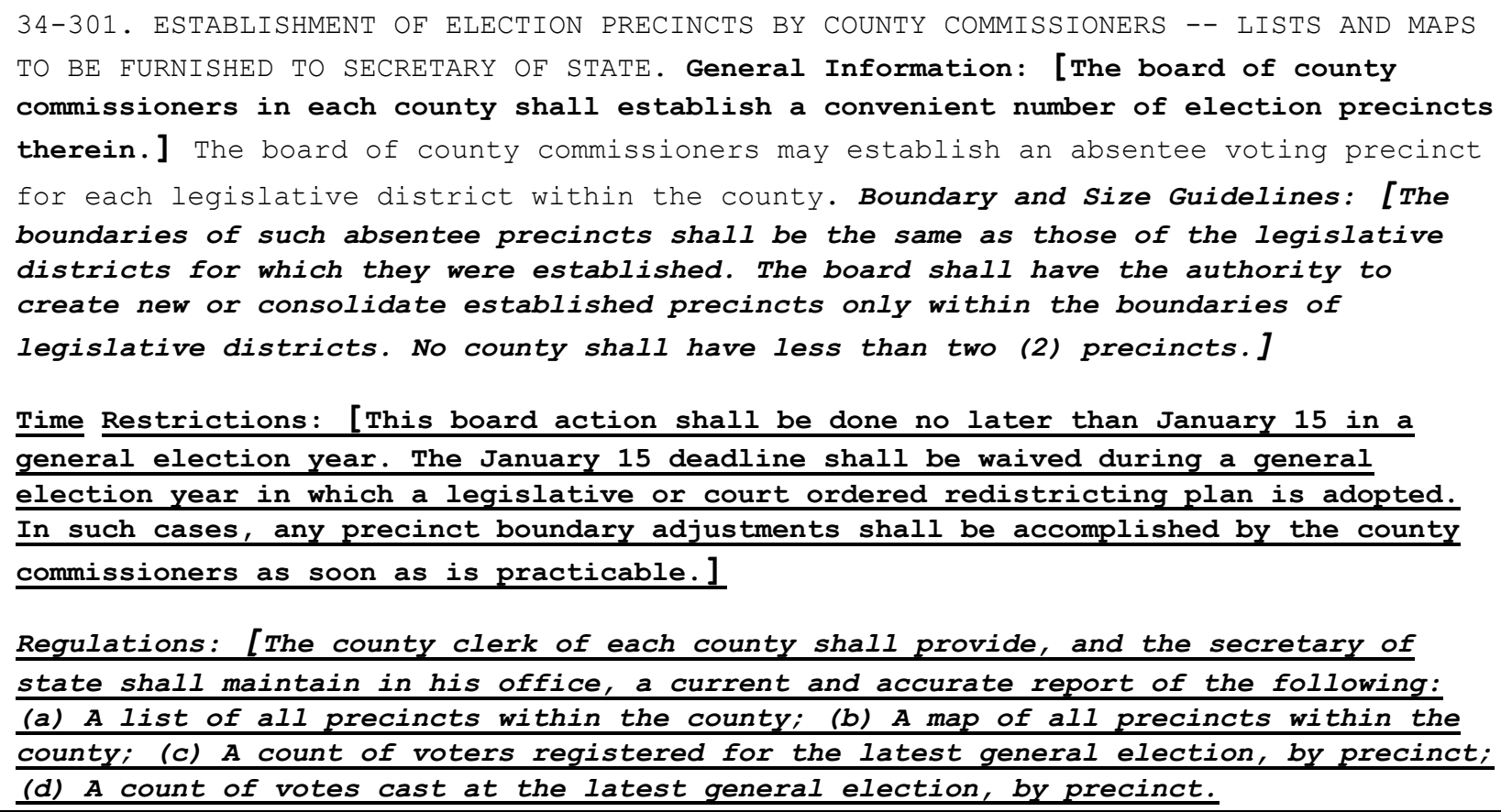

In the two examples provided in table 2-4, all four criteria that I mentioned above are codified. However, some of the language may differ. Take boundary and size guidelines, in the first example, New York, the law specifies the minimum and maximum number of voters allowed in each precinct, whereas in the second example, Idaho, did not mention a requirement for the number of voters per precinct but provided information on the minimum total number of precincts per county. The reason is the difference in the sizes of the two states. For example, New York has one of the largest populations in the United States, which means there are many voters, and thus the precincts need to be big enough to accommodate everyone and allow them to vote within a reasonable amount of time. In short, stating a minimum and maximum number of voters makes sense for a state as large as New York. Idaho, on the other hand, has one of the smaller populations in the United States, so precincts being over-crowded with voters is most likely not a priority. In short, the wording may be different in each state's laws regarding precinct changes, but the criteria remain the same. 


\section{Reprecincting in a Post-Shelby America}

As I mentioned in the last section, understanding how precinct boundaries are drawn is important because those boundaries affect the location of the traditional polling place for that precinct. For example, suppose that prior to an upcoming election, precinct A was closed due to low voter turnout in the previous election. The registered voters of what formerly precinct A will now have to cast votes at a polling place located in the new precinct that their previous precinct was merged with, precinct B. Precinct B's polling place may be 5 miles away from where precinct A's polling place was originally located. Because of this decision by local election and government officials to consolidate precincts, the registered voters who previously voted in precinct A must now travel an additional 5 miles to vote. Despite this being a hypothetical example, precinct changes like this have become more common since the Shelby ruling in 2013. For example, The Leadership Conference Education Fund (LCEF) identified several former preclearance states (Arizona, Texas, Louisiana, Mississippi, Alabama, South Carolina, North Carolina, and Georgia) as having made significant numbers of precinct changes following Shelby. Arizona led the way in poll closures, leaving it with 212 fewer places to vote in 2016 than in 2012. ${ }^{12}$ Maricopa County accounted for a large percentage of the 212 closures. In the weeks leading up to the March primary, Maricopa County's Board of Supervisors announced a new precinct plan that would close almost half of the precincts that were open during the 2012 election cycle. As a result of this poorly executed plan, wait times to vote sometimes exceeded five hours, and turnout rates were lower among poorer citizens and residents of more rural areas. In defense of the plan, a member of the Supervisor's Board stated that “it isn't a big deal if you have to drive five miles to get to a 
polling place in Buckeye [rural town in Arizona], because you have to drive 5 miles to get to the grocery store" (O'Dell and McGlade 2016). Public outrage, media attention, and litigation eventually led the County Supervisor's Board to reopen the polling places that were available in 2012 .

Maricopa County was not the only county in Arizona to cut its number of precincts in half. Pima County, the state's second largest county (behind Maricopa), closed more polling places than any other jurisdiction in the LCEF sample. Since Shelby, 62 polling precincts have been shut down in Pima County, a county that happens to have one of the largest Latino populations in the United States. In 2012, there were 280 precincts, but by 2016, there were only 216 .

Though not every county in North Carolina was a covered jurisdiction, the state also saw controversial precinct changes since Shelby. As mentioned earlier, hours after the Shelby decision was made, North Carolina passed an expansive voting law that affected voter ID requirements and wait-times. A U.S. Court of Appeals Judge called it "a monster voter suppression law" and argued that it discriminated against voters with "almost surgical precision" (LCEF 2016). There were 40 formerly preclearance districts in North Carolina, and across 12 of those districts roughly 12 percent of precincts were closes, resulting in there being roughly 27 fewer places to vote in the 2016 election (LCEF 2016). For example, in Cleveland County, which is $40 \%$ Black, local election officials merged five precincts into two in an urban area. A local NCAAP leader stated that "we know that this is part of a bigger trend - a movement to suppress people's right to vote" (LCEF 2018). 
Many polling places also closed in Georgia following Shelby. Since 2012, Georgia has closed over 200 precincts, especially in more rural areas (Niesse 2019). In 15 of Georgia's 159 counties, citizens only have one precinct in which to cast their votes. This is problematic for those citizens who live far from polling locations or do not have easy access to transportation. Local election officials argue the changes were necessary because they helped the counties save money, but advocates say otherwise. A member of the Georgia ACLU, Sean Young, argued that "the reason so many polling place closures have happened is because election officials no longer have to get them precleared" (Niesse 2019). According to the Atlanta-Journal Constitution, in 2015, the former Secretary of State, Brian Kemp, reminded the local election officials in a memo, that "counties are no longer required to submit precinct changes to the federal government because of the Supreme Court decision" (Niesse 2019). Kemp, who is now the current governor, later stated that he did not encourage LEOs to alter precincts a certain way and that his memo reminded local election officials "to follow the law when considering polling place changes" (Niesse 2019).

The Georgia example as well as the other examples provided in this section are microcosms of the potential voting rights issues associated with reprecincting. Is it a coincidence that when the preclearance provision of the Voting Rights Act became inactive, the number of traditional polling places decreased, especially in areas that were in former pre-clearance states, especially in areas with large non-white populations? Alternatively, do declining numbers of voters who vote at traditional polling places explain election officials' decisions to consolidate or close precincts? In the next chapter, I answer these questions by looking at polling place data from over 2,270 voting jurisdictions. I test whether each of several factors, including LEO 
selection method and the size of the non-white population are significantly associated with polling place closures. 


\section{CHAPTER 3: Explaining "The Great Poll Closure"}

As stated in the previous chapters, due to the invalidation of the $4^{\text {th }}$ and $5^{\text {th }}$ sections of the Voting Rights Act by the Shelby case, the 2016 election was the first presidential election held in over 50 years during which the full protection of the VRA was not guaranteed. As a result, there were over 800 precinct closures in formerly preclearance areas prior to that election. The Leadership Conference Education Fund (LCEF) coined this precinct closure phenomena as "The Great Poll Closure" in their 2016 study. ${ }^{15}$ Because The Great Poll Closures is still relatively new, political science scholarship on the phenomenon is scarce. However, news outlets and organizations such as the LCEF, ${ }^{16}$ the Thurgood Marshall Institute, ${ }^{17}$ and the Washington Post $^{18}$ have published several descriptive reports regarding the closing of polling places. For example, in September of 2019, the Leadership Conference Education Fund(LCEF) updated their 2016 study by analyzing the number of poll closures from the 2012 general election to the 2018 midterm election. ${ }^{19}$ They found that on average, former preclearance jurisdictions were more likely to close precincts than jurisdictions in non-preclearance states. In total, they found over 1,100 fewer polling places in 2018 than in 2012.

In both its 2016 and 2019 reports, the LCEF also identified another pattern in polling place closures. Counties who closed precincts in both 2016 and 2018 were more likely than other counties to have large non-white populations. Both the preclearance and non-white population patterns can be seen in table $3-1$. The 15 counties that experienced the most poll closings between 2012 and 2016 were all in states formerly subject to preclearance and had

\footnotetext{
${ }^{15}$ The Leadership Conference Education Fund. 2016. "The Great Poll Closure". http://civilrightsdocs.info/pdf/reports/2016/poll-closure-report-web.pdf

${ }^{16}$ The Leadership Conference Education Fund. 2016. "The Great Poll Closure". http://civilrightsdocs.info/pdf/reports/2016/poll-closure-report-web.pdf

${ }^{17}$ Thurgood Marshall Institute at LDF. "Democracy Diminished: State and Local Threats to Voting”. https://www.naacpldf.org/wp- content/uploads/DemocracyDiminished-State-and-Local-Threats-to-Voting-Post-Shelby-County-Alabama-v.-Holder.pdf

${ }^{18}$ Ingraham, Christopher. 2018. "Thousands of Polling Places Were Closed Over the Past Decade. Here's Where". Washington Post.

https://www.washingtonpost.com/business/2018/10/26/thousands-polling-places-were-closed-over-past-decade-heres-where/

${ }^{19}$ The Leadership Conference Education Fund. 2019. "Democracy Diverted". http://civilrightsdocs.info/pdf/reports/Democracy-Diverted.pdf
} 
relatively large non-white populations.

\begin{tabular}{|c|c|c|c|}
\hline \multicolumn{4}{|c|}{ Table 3-1. The 15 Counties with the Most Polling Places Closures } \\
\hline State & County & Total Change & $\%$ Non-white \\
\hline Arizona & Pima & -62 & $48 \%$ \\
\hline Texas & Williamson & -35 & $40 \%$ \\
\hline Arizona & Maricopa & -33 & $44 \%$ \\
\hline Arizona & Mohave & -32 & $23 \%$ \\
\hline Arizona & Cochise & -31 & $45 \%$ \\
\hline Texas & Nueces & -29 & $70 \%$ \\
\hline Texas & McLennan & -27 & $44 \%$ \\
\hline Texas & Brazoria & -24 & $52 \%$ \\
\hline Louisiana & Jefferson & -23 & $59 \%$ \\
\hline Texas & Fort Bend & -18 & $66 \%$ \\
\hline Texas & Jefferson & -17 & $59 \%$ \\
\hline Arizona & Gila & -16 & $37 \%$ \\
\hline Alabama & Elmore & -14 & $27 \%$ \\
\hline Texas & Smith & -14 & $40 \%$ \\
\hline Texas & Travis & -14 & $51 \%$ \\
\hline
\end{tabular}

Though journalistic reports do an excellent job of providing a reader with a basic understanding of The Great Poll Closure, they do miss some important aspects of the causes of polls closures following the Shelby case in 2013. As I explained in chapter 2, there are constitutionally valid reasons for jurisdictions to close or relocate a polling place such as a lack of voters, fiscal constraints, or the abundance of early voting options. The goal of this chapter is to establish why polls are closing more frequently following the Shelby case, and to do that, I must account both for constitutionally valid reasons for closures and for changes to election procedures that may have been enacted with discriminatory intent or had discriminatory effects. The chapter illustrates that voting jurisdictions previously subject to preclearance are in fact closing precincts more frequently following Shelby.

\section{Effects of Poll Closures}

Before explaining why poll closures take place, I believe it is important to discuss why 
these closures are significant and how they can affect voters. Based on previous research, there is a consensus that polling place closures do cause a significant decrease in turnout (Dyck and Gimpel 2005; Brady and McNulty 2011; Amos, Smith, and Ste. Claire 2017; Clinton et al. 2020). These scholars attribute the decline in turnout to the search and/or travel costs that poll closures entail. However, due to the typically relatively small distances between the new and old polling locations, scholars have found that the search costs seem to be the most important factor related to polling locations when citizens decide whether to vote in jurisdictions that have new polling places.

There are also several indirect effects of polling place closures on turnout. When closing or consolidating a precinct, there is a good chance that the new location will have to service a larger number of voters, which can ultimately lead to a number of problems that are detrimental for voter turnout. These problems include longer wait times (Herron and Smith 2016; Fortier et al 2018; Stein et al 2019), inadequate poll workers (Burden and Milyo 2015; Claasen, Magelby, Monson and Patterson 2008, 2013; Hall, Monson and Patterson 2009; Atkeson and Saunders 2007) and difficulties with voting equipment (Spencer and Markovits 2010). In short, polling place closures are significant to voters because they can cause a decrease in political participation. I will be taking a deeper dive into understanding how polling place closures affect voter turnout in chapter 4.

\section{Measuring Polling Places Closures}

In measuring polling place closures between elections, I will not be using a straight comparison of the raw number of precinct closures that occur in counties. I believe that it would be difficult to meaningfully compare precinct closures between jurisdictions of very different sizes, such as one jurisdiction with 400 voters and another with 10,000 voters. The impact of 
the number of closures would not be the same. For example, if we stick with those two hypothetical counties and they both had 10 closures, I would expect that citizens in the former jurisdiction would be affected by the closings to a much greater extent than citizens in the latter.

To account for the population size problem, the number of voters per precinct is measured in each county in each election year - 2008, 2012, and 2016. This value is the total number of active voters divided by the total number of traditional polling places. To measure precinct closures across the elections, I create a differenced variable referred to as the "percentage change in voters per precinct" or PCVPP. PCVPP is calculated by finding the percentage change in voters per precinct between the former and latter elections. In my analyses, there will be two PCVPP variables: one for percent change from 2008 to 2012 and another for percentage change from 2012 to 2016 (see the Appendix for more details). In sum, those voting jurisdictions with significant amounts of poll closures between elections will typically have positive values of PCVPP and voting jurisdictions that open many new polling places will typically have negative values.

\section{Why Do Polling Place Closures Occur?}

As noted in chapter 2, there are several reasons that a polling place might be shut down. I sort those reasons into two categories: (1) constitutionally valid reasons and (2) politically motivated reasons. Constitutionally valid reasons are ones that are "by the book" according to state and county laws and regulations (see chapter 2 for more details). These reasons include budgetary issues and the expansion of alternative voting options.

I label the second category of reasons for closures politically motivated because this category of reasons includes decisions to close polling places in order to further advance political agendas. One example would be related to the selection methods of the local 
election officials (LEOs), who play a large role in decisions related to precinct boundaries and polling place locations. ${ }^{20}$ If an LEO is elected, an example of a political motivation would be to appease the electorate in hopes of being re-elected, whereas if an LEO is appointed, that LEO might have a political motivation might to appease the officials who appointed them. I believe this dichotomy in selection method between elected and appointed officials is important to explaining polling place closures.

Another politically motivated reason for closing polls might be to discourage members of non-white populations from voting in ways that were not possible in the decades prior to the Shelby decision. As previously mentioned, the 2016 election was the first presidential election without the coverage formula and preclearance provision of the VRA being in effect since the early 1960's. Local lawmakers in these formerly preclearance areas now had the opportunity to make election law changes that they could not make in the preShelby era. I will explain whether election officials intended to discourage non-whites from voting or not by testing whether the size of jurisdictions' non-white populations was associated with decisions to close polling places in these areas. In the following paragraphs, I discuss each reason in turn and describe my expectations regarding poll closures from 2008-12 and 2012-16.

\section{Budgetary Constraints}

As explained in chapter 2, a number of budgetary factors play into decisions regarding creating and closing or moving precincts. These factors include costs associated with (1) poll workers, (2) voting machine equipment, and (3) polling place housing. In terms of election

\footnotetext{
${ }^{20}$ As described in chapter 2 , the county governing body usually determines the boundaries of the precincts in each jurisdiction. The LEOs are usually consulted in the precinct process and oversee determining the location of the action polling place.
} 
administration spending, states normally require local jurisdictions (i.e. counties and cities) to cover the expenses of elections. However, in more recent years, some states have offered to help jurisdictions with the large costs of elections in several different ways. For example, in Delaware and Alaska, where election administration is highly centralized, the state department handles all expenses surrounding elections. Some states pay a flat rate to jurisdictions for each election. For example, Kentucky reimburses each county's precincts for the costs of elections at a set rate of \$255 annually. Rhode Island covers the costs of their local jurisdictions' polling place supplies, ballots, and voting equipment (Hubler and Underhill 2018).

Some states are not as generous and have conditional relationships with local jurisdictions. For example, Alabama, Colorado, Hawaii, and Louisiana cover election expenses if there are state contests or issues on the ballot. Other states only pay for special state-wide elections that do not coincide with general or primary elections. In short, despite the efforts of particular states to cover all or most of their localities' election costs, most election administration expenses are still burdens on local jurisdictions, and this explains why budgetary constraints are important when it comes to determining whether to close polling places.

The first budgetary issue related to polling places is the cost associated with poll workers. In most cases, poll workers are registered voters, and some jurisdictions even require workers to be voters in the precincts in which they work. In terms of the relationship with poll closures, often the states require that there be a specific number of workers per polling station as well as an equal number of members of all major parties (Hall, Montjoy, \& Brown 2015). Along with these such guidelines, poll workers are often paid a small wage. Not only are poll workers difficult to find, they are also hard to retain given the small amount of pay. When local election officials make decisions on polling locations, one major consideration is the necessity of finding 
and paying for poll workers. Research has shown that poll worker staff quality can be detrimental to a voter's confidence (Hall, Monson, \& Patterson 2009). The inability to provide sufficient staffing can be one reason a polling place closure will take place.

The availability of sufficient numbers of voting machines can also play a role in poll closures. Two types of voting machines are used in American elections: paper ballot scanners and configured computers with touch screens that allow voters to record their choices electronically (Hale, Montjoy, \& Brown 2015). Both types of machines are purchased by local election jurisdictions (i.e. counties or townships). Following the voting controversies that arose during the 2000 presidential election, ${ }^{21}$ the federal government created the Help America Vote Act (or HAVA), which worked to standardize election administration. Jurisdictions benefited from HAVA in the early 2000s, when they received federal funds allocated by the act, but those funds have all but disappeared. Now, local jurisdictions are running into budgetary issues with the maintenance of voting machines. HAVA also required that jurisdictions have at least one machine accessible to people with disabilities. If jurisdictions cannot afford the new updates to machines, polling place locations will have to close or relocate.

The last budgetary issue that causes polling places to close is the high cost of renting polling place locations. In most cases, local jurisdictions rent locations for their election day polling places. For example, churches and volunteer fire halls are often used. With large sums of money going to poll workers, voting machine equipment, and rent, jurisdictions often have to close polling places and consolidate them with other precincts, which can lead

\footnotetext{
21 Between four and six million votes were discarded in the 2000 election. Of those votes, roughly two million votes were not counted due to faulty, aged equipment, or poorly designed ballots in the 2000 election. For more information on this, see this article: https://www.cnn.com/2001/ALLPOLITICS/07/16/voting.problems/index.html.
} 
to a number of different problems, such as long check-in and wait-times. In short, a major reason for closing precincts stems from budgetary issues. To account for this in my nationwide analysis, I use each jurisdiction's median household income, taken from the U.S. Census. ${ }^{22}$ I expect poorer jurisdictions (with smaller median incomes) to have more polling place closures in each election analyses. In sum, I believe poorer jurisdictions will see larger values of PCVPP in both the pre- and post- Shelby analyses.

\section{Alternative Voting Options}

Some of the most important things that a local election official must consider when altering precincts are the limitations on precinct size set forth by the state. For example, some states establish a minimum number of voters that must reside in a precinct for the precinct to remain open. Other states specify a maximum number to avoid overcrowding. One major factor that plays into the number of precincts set by local election officials each election year is the availability of alternative voting options. According to McDonald (2012), the percentage of the electorate in 2012 who cast a ballot before election day was up to $30 \%$, including a majority of voters in 9 states. If a state issues laws making it easier to vote early, by-mail, or absentee, there is a good chance that the number of traditional election day voters will decrease.

According to data reported by the Election Assistance Commission (EAC), over 130,000 traditional polling places were used nation-wide during 2008 while only 119,968 traditional polling places were used in 2012, meaning that the number of precincts declined by over 13,000. 3,000 fewer precincts were used in 2016 than in 2012, a smaller but still significant decrease. When factoring in alternative voting opportunities (as discussed above),

\footnotetext{
${ }^{22}$ I would have liked to have used election budgets for each jurisdiction, but unfortunately, within the scope of the project, I could not find the data for all 2,270 jurisdictions. I discuss this and other limitations of this variable in more detail in the discussion and conclusion sections of this chapter.
} 
these decreases do make sense in light of financial constraints. For example, as shown in table 3-2, states with stricter laws regarding early voting and absentee balloting (those with no early voting and excuse-only absentee balloting) had smaller values of percentage change in voters per precinct in 2012 and very small values in 2016. This makes sense given the lack of opportunity to cast votes outside of traditional polling places on election day in those states.

\begin{tabular}{|c|c|c|}
\hline \multicolumn{3}{|c|}{$\begin{array}{l}\text { Table 3-2. Average PCVPP by States' Types of Early Voting and } \\
\text { Absentee Voting Laws* }\end{array}$} \\
\hline & 2012 & 2016 \\
\hline No Early Voting/Excuse Only Absentee & $8 \%$ & $5 \%$ \\
\hline Early Voting/Excuse Only Absentee & $15 \%$ & $13 \%$ \\
\hline Early Voting/No-Excuse Absentee & $20 \%$ & $14 \%$ \\
\hline \multicolumn{3}{|c|}{$\begin{array}{l}\text { *This table features } 41 \text { states plus D.C. Reliable precinct data for at least one of the three election years in the } \\
\text { analysis (2008, 2012, \& 2016) was unavailable for Alaska, Utah, Illinois, Wisconsin, New York, and New Mexico. } \\
\text { Colorado, Washington, and Oregon are omitted because they do not have traditional polling places; all their elections } \\
\text { are administered by mail. }\end{array}$} \\
\hline
\end{tabular}

On the other hand, states with more relaxed laws towards early voting and absentee balloting (those that allowed early voting and no-excuse absentee balloting) saw larger values of PCVPP, with $+20 \%$ in 2012 and $+14 \%$ in 2016 on average. In short, based on the evidence from table 2 , the more relaxed states are in terms ofnon-traditional precinct voting, the more likely those states will close polling places.

Outside of early voting, some states also introduced voting centers to replace traditional polling places. Voting centers are "fewer in number than precinct-voting stations, centrally located to major population centers (rather than distributed among many residential locations), and rely on county-wide voter registration databases accessed electronically at each polling site" (Stein and Vonnahme 2008 489). In other words, voters can cast votes in any voting center inside their jurisdiction regardless of residential address. In the 2012 election, ten states passed legislation to allow voting centers (NCSL 2019). Like relaxed early voting laws, the opening of 
voting centers could also be contributing to precinct closures.

I also expect relaxed early voting laws and voting centers to have similar effects in 2016. According to the National Conference of State Legislatures, 39 states and the District of Columbia began to offer early voting options by 2016. All 50 states and the District of Columbia also offered some form of absentee balloting. Voting centers also gained traction in 2016, with six more states adding county-wide vote centers (NCSL 2019). In short, with the rise in non-traditional election-day voting opportunities in each election year, I expect the number of precincts to decrease, thus resulting in an increase in numbers of voters per precinct.

\section{Local Autonomy with Respect to Poll Closures}

In terms of election administration, one function that is often overlooked is the operation of elections at the local level. This includes decisions such as where elections will be held and who will work the polls. Local election officials often find public buildings such as schools or firehouses to serve as polling places to avoid the need to spend money on renting buildings. In short, although local election officials have to follow state or federal law when it comes to certain aspects of election administration, they do get to make key "nuts and bolts" decisions (e.g., decisions regarding precinct boundaries and polling place locations) that may influence voter turnout or even the outcome of an election itself.

In their seminal work, Kimball and Kropf (2006) identified four types of local election officials based on the method of selection: single individuals elected by voters; boards of individuals elected by voters; appointed boards of elections; and appointed individuals. Essentially, there are two types of features that make up the selection method: whether the 
official(s) are elected or appointed and whether there are individual officials or boards of officials.

Should we expect a strong relationship between how LEOs are selected and how effective they are in their roles? Based on past research, the selection method of a political official can play a significant role in political decision-making. For example, elected judges are more likely than their appointed counterparts to be tough on crime (Besley \& Coate 2003). The reason is that judges who are elected are more concerned with the opinion of the people in the electorate. Burden et al. (2013) found that selection methods also affect the preferences of public officials who decide election laws on ballot access and electorate size. The authors interviewed thousands of LEOs in Wisconsin and found that those who were elected were more concerned with voter access and making ballots more available to their constituents, whereas appointed LEOs were more concerned with administrative costs and ballot security (Burden et al. 2013).

In line with the theory discussed in Burden et al. (2013), I believe that because elected and appointed election officials are held accountable by different methods, they may "face different returns on policy performance and will pursue different goals" (907). I expect to see a substantial difference in the number of precinct closures between jurisdictions run by elected LEOs and those run by appointed LEOs. One reason is the difference in relationships the two types of LEOs have with voters.

Because of their indirect relationships with the public, appointed officials may be more inclined to make policy decisions that may not favor their constituents, but rather benefit the administration (or county government). The reason is that those who appoint local election 
officials (i.e. county executives and county commissions) are more concerned with the costs and security of elections rather than the overall experience of voting (Burden et al. 2013).

In contrast, elected LEOs, because they are chosen by the people, are more concerned with the opinions of the average voter rather than the county government. Katosh and Traugott (1982) found that in terms of election administration policies, voters are more concerned with shorter lines and convenient practices such as election day registration and early voting than the costs and security of elections. As such, I expect the value of PCVPP to be much greater in jurisdictions with appointed officials than in jurisdictions with elected LEOs. I argue that jurisdictions with appointed officials will be more likely to favor saving money, and thus close more polls, whereas jurisdictions with elected officials will be more likely want to keep voters happy and not close any precincts.

\section{The Effect of Shelby on Poll Closures}

Section 4(b) and 5 of the Voting Rights Act ensured that voting jurisdictions with histories of voting discrimination would have to receive preclearance from the Department of Justice (DOJ) or federal judges in the District of Columbia (D.C.) for any electoral administration change. However, the provisions in Sections 4 and 5 of the VRA were invalidated by the Supreme Court in Shelby v. Holder in 2013. Since Shelby, former preclearance jurisdictions have no longer needed to receive permission from the DOJ or D.C. to make election changes. In examining changes in precincts from 2012 to 2016, reports have found that former preclearance jurisdictions were 20 percent more likely to close precincts than non-preclearance jurisdictions (Arthur and McCann 2018). In my analysis, I will be examining the effect of the invalidation of the preclearance provision on the percentage change in voters per precinct. I compare changes that occurred from 2012-16, the period during which the preclearance was 
invalidated by Shelby, to changes that occurred from 2008-12, when the preclearance provision was still in effect. I expect jurisdictions that were subject to preclearance to see smaller (or even negative) values of PCVPP in the 2008-12 period. As for 2012-16, I expect the opposite to occur because the preclearance provision was no longer enforced.

Another important aspect of jurisdictions formerly subject to preclearance is that they also tend to have large non-white populations - specifically Black and Hispanic populations. To capture the possibility that the racial composition of jurisdictions had different effects on poll closures from 2012-16 than it did from 2008-12, I interact a dummy variable denoting (formerly) preclearance jurisdictions with the percentage of a district's population that was Black and the percentage that was Hispanic. In addition to not facing repercussions from the DOJ or the D.C. court, I believe another reason we may see poll closures in these particular areas is that local election officials (or local governments) may deliberately close polling places to hinder nonwhites from voting. Some scholarship has examined this possibility. For example, Amos, Smith, and Ste. Claire (2017) looked at polling place closures in Manatee County, Florida in 2014. They found that Black and Hispanic communities were much more likely to have their precincts changed than white communities. $57 \%$ of Black and $47 \%$ of Hispanic registered voters but only $41 \%$ of white registered voters had their polling places changed. Amos, Smith, and Ste. Claire also found that of those who had their polling places relocated, white respondents were more likely to find an alternative method to cast a ballot, whereas Black and Hispanic respondents were not as fortunate. In the next chapter, I dive further into the effects of poll closures on turnout.

Even when accounting for the constitutionally valid factors that can lead to polling closures, I hypothesize that having large non-white populations is one of the main reasons that 
jurisdictions formerly subject to preclearance experience so many closures following Shelby. In the 2012-16 (post-Shelby) analysis, I expect that both preclearance/non-white population interactions will have positive coefficients. For the 2008-12 period, I predict that both interaction terms - preclearance/Black and preclearance/Hispanic - will have small (or even negative) coefficients. The preclearance provision was still active from 2008-12, and that is why I expect to see a very small number of closures (or potentially even see openings) in these areas.

The last aspect of the effects of Shelby decision that I examine is the fact that jurisdictions with large non-white populations typically share similar socioeconomic characteristics such as having low median income levels, fewer residents with college degrees, and more young people. These socioeconomic factors are also some of leading causes of lower turnout rates (Verba et al. 1995; Leighley and Nagler 2014). Citizens with lower socioeconomic status may be less readily able to overcome hurdles - in this case polling place changes - that can keep citizens from casting votes. Amos, Smith, and Ste. Claire (2017), in addition to finding that Black and Hispanic voters were more likely to see their polling place change, also find that younger citizens were also most likely to experience polling place change. In terms of how this relates to the effects of Shelby, local governments may attempt to close precincts that have similar socioeconomic characteristics because voter turnout tends to be particularly low in areas where socioeconomic status levels tend to be lower. However, in doing so, local officials may also unintentionally hinder the ability of non-whites to vote in the process, because they nonwhite citizens tend to be concentrated in such jurisdictions.

In my analyses below, I control for socioeconomic factors other than race to see how they affect values of PCVPP in (formerly) preclearance jurisdictions with large non-white populations. Doing this allows me to show that the racial composition of jurisdictions may affect 
the number of poll closures in a jurisdiction not only directly through intentional efforts of election officials to deter non-white voting, but also indirectly. If LEOs close polling places for reasons related to socioeconomic status, such as low voter turnout levels being more common in poorer localities, the association between the socioeconomic characteristics of localities and the racial composition of localities means that polling changes made for reasons other than race and ethnicity may nonetheless have disparate effects on white and non-white citizens.

In my analyses of factors that influence PCVPP, if I were to observe a statistically significant coefficient on the racial composition variables when controlling for other socioeconomic factors, that would suggest that there is a direct relationship between racial composition and PCVPP. However, even if the coefficients on the racial composition variables were not significant, if the coefficients on the socioeconomic status variables are significant, and if Black and Hispanic citizens tend to live in districts with lower average levels of socioeconomic status, Black and Hispanic citizens may still be more likely to face polling place closures than white citizens.

To account for this possibility, I create predicted PCVPP values for hypothetic jurisdictions with different racial compositions while setting the values of the SES variables at the lowest observed values in the dataset. This allows me to illustrate what happens to the predicted number of poll closures when I allow for race to have both direct and indirect effects.

Due to the strong association between levels of socioeconomic characteristics and racial composition, I expect that lower median income levels, lower percentages of residents aged 65 or older, and lower percentages of residents with college degrees will result in formerly preclearance jurisdictions with large non-white populations having higher values of PCVPP than 
in non-preclearance jurisdictions in 2012-16. I expect this difference to be muted for the 2008-12 period because election officials in jurisdictions subject to preclearance could not make many of the changes to election procedures that they would be allowed to make after Shelby.

\section{Data and Methods}

I use ordinary least squares regression analyses to model the percentage change in voters per precinct in roughly 2,270 voting jurisdictions across two different presidential election cycles: 2008-12 and 2012-16. In this analysis, voting jurisdictions are counties. I analyze the number of voters per precinct by utilizing data collected by the Election Administration Commission (EAC). After each midterm and general election, the EAC creates the Election Administration and Voting Survey (EAVS). It polls each voting jurisdiction across the United States on election administration procedures and voting registration. In this survey, the EAVS asks three questions about the total number of polling places in a jurisdiction: (1) physical polling places other than election offices, (2) election offices, and (3) other (see Appendix I for more information). For my research, I tally up the three answers and use that as the total number of election day polling places for jurisdictions for 2008, 2012, and 2016.

For this paper, I used the 2008, 2012, and 2016 EAVS datasets. One issue with the EAVS data is that states and their local jurisdictions are not required to complete the survey, and thus some states are missing from the dataset. Alaska, New York, Utah, Illinois, Wisconsin, New Mexico, and Virginia failed to complete the survey in at least one of the three years. I omitted Colorado, Washington, and Oregon because they do not have traditional polling places; all their elections are administered by mail. Figure 3-1 provides a visualization of my dataset. Altogether, I gathered precinct data for 40 states plus D.C. which equates to roughly 2,270 voting jurisdictions. 


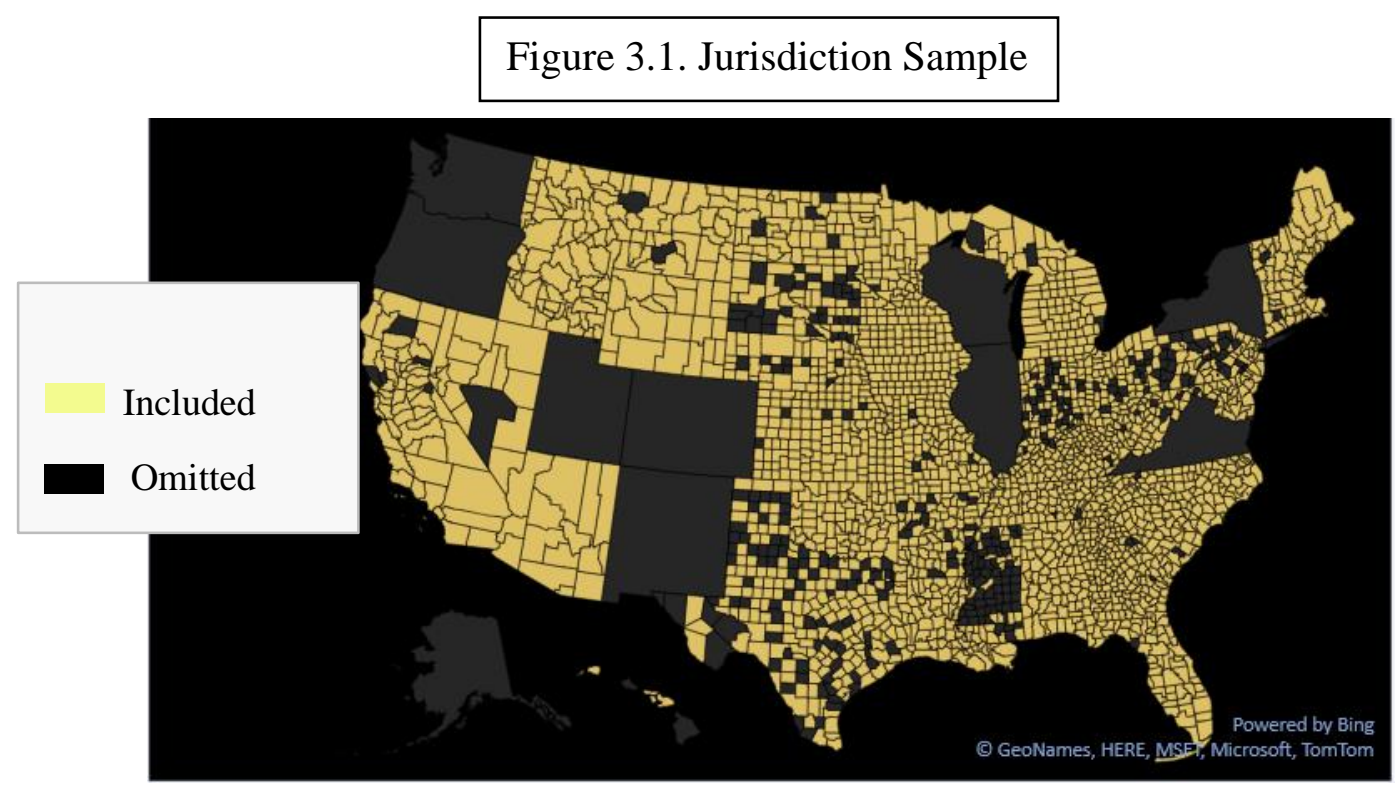

Polling Place Closures. To calculate PCVPP (percentage change in voters per precinct), I take the difference between the voters per precinct in 2016 (2012) and the voters per precinct in 2012 (2008) and then divide it by the voters per precinct in 2012 (2008). I then simply multiply the change in VPP by 100 . I rounded all values to the nearest tenth of a percent (see the Appendix for more information).

Despite sharing a similar average, this does not necessarily mean that 2008-12 had more polling place closures than 2012-16. As I mentioned earlier, PCVPP is not a direct measure of polling place closures, rather it measures the change in number of voters per precinct (VPP) between election years. Voters per precinct is made up of two important values in each year: citizen voting-age population and number of polling places. To understand how the percentage change in VPP works, I provide two hypothetical examples in tables 3-3a and 3-3b. As one can tell, Jurisdiction I and Jurisdiction II both had the same number of polling places in 2008, 2012, and 2016, but the values of PCVPP for 2008-12 and 
2012-16 differ significantly (although both show positive signs).

\begin{tabular}{|c|c|c|c|c|}
\hline \multicolumn{5}{|c|}{ Table 3-3a. Understanding PCVPP: Hypothetical Jurisdiction I } \\
\hline Election Year & CVAP & Polling Places & Voters Per Precinct & PCVPP \\
\hline 2008 & 4,000 & 10 & 400 & ------ \\
\hline 2012 & 6,050 & 8 & 756 & $+89 \%$ \\
\hline 2016 & 7,500 & 5 & 1,500 & $+100 \%$ \\
\hline
\end{tabular}

\begin{tabular}{|c|c|c|c|c|}
\hline \multicolumn{5}{|c|}{ Table 3-3b. Understanding PCVPP: Hypothetical Jurisdiction II } \\
\hline Election Year & CVAP & Polling Places & Voters Per Precinct & PCVPP \\
\hline 2008 & 7,500 & 10 & 750 & ----- \\
\hline 2012 & 6,050 & 8 & 756 & $+0.8 \%$ \\
\hline 2016 & 4,000 & 5 & 800 & $+6 \%$ \\
\hline
\end{tabular}

How can this be? Jurisdiction I noted a steady increase in population during each election year, whereas Jurisdiction II saw a decrease in population. In other words, Jurisdiction I did not account for the population increase when determining the number of polling places, whereas Jurisdiction II did. In short, PCVPP is a useful measure not only for understanding how many polling place closures took place between elections, but it also accounts for population change as well. PCVPP values for each jurisdiction in the sample along with population and polling place data in 2008, 2012, and 2016 are available in the supplementary data file.

Budgetary Constraints. To account for jurisdiction budgetary constraints, I use the median household income (in thousands of dollars) from the 5-year American Communities Survey from the U.S. Census Bureau. I expect jurisdictions with larger median incomes will have less severe fiscal constraints when it comes to election administration and will be better positioned to keep existing polling places open in the same locations from one election year to 
the next. I expect jurisdictions with smaller median incomes to have more severe fiscal constraints and thus struggle to keep polling places open. In terms of PCVPP, I expect wealthier jurisdictions to have smaller values of PCVPP, whereas poorer jurisdictions should have larger values of PCVPP, all else equal.

Implementation of Alternative Voting Methods. The best way to assess the effect of alternative voting methods is to create a measure that accounts for each state law regarding voting centers, early voting, and absentee balloting. Each year, the National Conference of State Legislatures (NCSL) identifies which states offer alternative voting options. I created a dummy variable for each law $(1=$ implemented; $0=$ not implemented $)$. I expect that jurisdictions with early voting periods will have higher values of PCVPP in both election cycles, all else equal. I also think the same relationship will appear for jurisdictions with no-excuse absentee balloting. As I explained in the theory section, states that make it easier to vote non-traditionally will see a significant decrease in the number of traditional polling places. In terms of voting centers, I also expect jurisdictions with voting centers to have positive values of PCVPP when compared to jurisdictions without across both election analyses. As explained in the theory section, voting centers are centrally located voting locations at which citizens can cast votes regardless of their residential address. However, one potential downside of these voting centers is that they lessen the need for traditional election-day polling places (Hale, Montjoy, \& Brown 2015), that some voters may find more accessible. In short, I believe that when there are more voting centers, there is less need for traditional election-day polling places.

The Effects of the Shelby Decision. To account for post-Shelby effects, I create a dichotomous preclearance variable which isolates the effect of a jurisdiction being subject to preclearance (or formerly subject to preclearance in the 2012-16 analysis). I expect large values 
of PCVPP in the former preclearance jurisdictions when looking at the difference between 201216. However, when looking at the 2008-12 analysis (when preclearance was still in effect), I expect covered jurisdictions to have smaller (or even negative values) of percentage change in voters per precinct.

I also expect (formerly) preclearance jurisdictions with large non-white populations to fall victim to a particularly large number of poll changes following Shelby. To account for this, I create two interaction terms: jurisdiction percent Black x preclearance and jurisdiction percent Hispanic x preclearance. The necessary population data was drawn from the 5-year population estimates of the American Communities Survey (ACS). Both variables capturing the size of nonwhite populations are defined as the percentage of the county's population that is either Black or Hispanic. I expect both interaction terms to be associated with small values of percentage change in VPP between 2008-12, but to be associated with large values of percentage change in VPP between 2012-16. This is because the preclearance provision of the VRA was still active in the former period, but inactive in the latter.

Selection Methods of LEOs. To obtain data on the selection method of local election officials across jurisdictions, I used Kimball and Kropf’s (2004) dataset on selection methods for LEOs. The authors contacted the offices of most states' secretaries of state or contacted county governments (or cities) directly. Kimball and Kropf categorize the selection method of LEOs into four groups: elected board, elected individual, appointed board, and appointed individual. However, for this analysis, I am only interested in the selection method, whether the LEO is elected or appointed, so I reduced the number of categories to two (appointed and elected). $65 \%$ of the jurisdictions have elected LEOs while the other 35\% have appointed ones. My variable is coded 1 in jurisdictions with elected LEOs and 0 in jurisdictions with appointed LEOs. As stated 
in my theory section, I expect that jurisdictions with elected LEOs (rather than appointed LEOs) will experience decreases (or smaller increases) in the number of voters per precinct, thus reporting smaller (or even negative) values of PCVPP.

\begin{tabular}{|c|c|c|c|c|}
\hline & Categories & 2008 & 2012 & 2016 \\
\hline & & Freq. & Freq. & Freq. \\
\hline \multirow[t]{2}{*}{ Early Voting Period } & $0-$ no early voting period & $35 \%$ & $37 \%$ & $28 \%$ \\
\hline & $1-$ early voting period & $65 \%$ & $63 \%$ & $72 \%$ \\
\hline \multirow[t]{2}{*}{ No-Excuse Absentee } & 0 - excuse only absentee & $40 \%$ & $47 \%$ & $44 \%$ \\
\hline & $1-$ no-excuse absentee & $60 \%$ & $53 \%$ & $56 \%$ \\
\hline \multirow{2}{*}{ Voting Centers } & 0 - state doesn't allow voting centers & $95 \%$ & $88 \%$ & $83 \%$ \\
\hline & $1-$ state does allow voting centers & $5 \%$ & $12 \%$ & $17 \%$ \\
\hline \multirow[t]{2}{*}{ Formerly Preclearance } & 0 - formerly not subject to preclearance & $68 \%$ & $68 \%$ & $68 \%$ \\
\hline & $1-$ formerly subject to preclearance & $32 \%$ & $32 \%$ & $32 \%$ \\
\hline \multirow{2}{*}{ Strict ID Laws } & $0-$ no photo-id required & $87 \%$ & $78 \%$ & $60 \%$ \\
\hline & $1-$ photo-id required & $13 \%$ & $22 \%$ & $40 \%$ \\
\hline \multirow[t]{2}{*}{ Method of LEOs } & $0-$ LEO is appointed & $35 \%$ & $35 \%$ & $35 \%$ \\
\hline & $1-\mathrm{LEO}$ is elected & $65 \%$ & $65 \%$ & $65 \%$ \\
\hline
\end{tabular}

\begin{tabular}{|c|c|c|c|c|}
\hline \multicolumn{5}{|l|}{ Continuous } \\
\hline & \multicolumn{2}{|c|}{2012} & \multicolumn{2}{|c|}{2016} \\
\hline & Mean & S.D. & Mean & S.D. \\
\hline$\%$ Black & $9.8 \%$ & $14.7 \%$ & $10.1 \%$ & $14.7 \%$ \\
\hline \% Hispanic & $8.7 \%$ & $13.4 \%$ & $9.4 \%$ & $13.7 \%$ \\
\hline$\%$ GOP Support & $59.8 \%$ & $14.7 \%$ & $64.6 \%$ & $15.6 \%$ \\
\hline$\%$ Over 65 & $16.8 \%$ & $4.2 \%$ & $18.4 \%$ & $4.5 \%$ \\
\hline \% Bachelor's Degree & $12.8 \%$ & $5.4 \%$ & $14.1 \%$ & $5.6 \%$ \\
\hline Median Income & $\$ 45,508$ & $\$ 11,794$ & $\$ 47,821$ & $\$ 12,490$ \\
\hline Residents Per Sq. Mile & 266.4 & 1774.4 & 272.7 & 1803.1 \\
\hline
\end{tabular}

Controls. I control for several demographic variables that could potentially play a role in a jurisdiction's decision to close precincts. I use estimates of the values of following variables in each jurisdiction from the 5-year American Communities Survey in both 2012 and 2016: percent 
college-educated, and percent over 65 . These variables are important because they help identify how socioeconomic factors play into the closing of polling places before and after Shelby, and they also are important to account for when attempting to determine why precincts close in jurisdictions with large non-white populations. I also utilize the 5-year American Communities Survey to control for the number of residents per square mile (population density). I control for jurisdiction partisanship by measuring the county's two-party vote share for the Republican presidential candidate (percent for Romney in 2012 and percent for Trump in 2016). Finally, I control for the implementation of strict photo ID laws as well. Table 3-4 shows the descriptive statistics for each variable.

Model Specification. I estimate two models. They are simple linear regression models predicting the percentage change in voters per precinct from 2008 to 2012 and from 2012 to 2016. The models are also difference-in-difference (DID) models. DID models model the change over time of an outcome variable as a function of explanatory variables that may influence such change. In the models, I observe the change in voters per precinct between two sets of election years (2008-12 and 2012-16). Because I am using difference-in-difference estimation, I also must account for the change (or "differences") in my independent variables. For example, I took my dummy variables for state laws and create differenced variables for both the 2008-12 and the 2012-16 models. In other words, in my 2012 analysis, the early voting variable is accounting for those states who implemented (or eliminated) an early voting period between 2008 and 2012. I also created differenced variables for the absentee and voting center dummies. However, variables such as jurisdiction Black population and Hispanic population (and other demographics) evolved too slowly over the four-years to have much effect on the dependent 
variable. The levels of these variables, however, are included, as they may account for crossjurisdiction changes in VPP.

Another important aspect of model specification for these analyses is the standard errors. In most analyses where there is mixed-level modeling, the standard errors are normally clustered at the aggregate level. For example, if there is both county and state level data in the model, the standard errors should be clustered at the state level. However, in terms of my analyses, this is not the case. If I were just implementing cross-sectional analyses (rather than DID), I could cluster the standard errors at the state level, but because I am using DID, clustering the standard errors at the state level would not account for the county-level correlated errors over time (Primo, Jacobsmeier, \& Milyo 2007; Burden et al. 2014; Burden et al. 2017). In other words, because each county is observed at two points in time (i.e. the 2008-12 and 2012-16 election cycles), the standard errors must be clustered at the county level.

\section{Explaining "The Great Poll Closure"}

Before describing the results, I believe it is important to discuss the interpretation of the regression coefficients. For example, suppose the variable Trump had a coefficient of +0.58 . This would suggest that the larger the jurisdictional support for Donald Trump in 2016, the larger the jurisdictional value of PCVPP. In other words, jurisdictions that had a larger proportion of Trump voters in 2016 tended to see significantly more polling place closures than jurisdictions with smaller proportions. In terms of the dummy variables, take the variable preclearance and suppose that its coefficient was -9.8. This would mean that the PCVPP in jurisdictions that were formerly under preclearance would be predicted to be 9.8 percentage points higher than nonpreclearance jurisdictions in 2016. This finding would suggest that compared to non- 
preclearance jurisdictions, preclearance jurisdictions were expected to experience significantly larger numbers of poll closures in the 2012-16 period. In short, the coefficients below represent estimated effects of unit changes in the independent variables on percentage change in voters per precinct (PCVPP) and should be interpreted as such.

\begin{tabular}{|c|c|c|}
\hline \multicolumn{3}{|c|}{$\begin{array}{l}\text { Table 3-5. Regression Results: Percentage Change in VPP } \\
\text { from 2008-12 \& 2012-16 }\end{array}$} \\
\hline & $(1)$ & $(2)$ \\
\hline & $\begin{array}{c}\text { PCVPP } \\
(2012)\end{array}$ & $\begin{array}{l}\text { PCVPP } \\
(2016)\end{array}$ \\
\hline$\Delta$ Early Voting & $\begin{array}{l}21.11^{* * * *} \\
(4.16)\end{array}$ & $\begin{array}{c}3.25 \\
(11.33)\end{array}$ \\
\hline$\Delta$ No-Excuse Absentee & $\begin{array}{l}-5.92^{*} \\
(3.18)\end{array}$ & $\begin{array}{l}-1.07 \\
(11.20)\end{array}$ \\
\hline$\Delta$ Voting Centers & $\begin{array}{l}-1.25 \\
(3.88)\end{array}$ & $\begin{array}{l}12.51 \\
(10.21)\end{array}$ \\
\hline $\begin{array}{l}\text { Median Income (Per Thousand U.S. } \\
\text { Dollars) }\end{array}$ & $\begin{array}{l}-0.15^{*} \\
(0.08)\end{array}$ & $\begin{array}{c}\mathbf{0 . 2 1} * \\
(\mathbf{0 . 0 9})\end{array}$ \\
\hline Preclearance & $\begin{array}{l}-5.41 \\
(3.84)\end{array}$ & $\begin{array}{l}11.44 * \\
(5.19)\end{array}$ \\
\hline Preclearance $\mathrm{x} \%$ Hispanic & $\begin{array}{c}0.32 \\
(0.17)\end{array}$ & $\begin{array}{l}-0.01 \\
(0.13)\end{array}$ \\
\hline Preclearance $\mathrm{x} \%$ Black & $\begin{array}{l}-0.01 \\
(0.13)\end{array}$ & $\begin{array}{l}0.08 \\
(0.16)\end{array}$ \\
\hline Elected LEO & $\begin{array}{l}-1.64 \\
(1.50)\end{array}$ & $\begin{array}{l}5.43^{*} \\
(2.12)\end{array}$ \\
\hline$\%$ Hispanic & $\begin{array}{c}0.13 \\
(0.10)\end{array}$ & $\begin{array}{c}0.04 \\
(0.07)\end{array}$ \\
\hline$\%$ Black & $\begin{array}{c}0.16 \\
(0.11)\end{array}$ & $\begin{array}{l}-0.01 \\
(0.10)\end{array}$ \\
\hline $\begin{array}{l}\text { Residents Per Sq. Mile (Per } \\
\text { Thousand People) }\end{array}$ & $\begin{array}{l}-1.49 * \\
(0.62)\end{array}$ & $\begin{array}{c}0.14 \\
(0.40)\end{array}$ \\
\hline$\%$ Support for GOP & $\begin{array}{r}\mathbf{0 . 2 1} * * \\
(0.08)\end{array}$ & $\begin{array}{c}0.14 * \\
(0.07)\end{array}$ \\
\hline$\% 65$ or Older & $\begin{array}{l}0.71 * * * * \\
(0.22)\end{array}$ & $\begin{array}{l}-0.30 \\
(0.18)\end{array}$ \\
\hline$\%$ College Degree & $\begin{array}{c}\mathbf{0 . 7 8 * * * *} \\
(\mathbf{0 . 2 3})\end{array}$ & $\begin{array}{l}-0.11 \\
(0.24)\end{array}$ \\
\hline$\Delta$ Strict ID Laws & $\begin{array}{c}1.10 \\
(2.25)\end{array}$ & $\begin{array}{l}-11.81 * \\
(5.15)\end{array}$ \\
\hline Constant & $\begin{array}{r}-13.78 \\
(7.92)\end{array}$ & $\begin{array}{l}-7.60 \\
(8.18)\end{array}$ \\
\hline $\mathrm{R}^{2}$ & 0.04 & 0.03 \\
\hline Observations & 2,266 & 2,266 \\
\hline
\end{tabular}


Table 3-5 displays the OLS results from both 2012 (compared to 2008) and 2016 (compared to 2012) difference-in-difference estimations. Starting with the state election law variables, I find mixed results with respect to my predictions. In the 2008-12 analysis, states who adopted early voting were predicted to have much larger values of PCVPP than states that did not adopt early voting laws. In other words, states that made it easier to vote before election day were predicted to close precincts more frequently between 2008-12. This finding was consistent with my predictions. However, in the 2012-16 model, there was no relationship between the adoption of early voting laws and precinct closures. The adoption of no-excuse absentee balloting had no significant effect in either model, which did not align with my predictions. This surprising finding may have to do with the relative lack of importance absentee balloting plays in the creation (or consolidation) of polling places. For example, if a voter were to cast an absentee ballot, they may still need to drop the ballot off at the election day polling location.

Lastly, the adoption of voting centers by states was expected to result in polling places being closed more frequently in jurisdictions in those states than in jurisdictions in states without voting centers. This expectation was borne out in the 2012-16 model but not in 200812. The PCVPP of jurisdictions in states that adopted voting centers was predicted to be 12.51 percentage points higher than in jurisdictions without voting centers in 2016. This finding makes sense given that voting centers are created to eliminate traditional neighborhood precincts and transition to one or two centrally located precincts where every voter in the county can cast a ballot.

As I mentioned in the theory section, among the primary reasons that polling places close are budgetary reasons. To account for this, I include each jurisdiction's median income in the models. In model 1, I find that jurisdictions that are poorer (or with smaller median 
incomes) saw larger values of PCVPP between 2008-12. This finding is congruent with my expectations that jurisdictions that have fewer financial resources may find it difficult to pay staff, rent polling place venues, and update voting equipment, and may therefore have to consolidate or close precincts. In the 2012-16 analysis, I find the opposite to be true. Wealthier jurisdictions were predicted to have larger values of PCVPP, whereas poorer jurisdictions were predicted to have smaller ones. This finding suggests that the budgetary issues may not have been the main reason for closing precincts following Shelby. However, I believe there needs to be some further exploration of the relationship between budgetary issues and The Great Poll Closure. For this reason, I take a deeper dive into the effects of jurisdictions' election budgets on PCVPP by conducting a small-N analysis that is described in the discussion section.

I now turn to the results regarding variables that capture politically motivated reasons for poll closures. In my theory section, I argued that jurisdictions with appointed LEOs would see more poll closures when compared to jurisdictions with elected officials. Appointed officials are more concerned with financial constraints of election administration and not as concerned with pleasing the electorate as elected officials are. This is because appointed officials are usually granted re-appointment by the decision of a governing body, whereas elected officials must be re-elected by voters to maintain their positions. Looking at the results from models 1 and 2, I find that jurisdictions with appointed officials were predicted to see larger values of PCVPP than jurisdictions with elected officials between 2008-12. The sign of the coefficient was consistent with my hypothesis but was statistically insignificant. In 2012-16, I find a significant relationship between LEO selection method and PCVPP, but in the wrong direction. The value of PCVPP for 
jurisdictions with elected officials was predicted to be roughly 5.43 percentage points higher than for jurisdictions with appointed officials.

One of the potential reasons for my inconsistent findings with LEO selection method was that partisanship may have been factor. Outside of selection method, election administration scholars have also focused on how the partisanship of LEO's affect bureaucratic behavior. Burden et al. (2013) argued that Republican LEOs created measures that limited ballot access if their constituencies were majority Democrat. Kimball and Baybeck (2013) also found that among larger jurisdictions, Democratic officials were more likely to put greater emphasis on voter access than Republican officials. Unfortunately, I lacked reliable data to conduct an analysis that included partisanship of LEO, so this endeavor will need to be tackled in a future research project.

The other possible politically motivated reason for closing precincts that I investigate involves the racial composition of jurisdictions. Interaction terms are used here because I hypothesize that the relationship between the racial composition of jurisdictions and poll closures will be stronger after the Shelby decision, once election officials were able to make election procedure changes that may have been objected to by the Department of Justice or the U.S. District Court for D.C. when preclearance was in effect. Three variables - preclearance, jurisdiction percent Black x preclearance, and jurisdiction percent Hispanic x preclearance allow me to explore this possibility. In the 2008-12 model, jurisdictions that were under preclearance were expected to have smaller values of percentage change in voters per precinct when compared to jurisdictions that were not under preclearance. This finding is no surprise given the fact that the preclearance provision was still active. In the 2012-16 model, I find the complete opposite. In other words, the PCVPP of jurisdictions who were formerly under 
preclearance were roughly 11.44 percentage points higher than jurisdictions that were never subject to preclearance.

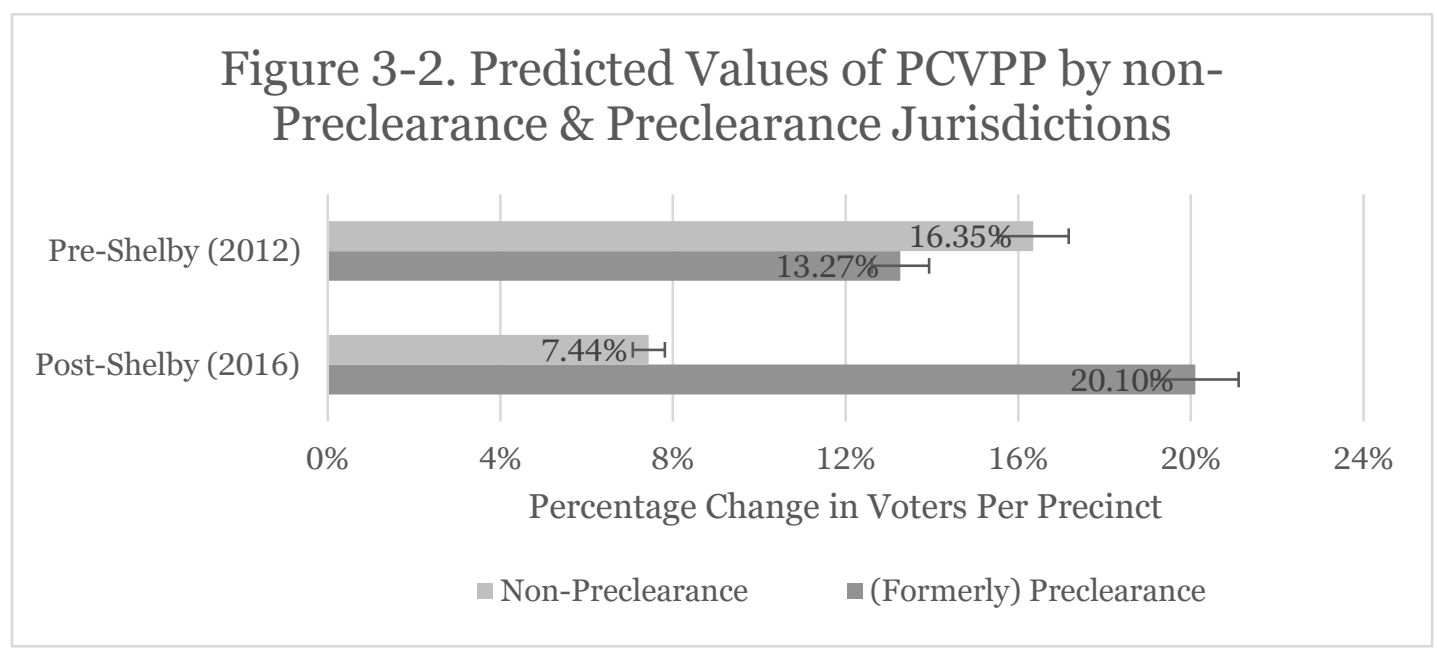

To visualize the effects of the Shelby decision on PCVPP in former preclearance jurisdictions, figure 3-2 above plots the predicted values of both non-preclearance and preclearance jurisdictions from models 1 and 2 with other variables held at their mean values. When looking at the pre-Shelby analysis (represented by the first group of bars), the predicted value of PCVPP in non-preclearance jurisdictions was roughly three percentage points higher than in preclearance jurisdictions. This makes sense given that the preclearance provision was still active, making it much more difficult for preclearance jurisdictions to close or change polling place locations.

Moving to the post-Shelby analysis (represented by the second group of bars), the opposite relationship held between preclearance and PCVPP. The predicted value of PCVPP for formerly preclearance jurisdictions was roughly 20 percent, which is more than 12 percentage points higher than the predicted value for formerly non-preclearance jurisdictions. Additionally, in districts where preclearance had been required prior to Shelby, the predicted value of PCVPP was roughly eight percentage points higher after Shelby than before it. These 
findings show that without the preclearance provision of the VRA being in effect, jurisdictions that were formerly under the supervision of the federal government were closing precincts at a much higher rate than they were when the provision was still active.

Another important effect of the Shelby decision involves the interaction between nonwhite population (Black and Hispanic) and preclearance. As mentioned by the LCEF and other journalistic outlets, in the wake of Shelby, formerly preclearance jurisdictions with large Hispanic and/or Black populations seemed to be popular targets for polling place closures. The results in table 3-5, provide mixed support for the claims made by the LCEF.

To facilitate the interpretation the estimated effects of jurisdiction racial composition (former) preclearance status on PCVPP, Figure 3-3 shows predicted values of PCVPP vs. the racial composition variables for preclearance and non-preclearance jurisdictions for each election analyses. Subfigures A and C deal with the interactions between jurisdiction percent Black and preclearance and plots B and D deal with jurisdiction percent Hispanic and preclearance. I first discuss then the former.

Between 2008-12, as the percentage of a preclearance jurisdiction's Hispanic population increased, the predicted value of PCVPP also increased significantly. This finding contradicts my expectations because one would imagine that a preclearance jurisdiction with a particularly large non-white population would not be able to close many polling places, especially while the preclearance provision was still active. Turning to the effects of percent Hispanic in nonpreclearance jurisdictions in 2008-12, there was also a slight increase in the value of PCVPP when the jurisdiction's Hispanic population increased, but as the slope was not as steep as in preclearance jurisdictions. The interaction term itself was statistically insignificant. 
Figure 3-3. Predicted Values of PCVPP vs. \% Black and \% Hispanic in Preclearance and Non-Preclearance Jurisdictions

A. PCVPP vs. Percent Black, 2008-12

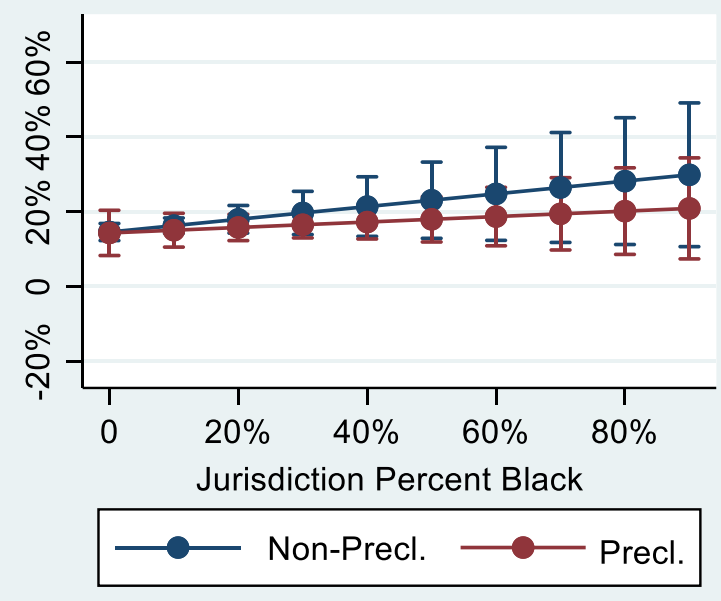

C. PCVPP vs. Percent Black, 2012-16

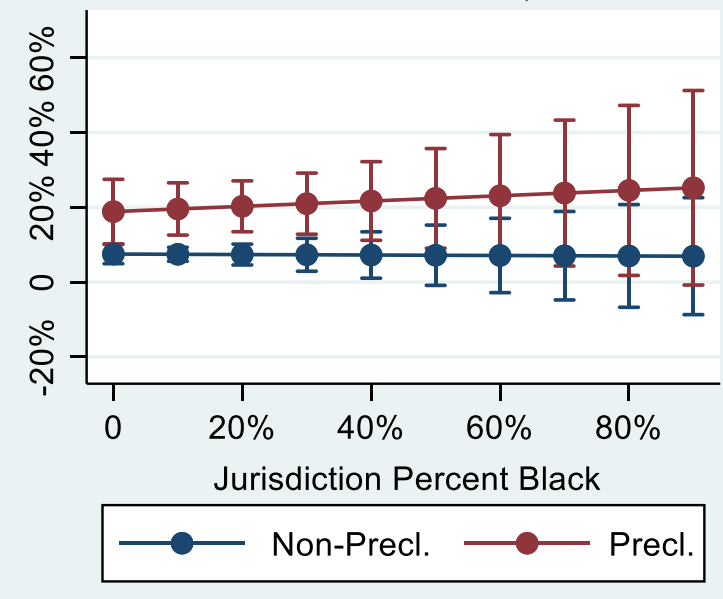

B. PCVPP vs. Percent Hispanic, 2008-12

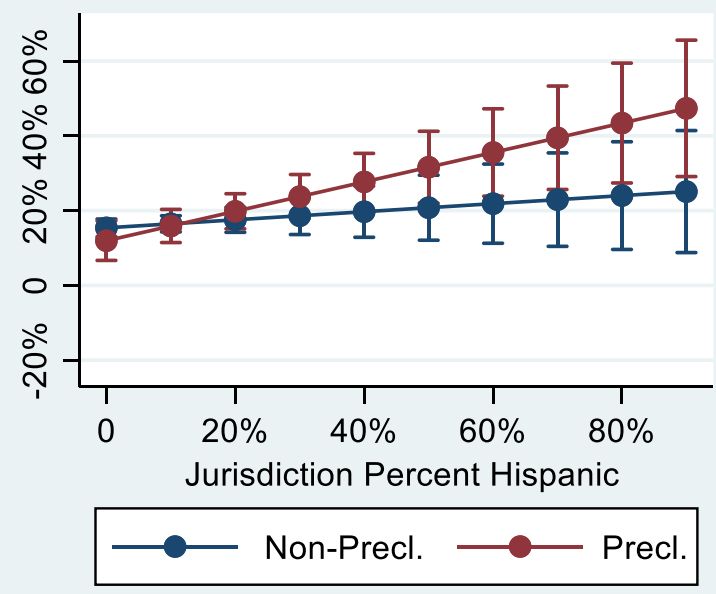

D. PCVPP vs. Percent Hispanic, 2012-16

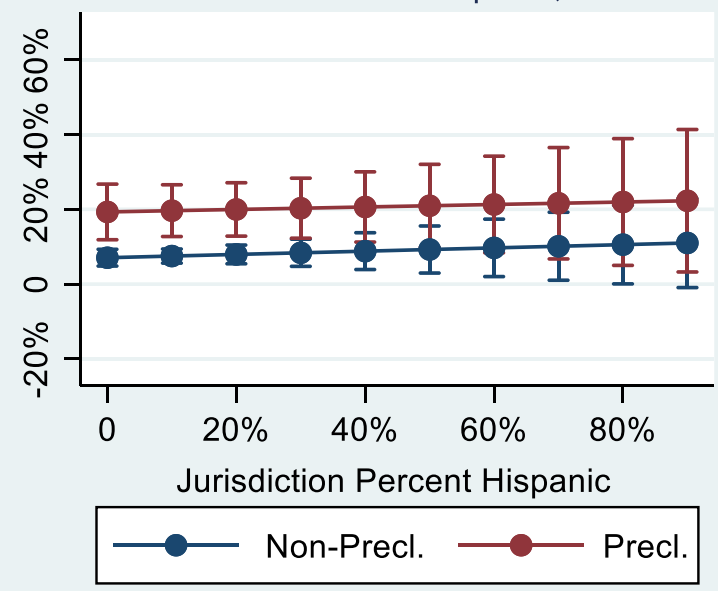

Looking at the estimated effect of percent Hispanic in preclearance jurisdictions between 2012-16, I find that the effect is very similar formerly preclearance and non-preclearance jurisdictions, and that that effect is small in magnitude. As percent Hispanic increases in each type of jurisdiction, the predicted value of PCVPP also increases, but only modestly. My expectation was that there would be a significant difference between formerly preclearance and non-preclearance jurisdictions with large Hispanic populations because the preclearance 
provision was no longer active. Unfortunately, that expectation was not borne out by the analysis.

Like the coefficient on Hispanic x preclearance, the coefficient on Black x preclearance in statistically insignificant, but I do find that the directions of some relationships are congruent with my expectations. For example, between 2008-12, I find that regardless of preclearance or non-preclearance status, as a jurisdiction's Black population increases, the predicted value of PCVPP also increases. However, the non-preclearance jurisdictions saw a more gradual increase than preclearance jurisdictions as percent Black increases. Given that the preclearance provision was still active, I would expect that any jurisdictions with large Black populations that experienced large numbers of closures between 2008-12, would be non-preclearance jurisdictions. As the figure shows, while the slopes of the two lines are not drastically different, closures were more likely in non-preclearance jurisdiction at any given value of percent Black.

Moving to 2012-16, I find the relationship between percent Black and PCVPP to be of the expected sign in preclearance jurisdictions, but the estimated effect of percent Black is not statistically significant. As percent Black increases in preclearance jurisdictions, the predicted value of PCVPP also increases. The opposite was true in non-preclearance jurisdictions, although again, the estimated effect was not statistically significant. While these results do suggest that, following Shelby, preclearance jurisdictions with large Black populations were predicted to close precincts more frequently than non-preclearance jurisdictions with large Black populations, the estimated effects were not large enough to meet the threshold of statistical significance. I return to the relationships between preclearance and racial composition in the next section.

In terms of my control variables, jurisdictions with larger percentages of people over the 
age of 65 were expected have larger values of PCVPP between 2008-12. The same is true for jurisdictions with larger percentages of college graduates. Both findings were statistically significant. When looking at these variables following Shelby, the reverse relationship held, but was statistically insignificant. The effects of the other control variables were also somewhat inconsistent across the two models. One constant, however, was jurisdiction partisanship. Jurisdictions that showed larger support for the Republican presidential candidate were expected to have larger values of PCVPP in both analyses. This finding might reflect the partisanship of the election officials in the jurisdictions. For example, in particularly large voting jurisdictions, Kimball and Baybeck (2013) found that Republican elected officials are in favor of limiting access to the polls when compared to Democrats. As noted in chapter 2, Texas (primarily a Republican state with majority Republican local governments) was one of the first states to attempt to implement stricter election laws following the Shelby court case. ${ }^{23}$ In short, the consistency of GOP jurisdictions having larger predicted values of PCVPP in each analysis was not surprising.

\section{Looking at Some Specific Types of Jurisdictions}

Given the large amount of descriptive evidence regarding poll closures in former preclearance areas with large non-white populations, I felt that an additional analysis was needed to better understand changes in PCVPP in such areas. How can the observation that polling places are closing more often in areas with large non-white populations be reconciled with the insignificant coefficients on the variables capturing the racial and ethnic composition of jurisdictions in the models shown in Table 3-5 in the previous section?

\footnotetext{
${ }^{23}$ Brennan Center. 2018. "Texas NAACP v. Steen (Consolidated with Veasey v. Abbott)". https://www.brennancenter.org/our-work/courtcases/texas-naacp-v-steen-consolidated-veasey-v-abbott
} 
One possible answer lies in the decision-making processes of election officials who may find it politically advantageous to make it more difficult for members of non-white populations to vote. Imagine a hypothetical jurisdiction encompassing a number of localities, with each locality having a different percentage of Black residents. Suppose that Black citizens make up four percent of the population in Locality A, five percent in Locality B, six percent in Locality C, 20 percent in Locality D, and 60 percent in Locality E. If the LEO in this hypothetical jurisdiction wished to discourage turnout among Black citizens, he or she would presumably be more likely to close polling places in localities with larger percentages of Black voters than in localities with smaller percentages. Closing too many polling places may cause an uproar or violate state law, however, so the number of potential closures may be limited. In which localities would such an LEO be likely to close polling places?

While Localities B and C each have more Black residents than Locality A, the difference in racial composition is very small, and the likelihood of the LEO closing a precinct in Locality B or C would most likely to be similar to or only negligibly greater than the likelihood of closing a precinct in Locality A. Even if the LEO wished to close a polling place in Locality D, he or she would likely consider the fact that closing a polling place may also discourage voting among the $80 \%$ of the population that is not Black. In contrast, the likelihood of the LEO closing a precinct in Locality E would presumably be quite large. While this hypothetical example is exactly that hypothetical - it seems feasible that any relationships between the racial composition of jurisdictions and polling place closures may be non-linear, and that if Black and/or Hispanic citizens are deliberately targeted by decisions to close polls, only localities with particularly large non-white populations are singled out for closures. If this is the case, using categorical variables to identify jurisdictions with particularly large percentages of Black or Hispanic residents may be 
more appropriate than including the continuous measures of racial composition employed until now.

\begin{tabular}{|l|c|}
\hline Table 3-6. Types of Jurisdictions \\
\hline Jurisdiction Type & Sample Size \\
\hline Non-Preclearance Jurisdictions & 1,665 \\
& $(73 \%)$ \\
\hline Preclearance with Large Black & 212 \\
Populations (> 30\%) & $(9 \%)$ \\
\hline Preclearance with Large Hispanic & 183 \\
Populations (>15\%) & $(8 \%)$ \\
\hline Preclearance with Neither Large & 216 \\
Black nor Hispanic Populations & $(10 \%)$ \\
\hline Total & 2,266 \\
& $(100 \%)$ \\
\hline
\end{tabular}

To account for the potential importance of jurisdictions with particularly large non-white populations, I create a categorical variable that categorizes jurisdiction types by non-white population and (formerly) preclearance status. The first category includes jurisdictions that were never required to receive preclearance. The second includes (formerly) preclearance jurisdictions in which Black residents made up at least $30 \%$ of the jurisdiction's total population. The third includes (formerly) preclearance jurisdictions in which Hispanic residents made up at least $15 \%$ of the jurisdiction's total population. The last category represents preclearance jurisdictions with neither Black populations larger than $30 \%$ nor Hispanic populations larger than $15 \%$ of the total population. I chose $15 \%$ and $30 \%$ as the non-white population thresholds because they allowed me to place a substantial number of jurisdictions into each group and allow for meaningful comparisons between the four groups. Table 3-6 (above) provides information on sample sizes for each category.

Table 3-7 presents the same two difference-in-difference regression analyses that were presented in table 3-5, but the preclearance and non-white population interactions were replaced 


\begin{tabular}{|c|c|c|}
\hline \multicolumn{3}{|c|}{$\begin{array}{c}\text { Table 3-7. Regression Results: Predicting PCVPP with } \\
\text { Different Types of Jurisdiction Scenarios. }\end{array}$} \\
\hline & (1) & (2) \\
\hline & $\begin{array}{l}\text { PCVPP } \\
(2012)\end{array}$ & $\begin{array}{l}\text { PCVPP } \\
(2016)\end{array}$ \\
\hline Large Black Preclearance & $\begin{array}{c}0.81 \\
(3.19)\end{array}$ & $\begin{array}{l}18.43 * \\
(8.10)\end{array}$ \\
\hline Large Hispanic Preclearance & $\begin{array}{c}2.22 \\
(5.17)\end{array}$ & $\begin{array}{l}16.59 * * * * \\
(4.94)\end{array}$ \\
\hline $\begin{array}{l}\text { Neither Large Black nor Hispanic } \\
\text { Preclearance }\end{array}$ & $\begin{array}{l}-1.98 \\
(2.30)\end{array}$ & $\begin{array}{l}\text { 7.81* } \\
(3.43)\end{array}$ \\
\hline$\Delta$ Early Voting & $\begin{array}{l}\text { 21.03**** } \\
(4.16)\end{array}$ & $\begin{array}{c}3.90 \\
(11.33)\end{array}$ \\
\hline$\Delta$ No-Excuse Absentee & $\begin{array}{l}-5.33 \\
(3.14)\end{array}$ & $\begin{array}{l}-1.82 \\
(11.11)\end{array}$ \\
\hline$\Delta$ Voting Centers & $\begin{array}{r}4.34 \\
(4.84)\end{array}$ & $\begin{array}{c}12.02 \\
(10.21)\end{array}$ \\
\hline $\begin{array}{l}\text { Median Household Income (per } \\
\$ 1000)\end{array}$ & $\begin{array}{l}-0.17 \\
(0.09)\end{array}$ & $\begin{array}{l}0.22 * \\
(0.08)\end{array}$ \\
\hline Elected LEO & $\begin{array}{l}-2.03 \\
(1.53)\end{array}$ & $\begin{array}{l}\text { 5.58** } \\
(\mathbf{0 . 0 2})\end{array}$ \\
\hline Residents Per Sq. Mile (per 1000) & $\begin{array}{ll}-1.11 * \\
(0.53)\end{array}$ & $\begin{array}{c}0.34 \\
(0.42) \\
\end{array}$ \\
\hline \% Support for GOP & $\begin{array}{l}\mathbf{0 . 1 4} * \\
(\mathbf{0 . 0 7})\end{array}$ & $\begin{array}{l}\text { 0.18* } \\
(\mathbf{0 . 0 8})\end{array}$ \\
\hline$\% 65$ or Older & $\begin{array}{c}0.53 * \\
(0.22)\end{array}$ & $\begin{array}{l}-0.33 \\
(0.19)\end{array}$ \\
\hline$\%$ College Degree & $\begin{array}{l}0.72 * * \\
(0.24)\end{array}$ & $\begin{array}{l}-0.07 \\
(0.24)\end{array}$ \\
\hline$\Delta$ Strict ID Laws & $\begin{array}{l}1.17 \\
(2.27)\end{array}$ & $\begin{array}{c}-13.05 * * \\
(4.65)\end{array}$ \\
\hline Constant & $\begin{array}{l}-2.94 \\
(6.89) \\
\end{array}$ & $\begin{array}{l}-0.10 \\
(0.08)\end{array}$ \\
\hline$\overline{\mathrm{R}^{2}}$ & 0.04 & 0.03 \\
\hline Observations & 2,266 & 2,266 \\
\hline
\end{tabular}

with the categorical preclearance variable. When comparing the three preclearance categories to the non-preclearance category, the results regarding formerly preclearance jurisdictions with large non-white populations are in line with expectations in a way that the results shown in table 3-5 were not. In the 2008-12 analysis, preclearance jurisdictions with large Black and Hispanic populations were both predicted to have larger values of PCVPP than non-preclearance 
jurisdictions, but the estimated effect of large non-white populations were relatively minimal, with preclearance jurisdictions with large Black and Hispanic populations being predicted to have values of PCVPP of 1 and 2 percentage points larger than non-preclearance jurisdictions, respectively. These estimated effects were also statistically insignificant. Preclearance jurisdictions with small non-white populations were predicted to have smaller values of PCVPP compared to non-preclearance jurisdictions, but the difference was not statistically significant.

In 2012-16 (post-Shelby), the value of PCVPP for formerly preclearance jurisdictions with large Black populations was predicted to be roughly 18 percentage points higher than formerly non-preclearance jurisdictions. Similarly, PCVPP in jurisdictions with large Hispanic populations was predicted to be roughly 17 percentage points higher. Both findings were statistically significant. In terms of formerly preclearance jurisdictions with small non-white populations, the predicted value of PCVPP was significantly higher than in areas that were never subject to preclearance as well. This is also in alignment with my original expectations, and is no surprise given the predicted value of PCVPP in preclearance jurisdictions following Shelby in the initial analysis (see figure 3-2).

These findings suggest that preclearance jurisdictions were indeed closing precincts more frequently than non-preclearance jurisdictions following Shelby, even when controlling for other important factors, and this was especially true in areas with large non-white populations. It is important to note that these findings regarding the effects of the racial composition of jurisdictions are derived from models that control for the relative wealth of those jurisdictions. As such, it seems unlikely that preclearance jurisdictions were closing precincts for purely fiscal reasons once they had the opportunity to do so without federal preclearance. Overall, these 
findings are not only congruent with my own expectations, but with the descriptive findings of the LCEF and other journalistic reports.

Based on the results above, it seems possible that local governments are closing precincts in formerly preclearance jurisdictions with large Black (or large Hispanic) populations because they want to discourage members of non-white populations from voting. The estimated effects of the indicators for jurisdictions with large majority populations are substantively large even when factors such as income, age, and education are controlled for, which suggests that racial composition has a more or less direct effect on the number of closures. At the same time, it is important to explore the indirect effects of racial composition on PCVPP that may arise because jurisdictions with large non-white populations often share similar socioeconomic characteristics such as being poorer, less educated, and younger.

\begin{tabular}{|l|c|c|c|c|}
\hline Table 3-8a. Average Values of SES in the Four Types of Preclearance/Non-white Jurisdictions in 2012. \\
\hline SES Variable & $\begin{array}{l}\text { Large Black } \\
\text { Pop. }(>30 \%)\end{array}$ & $\begin{array}{l}\text { Large Hispanic } \\
\text { Pop. }(>15 \%)\end{array}$ & $\begin{array}{l}\text { Neither Large } \\
\text { Black nor Hisp. }\end{array}$ & Non-Preclearance \\
\hline $\begin{array}{l}\text { Median Household } \\
\text { Income }\end{array}$ & $\$ 35,090$ & $\$ 44,950$ & $\$ 43,926$ & $\$ 45,744$ \\
\hline $\begin{array}{l}\text { (\%) Bachelor's } \\
\text { degree }\end{array}$ & $9.9 \%$ & $12.4 \%$ & $11.5 \%$ & $13.1 \%$ \\
\hline $\begin{array}{l}(\%) \text { Over the Age of } \\
65\end{array}$ & $15.1 \%$ & $15.6 \%$ & $15.8 \%$ & $17.3 \%$ \\
\hline
\end{tabular}

\begin{tabular}{|l|c|c|c|c|}
\hline \multicolumn{5}{|l|}{ Table 3-8b. Average Values of SES in the Four Types of Preclearance/Non-white Jurisdictions in 2016.} \\
\hline SES Variable & $\begin{array}{l}\text { Large Black } \\
\text { Pop. (>30\%) }\end{array}$ & $\begin{array}{l}\text { Large Hispanic } \\
\text { Pop. (>15\%) }\end{array}$ & $\begin{array}{l}\text { Neither Large } \\
\text { Black nor Hisp. }\end{array}$ & Non-Preclearance \\
\hline $\begin{array}{l}\text { Median Household } \\
\text { Income }\end{array}$ & $\$ 35,982$ & $\$ 48,107$ & $\$ 45,260$ & $\$ 48,423$ \\
\hline $\begin{array}{l}\text { (\%) Bachelor's } \\
\text { degree }\end{array}$ & $10.5 \%$ & $12.8 \%$ & $12.6 \%$ & $14.2 \%$ \\
\hline $\begin{array}{l}\text { (\%) Over the Age of } \\
65\end{array}$ & $17.1 \%$ & $16.6 \%$ & $17.5 \%$ & $18.9 \%$ \\
\hline
\end{tabular}

Tables 3-8a and 3-8b provide the average values of the SES variables - median income, jurisdiction percent with a bachelor's degree, and jurisdiction percent over the age of 65 - in the 
four types of preclearance/non-white jurisdictions. I find that the three types of (formerly) preclearance jurisdictions had lower levels of income and education and were younger on average than non-preclearance jurisdictions. Furthermore, (formerly) preclearance jurisdictions with large Black populations had the smallest average values of each socioeconomic characteristic. This held across the two election years as well.

Given the results described above, it seems likely that the racial composition of jurisdictions affected closure rates both directly and indirectly, through associations between the socioeconomic characteristics and racial composition of jurisdictions. To examine the importance of the SES covariates, I calculate predicted values of PCVPP from the analyses in table 3-7 for the preclearance/non-white categories by using their corresponding mean values of the SES characteristics found in tables 3-8a and 3-8b. For example, when calculating the predicted value of PCVPP for preclearance jurisdictions with large Black populations in 2016, I set median income to $\$ 35,982$, the percentage of college graduates in the population to $10.5 \%$, and the percentage of the population over the age of 65 to $17.1 \%$. I do this for the other three hypothetical jurisdictions in both election periods (pre- and post- Shelby) as well. The resulted predicted values of PCVPP can be seen in Table 3-9 below.

\begin{tabular}{|c|c|c|c|c|}
\hline & $\begin{array}{l}\text { Large Black Pop. } \\
(>30 \%)\end{array}$ & $\begin{array}{l}\text { Large Hispanic } \\
\text { Pop. }(>15 \%)\end{array}$ & $\begin{array}{l}\text { Neither Large } \\
\text { Black nor Hisp. }\end{array}$ & $\begin{array}{l}\text { Non- } \\
\text { Preclearance }\end{array}$ \\
\hline $\begin{array}{l}\text { Pre-Shelby: 2008- } \\
12\end{array}$ & $15.5 \%$ & $17.2 \%$ & $13.2 \%$ & $16.1 \%$ \\
\hline $\begin{array}{l}\text { Post-Shelby: 2012- } \\
16\end{array}$ & $23.8 \%$ & $24.9 \%$ & $14.8 \%$ & $7.20 \%$ \\
\hline
\end{tabular}

Beginning with 2008-12, all four types of hypothetical jurisdictions have fairly similar predicted values of PCVPP. Given that the preclearance jurisdictions have significantly lower 
averages of socioeconomic characteristics compared to non-preclearance jurisdictions, this finding suggests that the preclearance provision was working effectively; large amounts of poll closures were not taking place in areas with histories of voter discrimination. However, when we look at the predicted values of PCVPP in the post-Shelby analysis, the strong association between lower levels of SES and racial composition become apparent especially with preclearance jurisdictions with large non-white populations.

For example, preclearance jurisdictions with large Black jurisdictions had a median income of roughly $\$ 35,000$ in 2016 , that is about $\$ 13,000$ less than the median income for nonpreclearance jurisdictions. In terms of percent of the population with formal education and over the age of 65 , preclearance jurisdictions with large Black populations also had significantly lower numbers compared to non-preclearance jurisdictions. Those comparisons of socioeconomic characteristics were also relatively similar in 2012, but there was only a small difference between the jurisdictions' values of PCVPP (15.5\% to 16.1\%). However, in 2016, the differences in the predicted values of PCVPP between formerly preclearance jurisdictions with large Black populations and non-preclearance jurisdictions was roughly 17 percentage points (23.8\% to $7.2 \%)$. What this shows is that even though the differences in levels of SES remained the same in both jurisdictions between 2012 and 2016, the values of PCVPP in preclearance jurisdictions with large Black populations and non-preclearance jurisdictions changed drastically, with an increase in the former and a decrease in the latter. There was also a similar relationship between formerly preclearance jurisdictions with large Hispanic populations and nonpreclearance.

These findings suggest that the racial composition of jurisdictions affected closure rates both directly and indirectly, through associations between socioeconomic characteristics and the 
racial composition of jurisdictions following Shelby. Based on the predicted values of PCVPP for the different types of jurisdictions that incorporate the typical socioeconomic characteristics of those jurisdictions -lower levels of median income, lower levels of college graduates, and lower percentages of people over the age of 65 - it is clear that polling place closures in former preclearance jurisdictions with large non-white populations may have resulted in part from those jurisdictions tending to have socioeconomic characteristics (other than race) that are associated with lower levels of turnout.

In conclusion, I believe it is important to consider the history of voting rights for nonwhite citizens in the United States when understanding the significance of these findings. For example, beginning in the period of reconstruction, Republicans attempted to prevent voter discrimination by sending federal election observers into areas with large Black populations. However, this was overturned several years later by Southern Democrats. ${ }^{24}$ Jim Crow ushered in a new era of discrimination. While in theory, Blacks and members of other non-white populations could vote in some jurisdictions, they often had to overcome significant obstacles such as the poll tax and literacy tests. Even with the coverage formula and the preclearance provision of the VRA, preclearance areas with large non-white populations were still attempting to create election laws that would discriminate against people of color up until the Shelby case. As such, any contemporary attempts to reduce turnout among members of minority groups would not be unprecedented; indeed, such attempts would only contribute to a long history of voter disenfranchisement in the United States. Although my findings do not demonstrate that

\footnotetext{
${ }^{24}$ Once example was the Enforcement Act of 1870; It was the first comprehensive federal statute that dealt with elections. Acts such as bribery, interference, false voting, etc. were made federal offenses. Federal judges would visit voting locations to see whether the voting actions warranted federal offenses. However, most parts of the Enforcement act were overturned by a Democratic Congress following the period of Reconstruction. To see a comprehensive breakdown of pre-1965 voting rights legislation, please visit: https://constitution.congress.gov/browse/essay/artI S4 C 1 1 11 1 12 2/.
} 
local election officials were intentionally closing polling places to deliberately hinder people of color from voting after Shelby, they are consistent with what we would expect to see if an election official did intend to do so.

\section{Discussion: A small-N analysis}

One major methodological issue that I faced in my nation-wide analysis was how to account for the budgetary constraints faced by jurisdictions. The inclusion of the median household income allowed me to account for the level of wealth in each jurisdiction to some degree and served as a proxy for fiscal constraints. However, the median income variable is limited in at least two ways. The first limitation of the median income variable is that because it is an aggregate measure of a county's income, it does not account for variation of income across different precincts within the county. Although a county may be relatively wealthy based on the median income variable, the county could still have a good number of poorer precincts, and fiscal constraints faced by those precincts may not be adequately captured by the median income variable. In future projects, I believe nation-wide studies of polling place closures should look at precinct-level data rather than only county-level data. Unfortunately, the availability of precinctlevel data (such as demographic information and turnout figures) is scarce. However, I am optimistic that as voter technology becomes more advanced, so will the availability of voter data.

The second limitation of the median income variable is that it lacked information on the election budgets of each jurisdiction, which often play a large part in decisions to close precincts (Brady and McNulty 2011). Fortunately, I was able to access county election budget data for counties in Georgia from 2012 and 2016 through the Public Service and Outreach program at the University of Georgia.

Georgia is perhaps particularly well-suited for analysis here because it is a formerly 
preclearance state with a historically large Black population. Georgia also has characteristics that may result in for polls being closed for constitutionally valid reasons. For example, it offers a period of in-person early voting and no-excuse absentee balloting. ${ }^{25}$ In terms of finances, Georgia is one of the wealthier states in the South, with a median state income of roughly $\$ 55,390$. In terms of selection methods for LEOs, Georgia is unique in that the decision is up to the jurisdiction on how they select their local election officials. However, most of the jurisdictions in my sample selected their LEOs by appointment. Based on this description of Georgia, jurisdictions in the state should have the resources to keep polls open, but it may also close traditional precincts because it has made alternative voting opportunities available. It is possible, however, that the racial composition of jurisdictions plays into decision making regarding reprecincting.

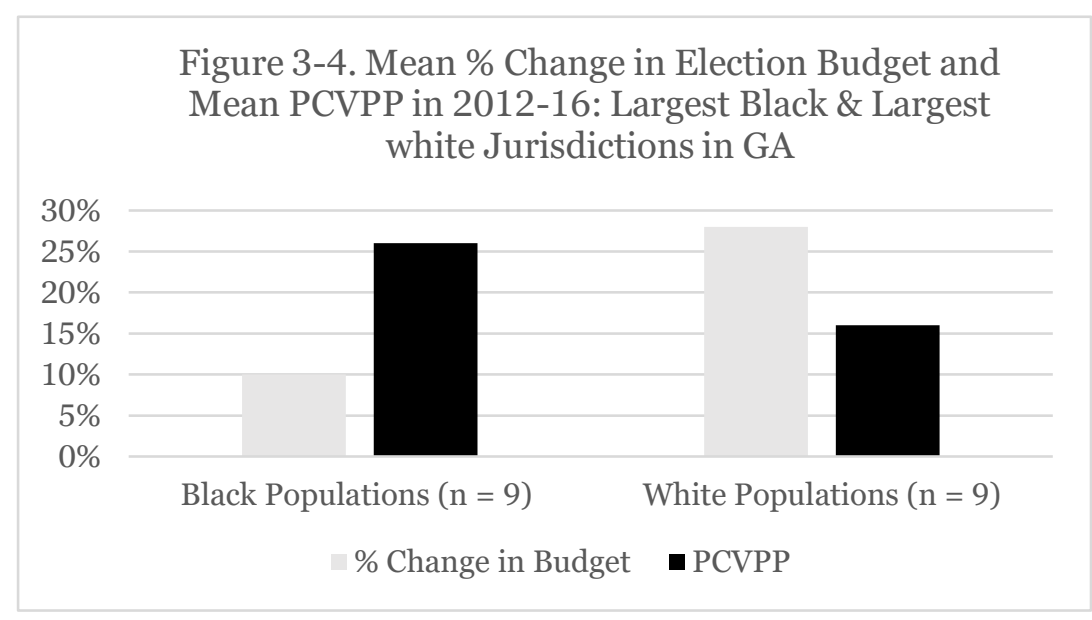

Limitations in the data resulted in my analyses being restricted to only nine Black jurisdictions and nine white jurisdictions. ${ }^{26}$ Looking at the first group of bars (representing large Black populations) in figure 3-4, the average change in election budgets was roughly $10 \%$, which suggests that most large Black jurisdictions saw increases in election budgets.

\footnotetext{
${ }^{25}$ As of 2016, the use of voting centers had not yet been adopted.

${ }^{26}$ The full dataset is available in the a $A$ ppendix: table B.
} 
However, the average value of PCVPP did not reflect that. Rather than the average value of PCVPP being near zero or being negative - which would likely have reflected jurisdictions adding additional polling places with the additional resources available to them - , the average value of PCVPP for those jurisdictions was roughly 26\%. When looking at the sample of white jurisdictions (represented by the second group of bars), the average change in election budgets was almost 18 percentage points higher than in Black jurisdictions at $28 \%$, while the value of PCVPP, at $16 \%$ was much lower than it was in Black jurisdictions.

Based on these figures, from one perspective, it seems that election budgets do matter when it comes to poll closures. Largely white counties in Georgia saw a significant increase in their election budgets between 2012-16 and saw smaller values of PCVPP when compared to the data for the large Black counties.

However, I believe it is also important to note that the data also suggests that closures take place when there are budget increases as well. For example, the average value of PCVPP in the largely white counties was still relatively large at $16 \%$ (although smaller when compared to the largely Black counties) even though these counties saw their election budgets grow between 2012 and 2016. The data surrounding the largely Black counties illustrates this as well. On average, these counties saw a 10\% increase in their budgets between 2012 and 2016, but average PCVPP was quite large at $26 \%$.

Election budgets decreased in three of the 18 counties in the sample, two of which were largely white counties. While White County, one of the largely white counties in the sample, experienced by far the largest budget decrease (33\%), the county's number of voters per precinct increased by only $4 \%$. In contrast, while largely Black Richmond County experienced a $9 \%$ decrease in its election budget, the number of voters per precinct in that county increased 
by $80 \%$. Not too much should be made of the values of PCVPP in White County and Richmond County, but large positive changes of $15 \%$ or more in the number of voters per precinct occurred in four of nine largely Black counties, but only two of nine largely white counties, and this was true despite the fact that budgets increased in five of the six counties with large positive changes in the number of voters per precinct.

As I mentioned, Georgia does offer alternative voting opportunities (and other factors) that may explain the large values of PCVPP, but that is difficult to verify within the scope of this project. I discuss that fact in more detail and describe my plans for future analyses in the next section.

\section{Conclusion}

In recent years, journalistic reports have documented an unusually high number of poll closures. The authors of many of these reports argue that the large number of closures is due to the Shelby $v$. Holder ruling that effectively invalidated the preclearance provision of the Voting Rights Act (LCEF 2016). The issue with these reports is that they are descriptive. They lack rigorous statistical analyses that test whether their claims are correct. In this paper, I filled this "statistical void" by using multiple regression models to understand the causes of The Great Poll Closure.

Even after accounting for several legal factors that may lead jurisdictions to close polling places, I find that formerly preclearance jurisdictions saw a significantly larger number of polling place closures following Shelby than non-preclearance jurisdictions. In the initial regression analysis (table 3-5), I did not find any significant evidence showing that the interaction between percent non-white and preclearance played a role in polling place closures.

However, when I employed an indicator that identified jurisdictions with particularly 
large proportions of Black and Hispanic residents, the results surrounding formerly preclearance jurisdictions with large non-white populations were consistent with my expectations. For example, in the 2012-16 analysis, preclearance jurisdictions with large Black populations were predicted to have a value of PCVPP roughly 18 percentage points greater than non-preclearance jurisdictions. Preclearance jurisdictions with large Hispanic populations were also predicted to have substantially higher values of PCVPP than non-preclearance jurisdictions. Both relationships were statistically significant. Looking at these same jurisdictions in the 2008-12, there were no statistically significant relationships. Based on the results of the 2012-16 analysis, I conclude that formerly preclearance jurisdictions with large Black and Large Hispanic populations were closing polling places at much larger rates following Shelby when compared to both non-preclearance jurisdictions and (formerly) preclearance jurisdictions with neither large Black nor Hispanic jurisdictions, even when controlling for other causes of poll closures.

To further highlight this, in the pre-Shelby analysis, most of the significant factors that led to polling place closures were constitutionally valid factors that are stated in the state's election code. For example, jurisdictions that implemented early voting laws between 20082012 were predicted to have larger values of PCVPP. Another constitutionally valid reason for closures is budgetary constraints. In the pre-Shelby analysis, jurisdictions that were relatively poor were predicted to see a significantly larger number of poll closures. Neither the enactment of early voting laws nor lower levels of income were significant in the post-Shelby analysis.

I also examined the effects of additional socioeconomic factors on PCVPP. This is especially important given the association between lower average socioeconomic status levels and jurisdictions with large non-white populations. I find that the number of closures may have 
also been due in part to additional socioeconomic characteristics of jurisdictions with large non-white populations such as age, income, and education. I find that preclearance jurisdictions with large non-white populations, which have significantly lower median incomes, fewer college graduates, and fewer people over the age of 65 than that of nonpreclearance jurisdictions, saw fairly similar averages of PCVPP when compared to nonpreclearance jurisdictions prior to the Shelby case. However, following Shelby, I find that although the differences in SES characteristics remained the same between formerly preclearance jurisdictions with large non-white populations and non-preclearance jurisdictions, the values of PCVPP changes drastically with large increases of PCVPP in the former and large decreases in the latter. These findings suggest that polling place closures in former preclearance jurisdictions with large non-white populations may have also occurred due to those jurisdictions having socioeconomic characteristics that are often associated with voter turnout.

In terms of future work, at least two avenues of research should be explored. First, although I believe my operationalization of budgetary issues is reasonable given the scope of this project, I feel a deeper dive into each jurisdiction's election budget would be ideal for better understanding the effects of budgetary constraints on poll closures. For example, I believe a more detailed investigation along the lines of my Georgia case study would be fruitful. At the same time, analyzing cases in and/or across multiple states with different election laws and demographics would help add even more nuance to our understanding of the lasting effects of The Great Poll Closure. If election budget data for all voting jurisdictions could be gathered, I believe a differenced election budget variable would make sense for a nationwide analysis (similar to the one I conducted in table 3-5); decreases in election budgets 
would result in decreases in the number of polling places and vice-versa.

Second, I believe my findings in this chapter contribute to studying the lasting effects of polling place closures, especially with my unique measure of polling place closures PCVPP. In the next chapter, I explore the effect of the PCVPP variable on county-level turnout across the same election years. However, as I will explain in that chapter, I believe the research should not stop at voter turnout. I believe studying the effect of PCVPP on other forms of political participation and other political behavior would provide lawmakers with important objective information to draw upon as they decide whether to replace the coverage formula and/or revise the preclearance provision of the Voting Rights Act in a way that passes constitutional muster according to Federal Courts.

In conclusion, many political scientists, legal scholars, historians, activists, and citizens familiar with the history of voting rights in the United States were concerned that the Shelby decision would result in changes in election administration that would make voting more burdensome, especially among Black and Hispanic Americans. The analyses in this chapter suggest that such concerns were well founded. I believe these findings will contribute to the already growing literature on the implications of the Shelby case. In other words, my findings illustrate that the " 40 -year old facts" that the Supreme Court argued were out of date in the justification of its invalidation of preclearance may not be as outdated as originally thought. 


\section{CHAPTER 4: The Effects of The Great Poll Closure on Turnout}

In chapter 2, I provided a legal primer for understanding how and why polling place closures take place. In chapter 3, I examined the factors that cause voting jurisdictions to close polling places. However, in this chapter, I am taking a more behavioral approach by analyzing the effects of The Great Poll Closure on voter turnout in 2016 compared to previous elections that occurred when the full protection of the Voting Rights Act, including the preclearance provision, was still in force. Using county-level turnout data from the 2008, 2012 and 2016 presidential elections, I implement difference-in-difference analyses to explore the effect of changes in polling places on the change in county voter turnout between 2008-12 and 2012-16.

I find that The Great Poll Closure had a significant effect on changes in county-level turnout in presidential elections between 2012, before the Shelby decision, and 2016, after Shelby effectively invalidated the preclearance provision of the VRA. In contrast, poll closures did not have a significant negative effect on the change in turnout between 2008 and 2012, before the Shelby case took place. Taking together the findings presented in chapter 3 and the fact that the preclearance provision was still active, this finding makes sense. Although there were poll closures between 2008 and 2012, the closures took place primarily in jurisdictions that were never subject to preclearance and unlike the factors associated with closures in jurisdictions (formerly) subject to preclearance, such as racial composition, the factors associated with closures in non-preclearance areas were less strongly associated with lower levels of voter turnout. To that point, in this chapter, I also find that formerly preclearance jurisdictions with large Black populations saw significant decreases in turnout due to the large 
number of poll closures. This relationship was only significant following Shelby. In short, the “40-year old facts" that Justice Roberts argued were outdated when invalidating the coverage formula of the VRA may not be as "outdated" as originally thought.

In addition to general voter turnout literature, I believe the findings of this chapter will also contribute to the growing literature on electoral procedures and non-white political participation. One example of an election procedure that has been highly contentious is the implementation of majority-minority districts. In general, with the implementation of majorityminority districts, Black and Latino representation in Congress has increased significantly (Lublin 1997). To that point, scholars have also found that Blacks that live in districts with Black legislators perceive their legislators as being responsive, evaluate their representatives more favorably, and (in some cases) participate at higher rates than in districts in which representatives are non-Black (Gay 2001; Tate 2003). In terms of Hispanic voters, Barreto, Segura, and Woods (2004) found that majority Latino districts significantly increase turnout for Hispanic voters living in those districts. However, scholars have also found majority-minority districts to be unhelpful - particularly for the Black community. Gay (2007) found that majority-minority districts are no more or no less responsive to their constituents than majoritywhite districts. Griffin and Flavin (2007) found that because Blacks score lower on average on measures of political knowledge, they may be less likely to know if their representatives are working in their favor. I believe the findings in this chapter surrounding polling place closures and non-white turnout will add nuance to the discussion of how election procedures affect nonwhite voters.

\section{Do Polling Place Closures Lower Turnout?}


Haspel and Knotts (2005) blazed the trail in "reprecincting" literature. They looked at two elections in the city of Atlanta. They found that changes in polling places increased voter turnout throughout Atlanta. However, the authors attribute their surprising results to two factors. First, local election officials sent out reminder postcards to all the voters roughly 30 days prior to the election so the voters would not forget that their polling place had changed. Second, the city of Atlanta added eight precincts from the first to the second election, giving more voters places to vote. Essentially, Haspel and Knotts showed that adding more precincts (which changes where people vote) had a positive influence on voter turnout.

Brady and McNulty (2011) looked at the effect of poll closures in the 2003 gubernatorial recall election in Los Angeles County, CA. They found that citizens who had their polling place moved were 1.85 percent less likely to vote than those whose polling place remained the same. Originally, Brady and McNulty found this 1.85 percent to be much higher, but part of the original figure was offset by accounting for absentee and early voting. In other words, they concluded that moving or closing a precinct does result in people not turning out to vote, but it also increases the chances of engaging in non-traditional forms of voting (i.e. voting by absentee ballot and early voting).

Brady and McNulty also found that the effect of closures was different for Democratic and Republican voters. Democrats were more sensitive to polling place changes than Republicans. While these effects did not determine the outcome of the election in question, they are worrisome enough "to make it possible for someone to affect outcomes by more extensive manipulation of polling place locations" (Brady and McNulty 2011 115). 
Amos, Smith, and Ste. Claire (2017) took this partisan concern to the next level by studying reprecincting as a partisan act. In their experiment, they looked at a 2014 midterm election in Manatee County, Florida. They chose this location because the local election official prior to this election was a Democrat, and the one during the election was a Republican. They found that when the Republican LEO was in office, precincts in Manatee County that were predominately non-white, younger, and Democratic were the most likely to be consolidated or closed. When looking at voter turnout, residents with those demographic characteristics were also the least likely to cast a ballot. In short, Amos, Smith, and Ste. Claire (2017) provided evidence that polling changes can be a partisan act that is detrimental to democracy in America.

In the most recent publication, Clinton et al. (2020) analyzed poll closures throughout the whole state of North Carolina across three general elections (2008, 2012, and 2016). They found that voters who had their polling places shut down or relocated were less likely to vote than those whose polling places remained the same, but this finding was completely offset when they accounted for the increase in early voting. In other words, when a person's polling place changes, it discourages them from turning out on election day, but not from voting entirely; they just vote earlier. One limitation of these findings is that the state of North Carolina offers a period of early voting in each county; isolating the effects of polling place closures in areas with no early voting has yet to be done, and when early voting is not an option or involves significant costs, polling place closures may result in reduced turnout.

The contributions made by the scholars mentioned above have advanced our understanding of the relationship between poll closures and voter turnout. Specifically, citizens whose polling places have been changed are less likely to vote than citizens whose polling places did not change. However, two important questions remain unanswered: first, does that pattern 
hold on a national level, especially when controlling for variation in state election laws? Second, did the effect of closures on turnout become stronger following Shelby? Before I explain my expectations, I believe it is necessary to explain why polling place closures decrease turnout.

\section{Theoretical Explanations}

There are at least three direct mechanisms that might explain the decrease in turnout caused by polling place closures: transportation costs, lack of information (or search costs), and the increase in wait time. The first mechanism, transportation costs, has been explored multiple times by scholars of electoral administration (Brady and McNulty 2011; Dyck and Gimpel 2005; Gimpel and Schuknecht 2003; Haspel and Knotts 2005; Cantoni 2016; Amos, Smith, and Ste. Claire 2017). The expectation with regard to this mechanism is that those citizens who had their precinct moved would be less inclined to vote if their new precinct location was farther away than the previous one. The transportation costs mechanism has received little empirical support. In their North Carolina sample, Clinton et al. (2020) found an average difference of less than 5 minutes for those voters who had their polling place changed.

The second mechanism seems to be the most widely agreed upon factor that explains the effect of precinct closures on voter turnout (Amos, Smith, and Ste. Claire 2017; Clinton et al. 2020). Scholars argue that a precinct change may "require voters to expend resources seeking out information about where their polling place has moved to and how to travel to it" (Clinton et al. 2020 5). These resources are things like the ability to get to city hall or having a permanent mailing address at which information about polling place changes can be received. Local election officials (those in charge of making changes) are required to notify constituents of precinct 
changes by a certain number of days before the election. Most LEOs notify citizens by mail or post the information at the county courthouse or city hall. Not having access to this type of information can hurt someone's chances of participating in elections.

As past research has shown, "any additional hurdle to voting, however small or large, can have a substantial impact on the likelihood of voting - especially among low-propensity voters" (Hajnal et al. 2017 366). For example, Hajnal et al. (2017) found that strict voter ID laws (must show a picture ID to vote) disproportionately reduce turnout among minorities, the poor, and younger citizens. ${ }^{27}$ Unfortunately, members of non-white populations, citizens with low income levels, and younger citizens also tend to have lower levels of political resources and are among the types of citizens least likely to vote (Leighley and Nagler 2014; Verba et al. 1995).

In addition to members of these groups (non-whites, the poor, young citizens, and those with lower levels of education) having difficulty overcoming hurdles to vote when their polling places have been relocated, the findings described in chapter 3 also suggest that members of these groups will also be more likely to face poll closures. For example, I found that formerly preclearance jurisdictions with large non-white populations were expected to see the largest amounts of poll closures following the Shelby election when compared to formerly nonpreclearance jurisdictions. I also found that other socioeconomic characteristics played into this relationship as well. Not only does race play a factor in poll closures following Shelby, but so do other socioeconomic characteristics of jurisdictions that are closely associated with race, such as low education levels, high poverty rates, and high percentages of young people. In short, the

\footnotetext{
27 Some scholars have questioned Hajnal et al's findings. Gelman (2018) describes the controversy here: https://www.washingtonpost.com/news/monkey-cage/wp/2018/06/11/a-new-controversy-erupts-over-whether-voter-identification-laws-suppressminority-turnout/.
} 
citizens who are most likely to lack the resources to find new polling place locations are also the citizens who experience poll closures more frequently.

The last mechanism - the effect of voter wait time - has not received as much scholarly attention as the previous two mechanisms when it comes to the possible reasons polling place closures can cause a decrease in turnout. Suppose a voter's precinct was consolidated with a new precinct across town that is roughly 3 miles away by car. This new precinct now must house the original voters from previous years along with the voters from the precinct that was consolidated with the original precinct. If the new combined precinct lacks the proper equipment and the appropriate amount of poll workers, the wait time to vote could increase significantly. Another factor affecting voter wait-times are the check-in stations. These can also cause voters to wait for long periods of time, especially if equipment or the number of workers is inadequate. Barreto et al. (2009) found that voter turnout was significantly lower in Los Angeles precincts with longer lines and check-in times. In short, because polling place closures can result in the over-crowding of new polling places, the length of lines at check-in stations and voting booths may increase significantly, resulting in people leaving those lines and not casting ballots.

\section{Expectations}

Based on the previous literature, and by way of the theoretical mechanisms just described, polling place closures do decrease the likelihood of individuals casting votes. I expect this negative relationship between closures and turnout to hold at the county level as well. However, in my research, I will not be estimating the effect of the raw number of polling place closures on turnout because I believe the effect of the raw number of precinct closures should vary by jurisdiction size. For example, take two hypothetical counties - one with 400 voters and 
the other with 4,000 voters - both with ten closures; I would imagine that turnout in the former county would be much more strongly affected by the closing of 10 precincts than the latter. To account for the population size problem, each county (in each election year - 2008, 2012, and 2016) is measured by the number of voters per precinct (or VPP). This value is the citizen voting age population divided by the total number of traditional polling places.

To illustrate the relationship between the number of voters in a precinct and voter turnout at a given point in time, I regressed county-level turnout in the last three presidential elections

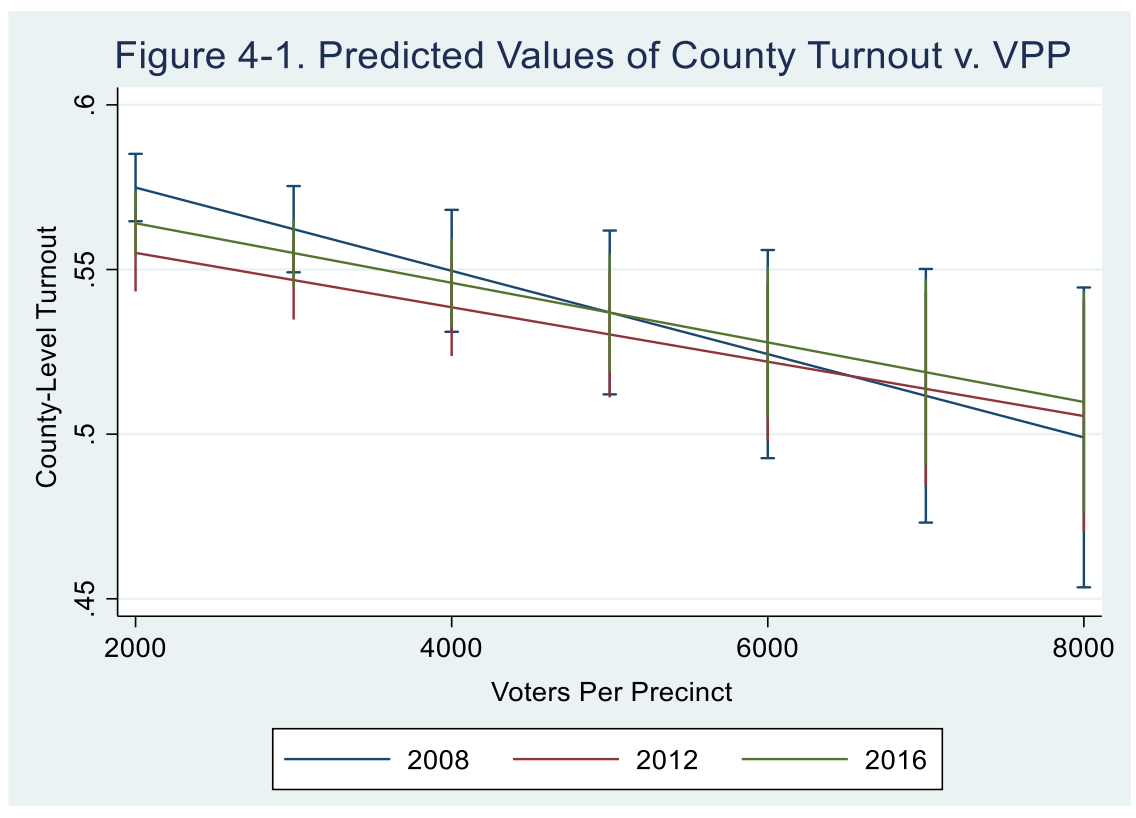

$\left(2008,2012\right.$, and 2016) on the number of voters per precinct. ${ }^{28}$ Figure $4-1$ plots predicted values of turnout vs. VPP based on those results. I find that there was a significant negative relationship between VPP and county-level voter turnout in all three elections. Jurisdictions with larger numbers of voters per precinct were predicted to have lower levels of turnout in each year. These findings were to be expected given the theoretical mechanisms explained in the section above.

\footnotetext{
28 The regression models include several control variables for both state-level election laws and county demographics. The full analyses are in Table $\mathrm{C}$ in the appendix. The controls are the same variables used in chapter 3's analyses (see chapter 3 data \& methods section for more information).
} 
Despite being congruent with my expectations, the analyses illustrated in figure 4-1 are only a starting point, as they account for neither the endogeneity issues one faces with the study of election changes nor the complexity of the effects of the Shelby decision.

Election scholars have found that endogeneity issues can be important when doing research on the net effects of election changes (Bowler, Brockington, Donovan 2001; Erikson and Minnite 2009; Giammo and Brox 2010; Hamner 2009; Leighley and Nagler 2009; Burden et al. 2014). When studying whether political behavior that may be influenced by some sort of election law change, it is important to consider the fact that election law changes "might be shaped in part by that behavior" (Burden et al. 2014, 105). To account for this problem, scholars suggest using difference-in-difference estimation (Bowler, Brockington, and Donovan 2001; Erikson and Minnite 2009; Giammo and Brox 2010; Hanmer 2009; Leighley and Nagler 2009; Burden et al. 2014). In this chapter, I utilize the same differenced variable from chapter 3, which I referred to as the "percentage change in voters per precinct" or PCVPP. PCVPP is calculated by finding the percentage change in voters per precinct (VPP) between the former and latter election. In my analyses, there will be two PCVPP variables: 2008-12 and 2012-16 (see Appendix I for more details). In sum, those voting jurisdictions with significant numbers of poll closures (openings) between elections will have positive (negative) values of PCVPP. I expect jurisdictions with higher values of PCVPP to see a larger decrease (or smaller increase) in county level turnout as compared to jurisdictions with lower values of PCVPP in both election analyses.

I believe the effects of increases in PCVPP on turnout will be particularly apparent when comparing preclearance and non-preclearance jurisdictions across the different election analyses. Recall that in the Shelby decision, the Court ruled that the coverage formula of the VRA was no 
longer valid. This eliminated required federal preclearance of election law changes in areas with histories of voter discrimination. Based on the descriptive findings of the LCEF, in 2016, there were over 800 polling place closures in formerly preclearance jurisdictions alone. Referring to figure 3-2 in chapter 3, I also found statistically significant evidence that preclearance jurisdictions were closing polling places at a much higher rate following Shelby.

For example, the mean value of PCVPP in non-preclearance jurisdictions was roughly three percentage points higher than in preclearance jurisdictions before Shelby. This made sense given that the preclearance provision was still active, which made it much more difficult for preclearance jurisdictions to close or change polling place locations. Moving to the post-Shelby analysis, the opposite relationship held between preclearance and PCVPP. The mean value of PCVPP in formerly preclearance jurisdictions was roughly 20 percent, which is more than 12 percentage points higher than the mean value in formerly non-preclearance jurisdictions. Additionally, comparing preclearance to formerly preclearance jurisdictions, the mean value of PCVPP was roughly eight percentage points higher in the former than in the latter. Based on those findings, without the preclearance provision of the VRA, jurisdictions that were formally under the supervision of the federal government were closing precincts at a much higher rate than they were when the provision was still active.

In addition to the large values of PCVPP in formerly preclearance areas, the population characteristics of these jurisdictions provide another reason that high values of PCVPP are particularly detrimental for turnout in those areas. Preclearance jurisdictions became "preclearance" states or counties because of their histories of discrimination against non-whites in their states and counties. These areas tend to have large non-white populations. As noted in the literature review, people of color are less likely to have the resources necessary to overcome 
obstacles to voting; adding another obstacle by closing polling places is likely to further reduce turnout.

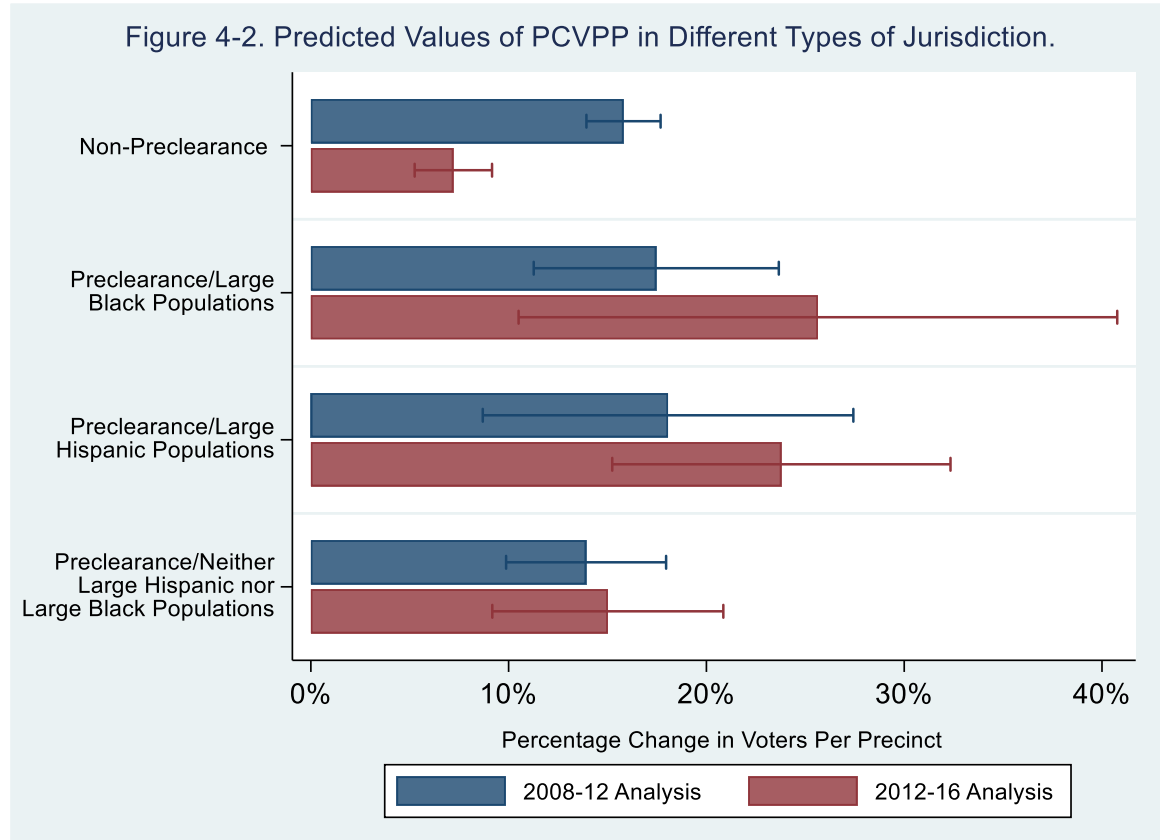

To illustrate this relationship, figure 4-2 shows the predicted values of PCVPP for different combinations of jurisdictions with different characteristics in terms of preclearance and non-white populations from the analyses conducted in chapter $3 .{ }^{29}$ Based on the figure, one can tell that the values of PCVPP in formerly preclearance jurisdictions with large non-white populations were much higher in the 2012-16 (post-Shelby) analysis than in the pre-Shelby analysis even when holding factors such as median income fixed. For example, preclearance jurisdictions with large Black populations (> 30\%) were predicted to have a PCVPP value of $26 \%$ in $2012-16$, which was roughly 9 percentage points higher than in $2008-12$. This was relatively similar in formerly preclearance jurisdictions with large Hispanic populations (> 15\%). Interestingly, predicted values of PCVPP for formerly preclearance jurisdictions with small non-

29 These predicted values are based on the analyses in Table 3-7 in chapter 3. All other variables are held at their means. 
white changed minimally following Shelby. This ultimately shows that among preclearance jurisdictions, those with large non-white populations were closing significantly more polling places following Shelby than those with smaller non-white populations. In conclusion, based on these predicted values, I expect the largest effects of PCVPP on the change in turnout will be found in preclearance jurisdictions with large non-white populations.

\section{Data \& Methods}

To analyze the relationship between polling place closures and county voter turnout, I use county-level election returns from three elections: 2008, 2012, 2016. I obtained this data from Dave Leip's Election Atlas. Each county's voter turnout is measured as a percentage of the voting-age population. The voting-eligible population would have been the more ideal measure, but it was not available at the county-level.

For data on polling places, I used the Election Administration and Voting Survey (EAVS), which is a biennial survey that collects data on a wide variety of election administration topics across voting jurisdictions in the U.S. I analyze the number of voters per precinct by utilizing data collected by the Election Administration Commission (EAC). After each midterm and general election, the EAC creates the Election Administration and Voting Survey (EAVS). It polls each voting jurisdiction across the United States on election administration procedures and voting registration. In this survey, the EAVS asks three questions about the total number of polling places in a jurisdiction: (1) physical polling places other than election offices, (2) election offices, and (3) other (see Appendix I for more information). For my research, I tallied up the three answers and used that as the total number of election day polling places in jurisdictions for 2008, 2012, and 2016. 
One issue with the EAVS is that states and their local jurisdictions are not required to complete the survey, and thus some states are missing from the dataset. Alaska, New York, Utah, Illinois, Wisconsin, New Mexico, and Virginia failed to complete the survey in at least one of the three years. I omitted Colorado, Washington, and Oregon because they do not have traditional polling places; all their elections are administered by mail. Altogether, I gathered precinct data for 40 states plus Washington, D.C. which equates to roughly 2,270 voting jurisdictions.

County-Level Turnout. For the purposes of my analyses, I employ two dependent variables that measure the change in county voter turnout; the first captures change from 200812 and the second captures change from 2012-16. To create these variables, I subtracted countylevel voter turnout rate in 2012 (2016) from turnout in 2008 (2012). The average change in turnout from $2008-2012$ was roughly $-2 \%$, whereas in $2012-2016$ it was $+1 \%$. The histogram in figure 4-3 illustrates the differences in turnout. As evident in the figure, the median county saw a decrease in turnout from 2008-12, while the median county saw an increase in turnout between 2012-16.

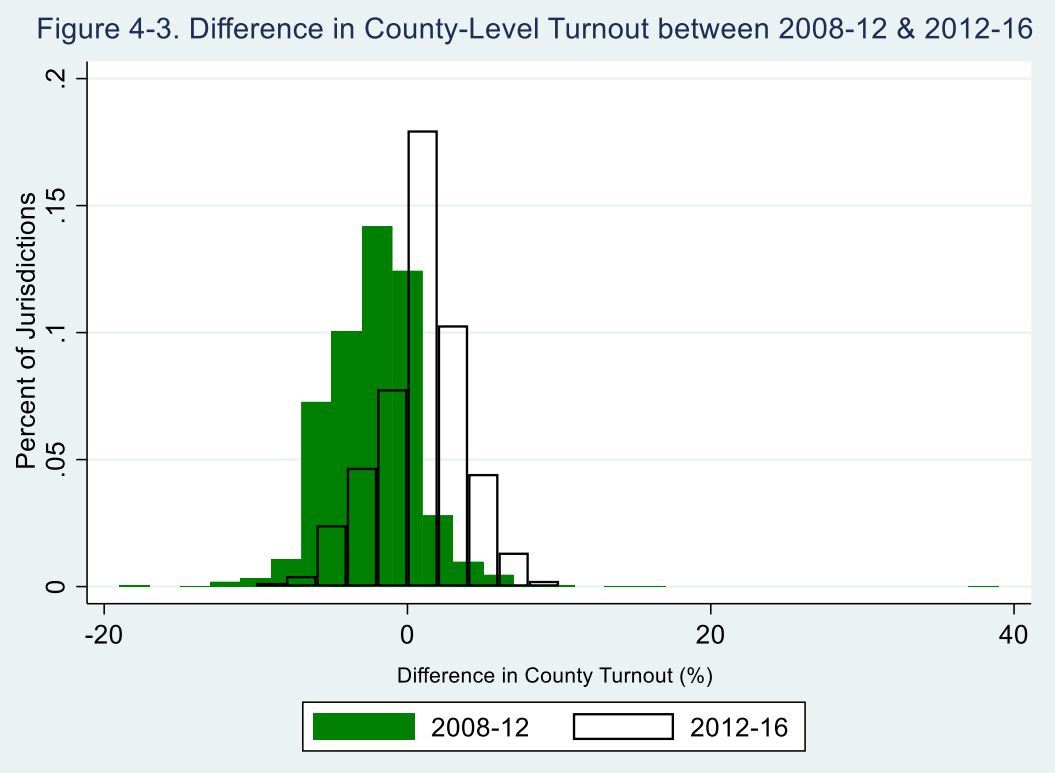


Polling Place Closures. To measure the change in polling places between elections, each county's number of voters per precinct is measured, and equals the total number of active voters divided by the total number of traditional polling places. To compare polling place closures between elections, I create a differenced variable referred to as the "percentage change in voters per precinct" or PCVPP. PCVPP is calculated by finding the percentage change in VPP between the former and latter election. In my analyses, there are two PCVPP variables: one for 2008-12 and one for 2012-16 (see Appendix I for more details). In sum, those voting jurisdictions with significant amounts of poll closures (openings) between elections will have a positive (negative) value of PCVPP. In terms of expectations, I predict that jurisdictions with large values of PCVPP will see significant decreases (or significantly smaller increases) in county turnout between both 2008-12 and 2012-16 compared to those with smaller values.

The Effects of the Shelby Decision. There is a two-step process when it comes to interpreting and understanding the effects of Shelby on the change in county-level turnout. First, I create two important county-level variables that interact whether a jurisdiction was formerly under preclearance and with the percentages of a county's population that is Black and Hispanic. I refer to these variables as jurisdiction percent Black x preclearance and jurisdiction percent Hispanic x preclearance. I include these variables in the model specification that includes all independent variables. I expect to see formerly preclearance jurisdictions with large Black (and large Hispanic) populations to see a decrease in county-level turnout between 2012-16 and a slight increase (or an insignificant decrease) between 2008-12. The reason for this expectation is that the preclearance provision was still active in the latter election analysis, thus ensuring no new discriminatory election procedures would be employed to hinder voting among non-whites. 
Second, to better understand the effects PCVPP, preclearance, and racial composition have on turnout, I create predicted values of county-level turnout for hypothetical jurisdictions with various characteristics and values of PCVPP. ${ }^{30}$ There are a total of four scenarios: nonpreclearance jurisdictions, preclearance jurisdictions with large Black populations (>30\%), preclearance jurisdictions with large Hispanic populations (>15\%), and preclearance jurisdictions with neither large Black nor large Hispanic populations. My expectations are that setting the value of PCVPP to a relatively high value will result in preclearance jurisdictions with large nonwhite populations seeing a significant decrease in predicted turnout, particularly following the Shelby case.

Election Law Controls. Clinton et al. (2020) found that although polling place changes did result in citizens not turning out to vote, if a state offers more relaxed early voting laws, the effect of poll closures is offset. Based on that finding, I believe it is imperative to control for early voting opportunities, specifically in-person early voting and no-excuse absentee balloting. Another voting law that may influence the effect of closures on turnout is the implementation of voting centers. Voting centers are "polling locations that are open to all voters in a county rather than geographically restricted precincts" (Stein and Vonnahme 2012 291). Given that voting centers are created to mitigate the hassle of finding a traditional polling place, I expect that the effect of closures on turnout will be weaker in states that implement voting centers.

The final state election law that may affect county turnout that I account for here is a strict voter identification requirement. Hajnal et al. (2017) found that the enactment of strict voter ID laws (i.e. photo ID required) caused a significant decrease in turnout among minorities

\footnotetext{
30 These predicted values of PCVPP are drawn from figure 4-2.
} 
in states that enacted those requirements. I code this variable as 1 if a state requires voters to show photo ID at the polls and 0 if a state does not require a photo ID.

County Demographics. According to scholars of voting behavior, demographics play a large role in determining voter turnout (Verba et al. 1995; Leighley and Nagler 2014). The demographic patterns identified by these scholars are often associated with voter turnout analyses at the individual-level. With that being said, I believe it is important to control for these demographics at the county-level as well. Using the 5-year American Communities Survey (ACS) provided by the U.S. Census, I control for the following county demographics: \% Black $\%$ Hispanic, percentage of adults with a college degree, percentage of citizens 65 or older, median jurisdictional income, and population density. ${ }^{31}$

Model Specification. I estimate linear regression models predicting the percentage change in county voter turnout from 2008 to 2012 and from 2012 to 2016. These models are also difference-in-difference (DID) models. DID models estimate the effects of explanatory variables (and changes of those variables) on the over-time change in an outcome variable. In the models, I observe the change in voters per precinct between two election years (2008-12 and 2012-16). Because I am using difference-in-difference estimation, I also must account for the differences in my independent variables. For example, I take my dummy variables for state laws and create differenced variables for both the 2012 and 2016 models. In other words, in my 2012 (2016) analysis, the early voting variable is accounting for those states who implemented (or eliminated) an early voting period between 2008 (2012) and 2012 (2016). I also created differenced variables for the absentee and voting center dummies. However, variables such as jurisdiction Black

\footnotetext{
${ }^{31}$ Being that population density (persons per square mile) and VPP (voters per precinct) may be very similar and maybe highly correlated, I ran a Pearson correlation test. I found no significant correlation between the two variables.
} 
population and Hispanic population (and other demographics) evolved to slowly over the fouryear comparison and the difference would have little effect on the dependent variable.

Another important aspect of model specification for these analyses is the standard errors. In most analyses where there is mixed-level modeling, the standard errors are normally clustered at the aggregate level. For example, if there is county and state level data in the model, the standard errors should be clustered at the state level. However, in terms of my analyses, this is not the case. If I were just implementing cross-sectional analyses (rather than DID), I could cluster the standard errors at the state level, but because I am using DID, clustering the standard errors at the state level would not account for the county-level correlated errors over time (Primo, Jacobsmeier, \& Milyo 2007; Burden et al. 2014; Burden et al. 2017). In other words, because each county is observed at two points in time (i.e. election cycles -2008 to $2012 \& 2012$ to 2016), the standard errors must be clustered at the county level.

\section{Findings}

To estimate the effect of the change in voters per precinct on the change in county-level turnout, I estimate a total of four models (1-2 for 2008-12 and 3-4 for 2012-16). ${ }^{32}$ Before I discuss the results, it is important to describe the interpretation of the coefficients. Because the dependent variable is the difference in turnout, each coefficient represents the predicted effect of a unit change on turnout, with the units of turnout being percentage points. For example, if there is a coefficient of 0.09 on one of the dummy variables, the predicted change in turnout between the two election years is roughly 0.09 percentage points higher in counties where the variable takes on a value of 1 than in counties where that variable takes on a value of 0 .

\footnotetext{
${ }^{32}$ For additional analyses that compare preclearance to non-preclearance jurisdictions between 2008-12 and 2012-16, please see table D in the appendix.
} 
As shown in table 4-1, model 1 is a bivariate regression analysis between PCVPP and change in county-level turnout between 2008-2012. I find that jurisdictions with higher values of PCVPP were predicted to see more negative changes in turnout between 2008-12 than those with

\begin{tabular}{|c|c|c|c|c|}
\hline \multicolumn{5}{|c|}{ Table 4-1. Difference-in-Difference Models of Change in County-Level Turnout } \\
\hline & \multicolumn{2}{|c|}{2008 to 2012} & \multicolumn{2}{|c|}{2012 to 2016} \\
\hline & $(1)$ & $(2)$ & $(3)$ & $(4)$ \\
\hline PCVPP & $\begin{array}{c}-0.003 \\
(0.002) \\
\end{array}$ & $\begin{array}{l}-0.002 \\
(0.002)\end{array}$ & $\begin{array}{l}-\mathbf{0 . 0 0 3} * * \\
(\mathbf{0 . 0 0 1 )} \\
\end{array}$ & $\begin{array}{l}-\mathbf{- 0 . 0 0 3} * * \\
(\mathbf{0 . 0 0 1 )}\end{array}$ \\
\hline Preclearance X \% Black & & $\begin{array}{l}0.040 * * * \\
(0.010)\end{array}$ & & $\begin{array}{l}-0.056 * * * \\
(0.012)\end{array}$ \\
\hline Preclearance X \% Hispanic & & $\begin{array}{l}\mathbf{0 . 0 3 6}^{* * *} \\
(0.014)\end{array}$ & & $\begin{array}{l}0.008 \\
(0.015\end{array}$ \\
\hline Preclearance & & $\begin{array}{l}-0.185 \\
(0.321)\end{array}$ & & $\begin{array}{l}1.812 * * * \\
(0.345)\end{array}$ \\
\hline$\%$ Black & & $\begin{array}{c}0.016 * \\
(0.008)\end{array}$ & & $\begin{array}{l}\mathbf{- 0 . 0 6 0} * * * \\
(0.009)\end{array}$ \\
\hline$\%$ Hispanic & & $\begin{array}{l}-\mathbf{0 . 0 2 1} * * \\
(0.007)\end{array}$ & & $\begin{array}{l}0.001 \\
(0.009)\end{array}$ \\
\hline$\Delta$ Early Voting & & $\begin{array}{l}-0.523 \\
(0.421) \\
\end{array}$ & & $\begin{array}{l}-0.520 \\
(0.572) \\
\end{array}$ \\
\hline$\Delta$ No-Excuse Absentee & & $\begin{array}{c}0.059 \\
(0.347)\end{array}$ & & $\begin{array}{l}-1.684 * * \\
(5.47)\end{array}$ \\
\hline$\Delta$ Voting Centers & & $\begin{array}{l}-1.415 * * * \\
(0.272)\end{array}$ & & $\begin{array}{l}-0.827 \\
(0.452) \\
\end{array}$ \\
\hline$\Delta$ Strict ID Laws & & $\begin{array}{l}-1.126 * * * \\
(0.141)\end{array}$ & & $\begin{array}{l}-1.399 * * * \\
(0.234)\end{array}$ \\
\hline Median Income & & $\begin{array}{l}0.046 * * * \\
(0.009)\end{array}$ & & $\begin{array}{l}-0.010 \\
(0.010)\end{array}$ \\
\hline Pop. Density & & $\begin{array}{r}0.118 \\
(0.206)\end{array}$ & & $\begin{array}{l}0.298 * * * \\
(0.063)\end{array}$ \\
\hline$\%$ Over 65 & & $\begin{array}{l}0.174 * * * \\
(0.017)\end{array}$ & & $\begin{array}{l}0.056 * * \\
(0.018)\end{array}$ \\
\hline$\%$ College Degree & & $\begin{array}{l}-\mathbf{- 0 . 0 9 3} * * * \\
(\mathbf{0 . 0 1 7 )}\end{array}$ & & $\begin{array}{c}-0.040 * * \\
(0.018) \\
\end{array}$ \\
\hline$\%$ Voted for GOP & & $\begin{array}{r}0.006 \\
(0.007)\end{array}$ & & $\begin{array}{l}0.004 \\
(0.007) \\
\end{array}$ \\
\hline Constant & $\begin{array}{l}-\mathbf{0 . 0 0 2} * * * * \\
(0.001)\end{array}$ & $\begin{array}{l}-\mathbf{0 . 0 6 7} * * * \\
(0.007)\end{array}$ & $\begin{array}{l}\mathbf{0 . 0 0 8}_{* * *}^{*} \\
(\mathbf{0 . 0 0 1 )}\end{array}$ & $\begin{array}{c}0.012 \\
(0.009) \\
\end{array}$ \\
\hline $\mathrm{R}^{2}$ & 0.01 & 0.15 & 0.01 & 0.22 \\
\hline $\mathrm{N}$ & 2,262 & 2,262 & 2,262 & 2,262 \\
\hline
\end{tabular}

lower values of PCVPP. However, that relationship was insignificant. Taking together the findings presented in chapter 3 and the fact that the preclearance provision was still active, this 
finding makes sense. Although there were poll closures between 2008 and 2012, the closures took place primarily in jurisdictions that were never subject to preclearance and unlike the factors associated with closures in jurisdictions (formerly) subject to preclearance, such as racial composition, the factors associated with closures in non-preclearance areas were less strongly associated with lower levels of voter turnout.

When looking at Model 3 - which shows the bivariate relationship between PCVPP and turnout between 2012-16, I find a similar relationship to the one found using Model 1, but this time PCVPP has a significant effect on change in turnout. Jurisdictions with higher values of PCVPP were predicted to see roughly a -0.003 percentage point change in turnout between 201216 when compared to those with lower values of PCVPP. This finding is significant at the $99 \%$ confidence level.

When accounting for a variety of additional factors (in Models 2 and 4), I find the same results as I did with the bivariate models. Jurisdictions with higher values of PCVPP were expected to see decreases in turnout between both sets of elections, but the effect was only significant in the 2012-16 analysis. These findings are congruent with existing literature in that PCVPP had a negative effect on change in turnout in both election analyses.

Models 2 and 4 account for the effects of Shelby using two different interaction terms preclearance $x$ jurisdiction percent Black and preclearance $x$ jurisdiction percent Hispanic.

Between 2008-12, turnout levels in preclearance jurisdictions were predicted to significantly increase when the jurisdictions' Black populations were relatively high. I also find a similar relationship when looking at the interaction between preclearance and \% Hispanic. These findings are not surprising given that the preclearance provision was still active. In other words, 
these two findings suggest that the preclearance provision was working properly - encouraging political participation by non-whites.

However, in the 2012-16 analysis, I find that the effect of a jurisdiction being formerly under preclearance was negative and significant when that jurisdiction's Black population was large. I did not find this same effect for formerly preclearance jurisdictions with large Hispanic populations. In fact, I found that the opposite effect held, although the estimated effect was not statistically significant. The estimated effect of the jurisdiction percent Black and preclearance interaction is noteworthy for two reasons. First, Barack Obama being on the ballot in 2012 could have been the reason for the significant increase in turnout between 2008-12. However, given the context of the 2016 election and the candidates who ran (Donald Trump and Hilary Clinton), overall Black voter turnout significantly decreased between $2012-16 .{ }^{33}$ This could be one potential reason for the decrease in turnout in formerly preclearance areas with large Black populations, although it would not explain why turnout in formerly preclearance jurisdictions with large Black populations decreased more than turnout in non-preclearance jurisdictions with large Black populations. Another reason for the decrease in turnout, however, could be attributed to poll closures and the effects of the Shelby decision.

To further evaluate this possible explanation, table 4-2 shows predicted values of turnout for various hypothetical jurisdictions while setting values of PCVPP to their predicted values found in chapter 3 (also shown in figure 4-2 in this chapter). Non-preclearance jurisdictions' values of PCVPP were set to $16 \%$ between 2008-12 and 7\% between 2012-16. PCVPP was set to $14 \%$ for preclearance jurisdictions with small non-white populations for the 2008-12 analysis and to $15 \%$ for the $2012-16$ analysis. PCVPP was set to $17 \%$ for preclearance jurisdictions with

33 https://www.pewresearch.org/fact-tank/2017/05/12/black-voter-turnout-fell-in-2016-even-as-a-record-number-of-americans-cast-ballots/ 
large Black populations for 2008-12 and to $26 \%$ for 2012-16. Finally, preclearance jurisdictions with large Hispanic populations were assigned PCVPP values of $18 \%$ and $24 \%$. I set all other variables (outside of non-white population size ${ }^{34}$ ) to their respective means.

When looking at preclearance jurisdictions with large Black populations, I find that the predicted value of change in turnout decreased significantly following the Shelby case. Between 2008 and 2012, the predicted change in turnout was an increase of roughly only a hundredth of a

\begin{tabular}{|l|c|c|c||c|}
\hline \multicolumn{5}{|c|}{ Table 4-2. Predicted Values of Change in Turnout for Hypothetical Jurisdictions Using Predicted } \\
& $\begin{array}{l}\text { Values of PCVPP from Chapter 3. } \\
\text { Preclearance } \\
\text { Large Black Pop. } \\
(>30 \%)\end{array}$ & $\begin{array}{l}\text { Preclearance } \\
\text { Large Hispanic } \\
\text { Pop. }(>15 \%)\end{array}$ & $\begin{array}{l}\text { Preclearance } \\
\text { Neither Large } \\
\text { Black nor Hisp. }\end{array}$ & $\begin{array}{l}\text { Non- } \\
\text { Preclearance }\end{array}$ \\
\hline $2008-12$ & $+0.01 \%$ & $-1.74 \%$ & $-1.89 \%$ & $-2.74 \%$ \\
\hline $2012-16$ & $\mathbf{- 2 . 6 3 \%}$ & $+2.25 \%$ & $+1.43 \%$ & $+0.66 \%$ \\
\hline N & 212 & 183 & 216 & 1,655 \\
\hline
\end{tabular}

percentage point, whereas between 2012-16, the predicted change was a decrease of almost three percentage points. These findings suggest that PCVPP played a major role in turnout in formerly preclearance jurisdictions with large Black populations. Interestingly, in comparing the other scenarios in both analyses, formerly preclearance jurisdictions with large Black populations were the only type to see a predicted decrease in turnout between 2012-16. Specifically, formerly preclearance jurisdictions with large Hispanic populations were predicted to see a two percentage point increase in turnout between 2012-16. Like the literature surrounding majority-minority districts on non-white turnout (Gay 2007; Griffin and Flavin 2007; Barreto, Segura, and Woods 2004), the effects of PCVPP also varied among the two racial groups with Black turnout significantly decreasing, while Hispanic turnout significantly increasing.

\footnotetext{
${ }^{34}$ In terms of non-white population size, the values were the average sizes in each of the four categories used in chapter 3 . For example, I set the preclearance jurisdictions with large Black populations to $50 \%$, preclearance jurisdictions with large Hispanic populations to $40 \%$, preclearance jurisdictions with neither large Black nor Hispanic to $15 \%$ and $10 \%$. Finally, I set non-preclearance jurisdictions to $5 \%$ for both Hispanic and Black populations.
} 
To conclude the results section, I will discuss the important effects of the control variables in Models 2 and 4 from table 2. The implementation of in-person early voting, voting centers, and strict voter identification laws for the 2012 election were associated with more negative changes in county-level turnout compared to 2008 . The in-person early voting and strict ID laws findings are both congruent with previous literature (Burden et al. 2014; Hajnal et al. 2017). The finding regarding voting center laws, however, was not. Stein and Vonhamme found in their 2008 analysis that voting centers improved voter turnout. Their results were found at the individual level only. One reason for my contradictory findings could be that voting centers are still relatively new, and people who are traditional precinct voters may still not understand how voting at voting centers works. ${ }^{35}$

In the 2012-2016 analyses, I find results similar to those for the 2008-2012 model. For example, states that implemented in-person early voting between 2012-16 saw more negative changes in county-level turnout than states that did not. States that enforced strict identification laws also saw predicted negative changes in county-level turnout of about 1.4 percentage points between 2012 and 2016.

Two results related to my jurisdictional controls are worth a brief discussion. First, in both analyses, younger and less educated jurisdictions were predicted to see larger decreases in county-level turnout. These findings are not surprising given the large amounts of literature on voter turnout indicating that older and more educated people are more likely to vote (Verba et al. 1995). Second, it appears that poorer jurisdictions saw a decrease in turnout between 2008-2012, but not 2012-2016. I also find that less densely populated areas were predicted to see larger decreases in turnout between 2012-2016, but not 2008-2012. I believe these findings suggest

\footnotetext{
${ }^{35}$ Based on my data in 2012 , only $12 \%$ of the states allowed voting centers, whereas in 2016 that number only jumped to $17 \%$.
} 
further research is needed, especially concerning election outcomes and the legacy of preclearance.

Although the findings in this chapter imply that PCVPP caused a significant drop in county-level turnout, I think it is important to understand that the effects of PCVPP may not be the same across all states. For example, some states have more people, and thus have more polling places that are close to other polling places. When polling places close in a state such as New York, the average distance between the new and old locations may be very small. However, if you look at a state that is less densely populated, a polling place relocation may mean voters have to travel many miles further to vote. As an illustration of this point, the Brennan Center for Justice found that $32 \%$ of the Native American voters in South Dakota did not vote because of the long distances to the newly located polling places in the 2018 midterm elections. For some indigenous voters, the total distance to the polls was over 150 miles. ${ }^{36}$ When interpreting the results of this chapter, it is imperative to understand that the effects of PCVPP on turnout may not be identical across all contexts.

\section{Discussion}

As described in the previous section, I find that polling place closures do have a negative impact on voter turnout at the county-level. I also find that The Great Poll Closure - the significant amount of polling place closures following Shelby - had a significant effect on the change in turnout between 2012-16. This significant negative effect was not found between 2008-12 before the Shelby case took place. To further highlight the effects of post-Shelby on polling place closures on voter turnout, I find that due to the high values of PCVPP in formerly preclearance areas in 2016, especially those with large Black populations (>30\% Black), counties

\footnotetext{
${ }^{36}$ To see full article, please visit: https://www.brennancenter.org/our-work/analysis-opinion/state-native-american-voting-rights
} 
formerly subject to preclearance saw a significant decrease in turnout between 2012-2016. This relationship was not found when looking at these same jurisdictions prior to Shelby.

In conclusion, while Justice Roberts wrote in the Shelby decision that the coverage formula (and, by extension, preclearance) was based on "40-year-old facts having no logical relationship to the present day," many observers were concerned that in jurisdictions formerly subject to preclearance, reprecincting and other changes to electoral rules would lead to reduced electoral participation in those jurisdictions. The analyses in this chapter suggest that such concerns were well founded. In using a unique nation-wide study of the effects of the precinct closure phenomena on voter turnout, I find that polling place closures do have detrimental effects on voter turnout at the county level. This chapter's findings suggest that at the time that the preclearance provision of the VRA was effectively invalidated, it was still needed to prevent certain jurisdictions from creating election procedures that might hinder voter turnout.

Moving forward, a great deal of research could be conducted on the relationship between poll closures and the lack of federal oversight of election procedures. For example, it would be interesting to estimate the effects of $P C V P P$ on turnout in the 2020 presidential election (or any election following 2016). If the goal of the Voting Rights Act is to protect the voting rights of all citizens and patterns like those described in this chapter continue, required federal preclearance of changes in electoral procedures in areas with histories of discriminatory election administration may be key to the VRA achieving its goals. Preclearance, however, cannot return unless either Congress updates the coverage formula in a manner that meets constitutional muster, or the Supreme Court drastically alters it's thinking as put forth by Justice Roberts in Shelby Court v. Holder. Outside of the election administration and voter turnout literatures, my findings in this chapter also contribute to the growing literature on the lasting effects of Shelby 
(Hajnal et al. 2017; Schuit \& Rogowski 2017; Ang 2019). That literature suggests that congressional revision of the VRA or the passage of new voting rights legislation may be necessary if the levels of electoral participation made possible by the Voting Rights Act are to be maintained $-:$ 


\section{CHAPTER 5: Conclusion}

The research described in this dissertation suggests that The Great Poll Closure had a negative impact on non-white citizens - especially Black citizens - living in areas that were formerly under preclearance. As shown in chapter 3, jurisdictions formerly subject to preclearance that had large Black populations saw the largest number of closures following Shelby. In chapter 4, I also found that these former preclearance jurisdictions with large Black populations experiences a significant decrease in turnout following the Shelby ruling. The findings in this dissertation strongly suggest the re-instatement of the coverage formula and preclearance provision of the Voting Rights Act would increase turnout, particularly among former preclearance jurisdictions with large Black populations.

This research contributes to the discipline of political science in at least three unique ways. First, in conducting my research I drew from, synthesized, and added to the literature in three major areas of scholarship in political science: constitutional law, political institutions, and political behavior. Second, although research on poll closures has been conducted in the past, I believe the research described in this dissertation provides one of the first nation-wide studies of the effects of poll closures - specifically closures leading up to the first presidential election without the full protection of the VRA. Lastly, I believe my measure of polling place closures, PCVPP, is an important innovation and may be useful for future research. This concluding chapter summarizes each substantive chapter's findings and then provides a short case study to contextualize those findings. In concluding, I discuss the real-world implications of this dissertation and some potential directions for future work. 


\section{Chapter 2}

Chapter 2 has three main takeaway points. First, it provides a "legal primer" on nonwhite voting rights in the U.S., beginning with the period of Reconstruction, and concluding with the Shelby $v$. Holder case. I believe it was necessary to describe the progression of voting rights for minorities before discussing the process of reprecincting and other election administration processes. Second, it describes how election administration works and how local, state, and federal governments are connected in the process. Lastly, it describes four criteria by which states' reprecincting laws can be compared: authorization, time limits, precinct size, and state regulation. The goal of this chapter was to not only provide the reader with some background on reprecincting but also to help make sense of the findings for my final two quantitative chapters regarding precinct changes since Shelby.

\section{Chapter 3}

In recent years, journalistic reports have documented an unusually high number of poll closures. Many of the authors of these reports argue that the large number of closures is due to the Shelby v. Holder ruling that eliminated the preclearance provision of the Voting Rights Act (LCEF 2016). While important, these reports are largely descriptive in nature and in some cases anecdotal. They lack rigorous statistical analyses that test whether the claims made are correct. In this chapter, I filled this "statistical void" by using multiple regression models to understand the causes of The Great Poll Closure.

After accounting for several constitutionally valid factors that may result in the closure of polling places, I found that formerly preclearance jurisdictions saw a significant number of polling place closures following Shelby when compared to non-preclearance jurisdictions. In the original regression analysis (table 3-5), I did not find any significant evidence that the 
interaction between percent non-white and preclearance (the Shelby effect) played a factor into polling place closures. However, when I employed a categorical variable that identified jurisdictions with particularly large proportions of Black and Hispanic residents, the results matched my expectations. For example, in the 2012-16 analysis, preclearance jurisdictions with large Black populations were expected to have a value of PCVPP roughly 18 percentage points greater than non-preclearance jurisdictions. Preclearance jurisdictions with large Hispanic populations were also expected to have similarly large values of PCVPP. Both relationships were statistically significant. Looking at these same jurisdictions in the 2008-12 analysis, there were no statistically significant relationships between the racial composition of districts, preclearance, and PCVPP. Based on these findings in the 2012-16 analysis, I conclude that formerly preclearance jurisdictions with large Black and Large Hispanic populations were closing polling places at much higher rates following Shelby when compared to formerly non-preclearance jurisdictions.

I also found it necessary to examine the effects of additional socioeconomic factors on PCVPP, especially given the association between lower SES and jurisdictions with large nonwhite populations. I found that the number of closures may have also been due to additional socioeconomic characteristics that are common in jurisdictions with large non-white populations, such as age, income, and education. I found that preclearance jurisdictions with large non-white populations that are home to fewer college graduates and fewer people over the age of 65 saw significant increases in the value of PCVPP following Shelby. I also found that non-preclearance jurisdictions with similar socioeconomic characteristics saw decreases in the value of PCVPP following Shelby. These findings suggest that polling place closures in former preclearance jurisdictions with large non-white populations may have also occurred due 
to socioeconomic factors that are often associated with low voter turnout.

In conclusion, many political scientists, legal scholars, historians, activists, and citizens familiar with the history of voting rights in the United States were concerned that the Shelby decision would result in changes in election administration that would make voting more burdensome, especially among Black and Hispanic Americans. The analyses in this chapter suggest that such concerns were well founded. I believe these findings will contribute to the already growing literature on the implication of the Shelby case. In other words, my findings illustrate that the "40-year old facts" that Justice Roberts argued were out of date in the justification of its invalidation of preclearance may not be as outdated as originally thought.

\section{Chapter 4}

Chapter 4 took a more behavioral approach in studying the effects of The Great Poll Closure. In this chapter, I implemented difference-in-difference analyses to explore the effects of changes in polling places on changes in county voter turnout between 2008-12 (pre-Shelby) and 2012-16 (post-Shelby). My findings suggest that polling place closures have a negative impact on voter turnout at the county-level. I also found that the Great Poll Closure had a significant effect on changes in county-level turnout between 2012-16. This significant negative effect was not found between 2008-12, before the Shelby case took place. To highlight the effect of post-Shelby on polling place closures on voter turnout, I showed that due to the high values of PCVPP in formerly preclearance areas in 2016, those jurisdictions, especially those with large Black populations, saw a significant decrease in turnout between 2012-16. This relationship was not found when looking at these same jurisdictions prior to Shelby.

In short, while Justice Roberts wrote in the Shelby decision that the coverage formula (and, by extension, preclearance) was based on "40-year-old facts having no logical relationship 
to the present day," many observers were concerned that in jurisdictions formerly subject to preclearance, reprecincting and other changes to electoral rules would lead to reduced electoral participation in those jurisdictions. By using a unique nation-wide study of the precinct closure phenomena on voter turnout, I found that those concerns were warranted in that polling place closures do have detrimental effects on voter turnout at the county-level. This chapter's findings suggest that the preclearance provision of the VRA was still needed to prevent certain jurisdictions from creating election procedures that might hinder voter turnout.

In conclusion, while the statistical results in this dissertation do not definitively establish that election officials closed precincts with the intent of lowering voter turnout among members of non-white populations, they are consistent with what we would expect to see if an election official did intend to do so.

\section{Contextualizing My Substantive Findings}

Following the Supreme Court's decision in Shelby v. Holder, jurisdictions that had been subject to the constant scrutiny of the federal government when proposing changes to election procedures could now make changes with ease. In invalidating the coverage formula, however, the Court noted that that the VRA provides for other ways to challenge changes to election laws that seem to have discriminatory intent or effects. Section 2 of the VRA, for example, prohibits the use of any voting practices or procedures that may be discriminatory

While challenges to election procedures under Section 2 can be filed, as chapter 2 pointed out, lawsuits filed by the federal government against states or jurisdictions may take years to work their way through the court system. Kousser (2015) also found that when looking at election law objections under the VRA from its conception until after Shelby (1957 to 2014), 
over $93 \%$ of those objections took place in covered jurisdictions through sections $4 \mathrm{~b}$ and 5 of the VRA. Another important aspect of Kousser's findings was that he considered the effects of demographic differences between non-preclearance and preclearance jurisdictions on the number of objections. In comparing covered and non-covered jurisdictions in which white citizens make up less than $80 \%$ of the population, covered jurisdictions were five times more likely to face an objection to an election law. His findings suggest that although the VRA provides for other ways to prevent voter discrimination, the coverage formula and preclearance are the act's most effective and important provisions.

Another reason the Court invalidated the coverage formula was that the justices signing the majority opinion felt that the formula was outdated and that jurisdictions no longer created laws to deliberately discriminate against people of color. However, within hours of the Shelby ruling, Texas and North Carolina, two states in formerly preclearance areas, passed strict voter ID laws. ${ }^{37}$ Furthermore, the evidence presented in this dissertation suggests formerly preclearance states and counties were closing precincts at much higher rates than they were in previous years before Shelby. Along with research by other scholars, findings described in this dissertation suggest that the majority's belief that state and local officials no longer attempt to discriminate against non-white voters may not be well-founded.

To further illustrate this, I describe a case in which a (formerly) preclearance state proposed an election law change that was objected to by the DOJ when preclearance was in effect, but then implemented that change following Shelby. In this case, the change was proposed by the state of Louisiana rather than by a specific jurisdiction. For background purposes,

\footnotetext{
${ }^{37}$ This link provides more information on this: https://www.brennancenter.org/our-work/policy-solutions/effects-shelby-county-v-holder.
} 
Louisiana was one of the states originally subject to preclearance when the VRA was passed in 1965. As I explained in chapter 2, being a preclearance state meant that a state had a history of voter discrimination and had historically low voter turnout among minorities. Louisiana has the fifth highest percentage of Black residents in the United States, at roughly 30\%. Because of its large Black population and its history of significant voter discrimination, Louisiana was the "poster-state" for preclearance. According to Bullock, Gaddie, and Wert (2016), between 1995 and 2005, the Bayou State received the largest number of election proposal objections from the Department of Justice, with 19 objections being made. As mentioned above, instead of objecting to states' or jurisdictions' election proposals, the DOJ can also ask for more information by issuing more information requests (or MIR). According to Fraga and Ocampo (2016), between 1990 and 2006, Louisiana also received 983 MIRs. The most frequent type of election proposal that was responded with an MIR involved precinct boundary formation. Based on this information about Louisiana and its history with preclearance, the state was no stranger to receiving objections and MIRs from the DOJ.

In 2008, the state of Louisiana attempted to edit their precinct boundary formation law across the whole state. They wanted to extend the precinct boundary "freeze" from one year to four years. In other words, they wanted to keep the precinct boundaries the same for multiple years at a time. In 2008, the Louisiana state law stated that no precinct should be changed between January 2009 and December 2010. In their 2008 election change proposal, Louisiana wanted to extend the freeze on voting precinct boundaries from January of 2009 to December of 2013.

The DOJ objected to this election proposal in part because they determined that the new law would be a large departure from the original law. Another was that the DOJ felt that the 
freeze would not allow for local election officials to make adjustments to precinct boundaries (and polling place locations) that might strengthen non-white voter turnout. In short, the state of Louisiana's precinct boundary law was rejected by the DOJ because they were afraid that the freeze would not allow for LEOs to readjust boundaries if non-white voting was diluted in the previous precinct formation. ${ }^{38}$

The boundaries of precincts in counties (referred to as parishes in Louisiana) are often affected by the redistricting that takes place after each census. As such, the extended precinct boundary freeze that Louisiana wished to propose only really matters when the end of a decade is near. For example, the 2008 proposal was made because the 2010 census was approaching. In 2008, the preclearance provision of the VRA resulted in the proposed law not going into effect. As 2020 approached, however, due to the Shelby decision, preclearance was no longer required. In 2018, Louisiana passed a nearly identical law and it went into effect. The revision to the state of Louisiana's election code reads that "no election precinct shall be created, divided, abolished, or merged or the boundaries thereof otherwise changed between December thirty-first of any year of which the last digit is nine and January first of any year of which the last digit is three." 39 In the state of Louisiana, which has a clear history of voter discrimination, the precinct freeze is now four years instead of two. The election law that the DOJ had objected to in 2008 because of its potentially discriminatory effects is now written into law.

\begin{tabular}{|c|c|c|}
\hline \multicolumn{2}{|c|}{ Table 5-1. Large Black Jurisdictions (>30\%) in Louisiana } \\
\hline Years & PCVPP & Change in Turnout \\
\hline Pre-Shelby (2008-12) & $2 \%$ & $0 \%$ \\
\hline Post-Shelby (2012-16) & $5 \%$ & $-1 \%$ \\
\hline
\end{tabular}

\footnotetext{
38 The full objection letter can be found at https://www.justice.gov/sites/default/files/crt/legacy/2014/05/30/1 090810.pdf.

${ }^{39}$ Louisiana. Stat. § 532.1(4D.1a) 2018.
} 
To utilize the findings of this dissertation and to show how this law regarding precinct changes can be a major problem, I tabulated the values of PCVPP and change in turnout in Louisiana jurisdictions with large Black populations from 2008-12 and 2012-16 in table 5-1. The mean value of PCVPP was roughly three percentage points higher in these jurisdictions in 201216 than in 2008-12. The change in turnout was also different; change over the 2012-16 period was roughly $-1 \%$, whereas there was essential no change over the $2008-12$ period. This suggests that following Shelby, jurisdictions in Louisiana with large Black populations saw a significant increase in polling place closures followed by a significant decrease in turnout. This was not the case pre-Shelby.

\section{Implications}

This research described in this dissertation has two important real-world implications. First, I believe my findings can encourage local government officials to become more aware of the implications of closing polling places. Obviously, local election officials with small election budgets will be more likely to close the polls because they have no choice but to do so, but I believe with the information provided in this dissertation, LEOs may be more attentive to the fact that any change in location of the polls can deter someone from voting, and that people of color may be particularly likely to be deterred. I believe my description of the reprecincting process in chapter 2 could be useful for state and local government that wish to enact laws that may prevent intentional, politically motivated closures.

Another useful aspect of this research is that it demonstrates that the coverage formula of the Voting Rights Act was important in providing citizens with ample opportunities to vote. I am not the only scholar who has expressed concern over the lasting impacts of Shelby. Schuit and Rogowski (2017) found that members of Congress who were representatives of a preclearance 
district were more likely to favor civil rights legislation compared to representatives of nonpreclearance districts. Other political scientists, such as Hajnal et al. (2017), found that certain states or specific counties are still in need of federal preclearance when making voting and election laws because state officials continue to find ways to alienate or discourage members of certain groups from voting. For example, Hajnal et al. found that states, who generally vote more Republican (based on past presidential votes) deliberately use stricter voter ID laws to narrow the voting population and leave it with a larger percentage of affluent, white voters.

Some lawmakers have recently shown interest in revisiting the coverage formula. In 2019, members of the House of Representatives drafted a bill, the John Lewis Voting Rights Act, which would replace the VRA's coverage invalidated formula with a (potentially) constitutionally valid one and essentially reinstate the preclearance provision. The bill died in the Republican led Senate. In the current Congress, the House has yet to bring the bill the floor for a re-vote. According to Representative Terri Sewell of Alabama, the House plans to bring the bill to a vote in September 2021. However, Sewell expects the bill to receive the same lack of support from Senate Republicans as it did in 2019. I believe my research and other research on similar topics surrounding the impacts of Shelby can shed light on the negative effects of the Shelby decision on voter turnout and how the revision of the coverage formula and resumption of the preclearance process would likely lead to greater political participation, particularly among members of non-white populations.

\section{Future work}

This dissertation also suggests two important avenues for future research. First, I believe a deeper dive into the politics of local government may provide more evidence that preclearance jurisdictions were closing precincts at a much higher rate following Shelby for politically 
motivated reasons. For example, a small-N case study comparing preclearance and nonpreclearance jurisdictions using the same variables that I used for my large-N observational analysis may be a useful direction to pursue. Following this route, researchers could study the budgetary aspects of reprecincting in more detail as well as the effects of the partisanship of the local election officials on polling place closures. I believe this type of research would pair nicely with the research that I present in this dissertation.

Second, the 2020 general election took place during the COVID-19 pandemic, which seriously hindered the availability of in-person traditional polling places. Most jurisdictions made alternative voting much easier than in had been in years past. I believe this would be an excellent opportunity to study the interjurisdictional differences in numbers of polling places. For example, did the closure phenomena continue? Or was everyone closing precincts due to the pandemic? I believe this would be an interesting avenue to pursue once precinct data for the 2020 election become readily available. 


\section{REFERENCES}

Alesina, A., \& Tabellini, G. 2007. "Bureaucrats or Politicians? Part I: A Single Policy Task". American Economic Review, 97, 169-179.

Allen v. State Board of Elections. 1969. 268 F. Supp 218.

Amos, Brian, Daniel A Smith and Casey Ste Claire. 2017. "Reprecincting and Voting Behavior." Political Behavior 39(1):133-156.

Ang, Desmond. 2019. "Do 40-Year-Old Facts Still Matter? Long-Run Effects of Federal Oversight under the Voting Rights Act." American Economic Journal: Applied Economics 11(3): 1-53.

Arthur, Robert and Allison McCann. 2018. "How the Gutting of the Voting Rights Act Led to Hundreds of Closed Polls". Vice News. https://news.vice.com/en_us/article/kz58qx/howthe-gutting-of-the-voting-rights-act-led-to-closed-polls.

Atkeson, Lonna, and Kyle Saunders. "The Effect of Election Administration on Voter Confidence: A Local Matter?” Political Science and Politics, 40, no. 4 (2007): 655-660.

Baker v. Carr. 1962. 369 U.S. 186.

Barreto, Matt A., Mara Cohen-Marks, and Nathan D. Woods. 2009. "Are All Precincts Created Equal? The Prevalence of Low-Quality Precincts in Low-Income and Minority Communities." Political Research Quarterly 62(3): 445-458.

Barreto, Matt A., Gary M. Segura, and Nathan D. Woods. 2004. "The Mobilizing Effect of Majority-Minority Districts on Latino Turnout." American Political Science Review 98(1): 65-75.

Beer v. United States. 1976. 425 U.S. 130.

Besley, T., \& Coate, S. 2003. Elected Versus Appointed Regulators: Theory and Evidence.

Bobo, L., \& Gilliam, F. D. 1990. "Race, Sociopolitical Participation, and Black Empowerment". The American Political Science Review, 84, 377-393.

Brady, Henry E and John E McNulty. 2011. "Turning Out to Vote: The Costs of Finding and Getting to the Polling Place." American Political Science Review 105(1):115-134.

Brennan Center. 2018. "Texas NAACP v. Steen (Consolidated with Veasey v. Abbott)". https://www.brennancenter.org/our-work/court-cases/texas-naacp-v-steen-consolidatedveasey-v-abbott

Bullock, Charles, Ronald Gaddie, and Justin Vert. 2016. The Rise and Fall of the Voting Rights Act. Norman: University of Oklahoma Press. 
Burden, Barry C., David T. Canon, Kenneth R. Mayer, and Donald P. Moynihan. 2017. “The Complicated Partisan Effects of State Election Laws". Political Research Quarterly, 70(3): 564-576.

Burden, Barry and Jeffrey Milyo. 2015. “The Quantities and Qualities of Poll Workers”. Election Law Journal, 14(1): 38-46.

Burden, Barry C., David T. Canon, Kenneth R. Mayer, and Donald P. Moynihan. 2014.

"Election Laws, Mobilization, and Turnout: The Unanticipated Consequences of Election Reform." American Journal of Political Science, 58:95-109.

Burden, Barry, David Canon, Stephane Lavertu, Kenneth Mayer, and Donald Moynihan. 2013. "Selection Method, Partisanship, and the Administration of Elections. American Politics Research, 41(6): 903-936.

Byrd, Jeff. 2015. "Reaction to Precinct Changes". Meridian Star. https://www.meridianstar.com/news/reaction-mixed-to-precinctchanges/article 8233c35c-f6ca-11e4-aff9-83517e2166dc.html. (May 10 ${ }^{\text {th }}, 2015$ ).

Cantoni, Enrico. 2015. “A Precinct Too Far: Turnout and Voting Costs.”. URL: http://economics.mit.edu/files/11997

Claassen, Ryan, David. B. Magleby, J. Quin Monson, and Kelly D. Patterson. 2008. "At Your Service: Voter Evaluations of Poll Worker Performance". American Politics Research 36:612-34.

Claassen, Ryan, David. B. Magleby, J. Quin Monson, and Kelly D. Patterson. 2012. "Voter Confidence and the Election-Day Voting Experience". Political Behavior, 35: 215-235.

Clinton, Joshua D, Nick Eubank, Adriane Fresh and Michael E. Shepherd. 2020. "The Politics of Precincts and Polling Places: Race and Partisanship in U.S. Election Administration, 2008-2016."

Cooperative Congressional Elections Survey (https://cces.gov.harvard.edu/pages/welcomecooperative-congressional-election-study). 2012 \& 2016.

Department of Justice: Civil Rights Division. 2015. "Jurisdictions Previously Covered by Section 5". https://www.justice.gov/crt/jurisdictions-previously-covered-section-5

Department of Justice: Civil Rights Division. 2015. "Section 4 of the Voting Rights Act". https://www.justice.gov/crt/section-4-voting-rights-act

Department of Justice: Civil Rights Division. 2015. "Section 5 Changes by Type and Year". https://www.justice.gov/crt/section-5-changes-type-and-year-2

Department of Justice: Civil Rights Division. 2015. "Section 5 of the Voting Rights Act". https://www.justice.gov/crt/about-section-5-voting-rights-act

Department of Justice: Civil Rights Division. 2015. "Voting Determination Letters for LA". https://www.justice.gov/sites/default/files/crt/legacy/2014/05/30/1_090810.pdf. 
Dunphy, Peter. 2019. "The State of Native American Voting Rights". The Brennan Center for Justice. https://www.brennancenter.org/our-work/analysis-opinion/state-native-americanvoting-rights.

Dyck, Joshua J and James G Gimpel. 2005. "Distance, Turnout, and the Convenience of Voting." Social Science Quarterly 86(3):531-548.

Fortier, John C., Stewart, Charles, Pettigrew, Stephen, Matthew, Weil, Harper, Tim. 2018. Improving the Voting Experience. Washington, DC: Bipartisan Policy Center.

Fraga and Maria Lizet Ocampo, "More Information Requests and the Deterrent Effect of Section 5 of the Voting Rights Act," in Voting Rights Act Reauthorization of 2006: Perspectives on Democracy, Participation, and Power (Berkeley, CA: Berkeley Public Policy Press, 2007), 47-82.

Gay, Claudine. 2007. "Legislating Without Constraints: The Impact of Constituency Preferences on Policy Representation in Majority-Minority Districts." Journal of Politics. 69(2):442-456.

Gay, Claudine. 2001. "The Effect of Black Congressional Representation on Political Participation." American Political Science Review 95(3):589-602.

Gibson, John, Bonggeun Kim, Steven Stillman and Geua Boe-Gibson. 2013. "Time To Vote?" Public Choice. 156:517-536.

Gimpel, James G and Jason E Schuknecht. 2003. "Political Participation and the Accessibility of the Ballot Box." Political Geography 22(5):471-488.

Griffin, John D. and Patrick Flavin. 2007. "Racial Differences in Information, Expectations, and Accountability." Journal of Politics 69(1):220-236.

Grimmer, Justin, Eitan Hersh, Marc Meredith, Jonathan Mummolo, and Clayton Nall. 2018. “Obstacles to Estimating Voter ID Laws' Effect on Turnout". Journal of Politics, 80(3): 1045-1051.

Hajnal, Zoltan, Nazita Lajevardi, and Lindsay Nielson. 2017. "Voter Identification Laws and the Suppression of Minority Votes". The Journal of Politics, 79(2): 363-742.

Hale, Kathleen, Robert Montjoy, and Mitchell Brown. 2015. Administrating Elections, How American Elections Work. New York, NY: Palgrave MacMillan.

Hall, T., Quin Monson, J., \& Patterson, K. D. (2009). The Human Dimension of Elections: How Poll Workers Shape Public Confidence in Elections. Political Research Quarterly, 62, 507-522.

Haspel, Moshe and H Gibbs Knotts. 2005. "Location, Location, Location: Precinct Placementand the Costs of Voting." The Journal of Politics 67(2):560-573.

Herbert, Gerald. 2007. "An Assessment of the Bailout Provisions of the Voting Rights Act". California-Berkeley Law Review. 
Herron, Michael and Dan Smith. 2016. "Precinct Resources and Voter Wait Times". Electoral Studies, 42(1), 249-263.

Holt, Thomas. 1979. Black over White: Negro Leadership in South Carolina during Reconstruction. Urbana: University of Illinois Press.

Hubler, Katy O. and Wendy Underhill. 2018. "Election Costs: Who Pays and With Which Funds". NCSL (National Conference of State Legislatures). https://www.ncsl.org/research/elections-and-campaigns/election-costs-who-pays-andwith-which-funds.aspx.

Ingraham, Christopher. 2018. "Thousands of Polling Places Were Closed Over the Past Decade. Here's Where". Washington Post. https://www.washingtonpost.com/business/2018/10/26/thousands-polling-places-wereclosed-over-past-decade-heres-where/

Johnson, Lyndon B. 1963. "Address Before a Joint Session of Congress". The American Presidency Project. https://www.presidency.ucsb.edu/documents/address-before-jointsession-the-congress-0

Katosh, J. P., \& Traugott, M. W. 1982. "Costs and Values in the Calculus of Voting." American Journal of Political Science, 26, 361-376.

Kennedy, John F. 1963. "Radio and Television Address on Civil Rights". The John F. Kennedy Presidential Library. https://www.jfklibrary.org/assetviewer/archives/JFKPOF/045/JFKPOF-045-005

Kousser, Morgan. 2015. "Do The Facts of Voting Rights Support Chief Justice Roberts's Opinion in Shelby County?", Transatlantica, 1.

Kimball, David and Brady Baybeck. 2013. "Are All Jurisdictions Creating Equal? Size Disparity in Election Administration". Electoral Studies, 12(2): 130-145.

Kimball, David and Martha Kropf. 2006. "The Street- Level Bureaucrats of Elections: Selection Methods for Local Election Officials. Review of Policy Research, 23(6): 559-575.

Leighley, Jan E and Jonathan Nagler. 2014. Who Votes Now?: Demographics, Issues, Inequality, and Turnout in the United States. Princeton, NJ: Princeton University Press

"Local Government Financial Documents Online". Georgia Local Government Financial Documents. Accessed June 10, 2021. https://ted.cviog.uga.edu/financialdocuments/welcome.

Louisiana. Stat. § 532.1(4D.1a) 2018.

Lublin, David. 1999. The Paradox of Representation: Racial Gerrymandering and Minority Interests in Congress. Princeton, NJ: Princeton University Press. 
Manza, Jeff, and Chris Uggan. 2004. "Punishment and Democracy: Disenfranchisement of Nonincarcerated Felons in the United States". Perspective on Politics, 9(2:3), 491-505.

McDonald, M. (2012). Early voting statistics (United States Elections Project). Retrieved from http://elections.gmu.edu/early_vote_2012.html

McNulty, John, Conor Dowling, and Margaret Ariotti. 2009. "Driving Saints to Sin: How Increasing the Difficulty of Voting Dissuades Even the Most Motivated Voters". Political Analysis, 17 (4): 435-455.

NCSL (National Conference of State Legislatures). 2019. "Absentee and Early Voting". http://www.ncsl.org/research/elections-and-campaigns/absentee-and-early-voting.aspx

NCSL (National Conference of State Legislatures). 2019. "Voting Centers". https://www.ncsl.org/research/elections-and-campaigns/vote-centers.aspx

Niesse, Mark. 2019. "Precincts Have Closed Across Georgia and Nation Since Court Ruling". Atlantic Journal Constitution. https://www.ajc.com/news/state--regional-govt-politics/precincts-have-closed-across-georgia-and-nation-since-courtruling/ecgFnCOcs46mJkpXehwm2L/. (September 10 $0^{\text {th }}, 2019$ ).

Northwest Austin Municipal Utility District No. 1 v. Holder. 2009. 557 U.S. 193.

O’Dell, Rob and Caitlin McGlade. 2016. "Rich, Poor Both Underserved by Slim Polling Options". The Republic. https://www.azcentral.com/story/news/politics/elections/2016/03/27/slim-pollingoptions-maricopa-county/82278474/. (March 26 $\left.{ }^{\text {th }}, 2016\right)$.

Persily, Nathaniel. 2007. "The Promise and Pitfalls of the New Voting Rights Act". Yale Law Review. 117:174.

Pildes, Rick and Dan Tokaji. 2013. "What Did VRA Preclearance Actually Do? The Gap between Perception and Reality". Election Law Blog.

Primo, David, Matthew L. Jacobsmeier, and Jeffrey Milyo. 2007. "Estimating the Impact ofState Policies and Institutions with Mixed-Level Data". State Politics \& Policy Quarterly, 7(4): 446-459.

Reno v. Bossier Parrish School Board. 2000. 528 U.S. 320.

Schuit, Sophie and Jon C. Rogowski. 2017. "Race, Representation, and the Voting Rights Act." American Journal of Political Science. 61: 513-526.

Shelby County v. Holder. 2013. 570 U.S. 529.

Smith v. Allwright. 1944. 321 U.S. 649, 664.

Spencer, Douglas M., and Zachary S. Markovits. "Long Lines at Polling Stations? Observations from an Election Day Field Study." Election Law Journal, 9, no. 1 (2010): 3-17.

StataCorp. 2019. Stata Statistical Software: Release 16. College Station, TX: StataCorp LLC. 
Stein, Robert and Greg Vonnahme. 2008. "Engaging the Unengaged Voter: Vote Centers and Voter Turnout". Journal of Politics, 70(2): 487-497.

Stein, Robert M., Charles Stewart III, Christopher Mann, et al. 2019. "Waiting to Vote in the 2016 Presidential Election: Evidence from a Multi-County Study." Political Research Quarterly.

Tate, Katherine. 2003. Black Faces in the Mirror: African Americans and Their Representatives in the U.S. Congress. Princeton, NJ: Princeton University Press.

Texas Politics. 2012. "Historical Barriers to Voting". https://web.archive.org/web/20080402060131/http://texaspolitics.laits.utexas.edu/html/vc e/0503.html

The Election Administration and Voting Survey (https://www.eac.gov/research-anddata/election-administration-voting-survey/). 2012-2016.

The Leadership Conference Education Fund. 2016. "The Great Poll Closure". http://civilrightsdocs.info/pdf/reports/2016/poll-closure-report-web.pdf

The Leadership Conference Education Fund. 2019. "Democracy Diverted". http://civilrightsdocs.info/pdf/reports/Democracy-Diverted.pdf

Thurgood Marshall Institute at LDF. "Democracy Dimenished: State and Local Threats to Voting". https://www.naacpldf.org/wp-content/uploads/Democracy-Diminished-Stateand-Local-Threats-to-Voting-Post-Shelby-County-Alabama-v.-Holder.pdf

Tokaji, D. P. 2009. “The Future of Election Reform: From Rules to Institutions”. Yale Law \& Policy Review, 28, 125-154.

U.S. Census. American Community Survey Data (2009-2013).

U.S. Census. American Community Survey Data (2013-2018).

U.S. Commission on Civil Rights. 2018. "An Assessment of Minority Voting Rights Access in the United States". https://www.usccr.gov/pubs/2018/Minority_Voting_Access_2018.pdf

U.S. Congress. House. 2006. Voting Rights Act Reauthorization Act. $109^{\text {th }}$ Congress. https://www.congress.gov/bill/109th-congress/house-bill/9

Verba, Sidney, Kay Lehman Schlozman and Henry E Brady. 1995. Voice and Equality: Civic Voluntarism in American Politics. Cambridge, MA: Harvard University Press.

Wand, J.N., Shotts, K.W., Sekhon, J.S., Mebane, W.R., Jr., Herron, M.C.,\& Brady, H.E.(2001). "The Butterfly Did It: The Aberrant Vote For Buchanan in Palm Beach County, Florida". American Political Science Review, 95: 793-810.

White, Ariel, Noah Nathan, and Julie Faller. 2015. "What Do I Need to Vote?” Bureaucratic Discretion and Discrimination by Local Election Officials." American Political Science Review, 109(1):1-1 


\section{APPENDIX I - Coding Instructions}

Percentage Change in Voters Per Precinct (PCVPP)

MAJOR COMPONENTS

\section{Citizen Voting Age Population}

I consulted the 5-year American Communities Survey dataset for the citizen voting age population for each jurisdiction in my sample. The citizen voting age population (CVAP) is defined as the population of the United States that is over the age of 18.

\section{Traditional Election Day Polling Places}

To collect data for election day polling places for each jurisdiction, I consulted the Election Administration and Voting Survey (EAVS) by the Election Assistance Commission. The EAC sends this survey out following every midterm and general election to compile data on election administration across the United States. In terms of polling places, they ask each jurisdiction to list the number of election day polling places. However, they create three categories: (1) physical polling places, (2) election offices, and (3) other. Because they ask a separate question for early voting, I decided to use the sum of the three election day categories as my polling place value for each jurisdiction. I did this for 2008, 2012, and 2016 election years.

FORMULA

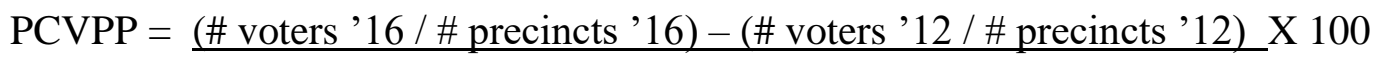

(\# voters '12 / \# precincts '12)

Based on the formula above, to get the PCVPP, I am taking the difference between the voters perprecinct in 2016 and the voters per precinct in 2012 and then dividing it by the voters per precinct in 2012. To get the percent change, I just simply multiplied the change in VPP by 100.

\begin{tabular}{|l|c|c|c|c|c|}
\hline Jurisdiction & CVAP '12 & Precincts '12 & CVAP '16 & Precincts '16 & PCVPP \\
\hline Autauga County, AL & 23,909 & 28 & 24,661 & 17 & $69 \%$ \\
\hline Allen County, IN & 146,505 & 327 & 145,787 & 338 & $-3 \%$ \\
\hline
\end{tabular}

In Autauga County, AL, due to the closings of 11 precincts and the increase in voter population, the jurisdiction had a $69 \%$ increase in voters per precinct in 2016 compared to 2012. In Allen County, IN, due to the openings of 11 precincts and the decrease in voter population, the jurisdiction had a 3\% decrease in voters per precinct in 2016 compared to 2012. 


\section{APPENDIX II - Supplementary Graphs, Figures, \& Tables}

Table A - Breakdown of Each State's Reprecincting Law

\begin{tabular}{|c|c|c|c|c|c|}
\hline State & Code & Authorization & Time Restrictions & $\begin{array}{l}\text { Boundary \& Size } \\
\text { Limitations }\end{array}$ & Regulation \\
\hline Alabama & $17-6-6$ & $\begin{array}{l}\text { County Governing } \\
\text { Authority }\end{array}$ & Not Specified & $\begin{array}{l}\text { Boundaries defined by } \\
\text { Census; No more than } \\
2,400 \text { voters per } \\
\text { precinct. }\end{array}$ & $\begin{array}{l}\text { Legislative } \\
\text { Committee }\end{array}$ \\
\hline Alaska & 15.10 .020 & $\begin{array}{l}\text { Chief Election Officer of } \\
\text { the State }\end{array}$ & $\begin{array}{l}\text { No Later than } 40 \\
\text { days of an election }\end{array}$ & $\begin{array}{l}\text { Boundaries defined by } \\
\text { Census; Not Specified }\end{array}$ & $\begin{array}{l}\text { Not Specified (but } \\
\text { reprecincting is } \\
\text { conducted by the } \\
\text { CEO) }\end{array}$ \\
\hline Arizona & $\begin{array}{l}16.411 \& \\
16.412\end{array}$ & $\begin{array}{l}\text { County Governing } \\
\text { Authority }\end{array}$ & $\begin{array}{l}\text { March 1st of } \\
\text { Election Year }\end{array}$ & Not Specified & Secretary of State \\
\hline Arkansas & $7-5-101$ & Local Election Official & $\begin{array}{l}\text { Less than } 60 \text { days } \\
\text { before election; if } \\
\text { there are more than } \\
3,000 \text { in a precinct, } \\
\text { that change must be } \\
\text { made no less than } \\
120 \text { days before an } \\
\text { election }\end{array}$ & $\begin{array}{l}\text { Boundaries defined by } \\
\text { Census; No more than } \\
3,000 \text { voters per precinct }\end{array}$ & Secretary of State \\
\hline California & $12-260$ & Local Election Official & Not Specified & Not Specified & Not Specified \\
\hline Colorado & $1-5-101$ & Local Election Official & Not Specified & $\begin{array}{l}\text { In counties that use } \\
\text { paper ballots, the county } \\
\text { clerk and recorder, } \\
\text { subject to approval by } \\
\text { the board of county } \\
\text { commissioners, shall } \\
\text { establish at least one } \\
\text { precinct for every six } \\
\text { hundred active eligible } \\
\text { electors, with boundaries } \\
\text { that take into } \\
\text { consideration municipal } \\
\text { and school district } \\
\text { boundary lines whenever } \\
\text { possible. However, the } \\
\text { county clerk and } \\
\text { recorder, subject to } \\
\text { approval by the board of } \\
\text { county commissioners, } \\
\text { may establish one } \\
\text { precinct for every seven } \\
\text { hundred fifty active } \\
\text { eligible electors. }\end{array}$ & $\begin{array}{l}\text { Not Specified } \\
\text { (although needs } \\
\text { approval from the } \\
\text { county governing } \\
\text { body) }\end{array}$ \\
\hline Connecticut & $9-169$ & $\begin{array}{l}\text { Township Governing } \\
\text { Body }\end{array}$ & $\begin{array}{l}\text { Less than } 90 \text { days } \\
\text { before an election }\end{array}$ & $\begin{array}{l}\text { Boundaries defined by } \\
\text { Census; Less than } 200 \\
\text { voters per precinct }\end{array}$ & Not Specified \\
\hline Delaware & $\begin{array}{l}4102,4103, \\
\& 4105\end{array}$ & Local Election Official & $\begin{array}{l}\text { March 1st of } \\
\text { Election Year }\end{array}$ & $\begin{array}{l}\text { Boundaries defined by } \\
\text { Census; minimum of } 500 \\
\text { and maximum of } 3,000 \\
\text { voters }\end{array}$ & $\begin{array}{l}\text { State Election } \\
\text { Commissioner }\end{array}$ \\
\hline
\end{tabular}




\begin{tabular}{|c|c|c|c|c|c|}
\hline $\begin{array}{l}\text { District of } \\
\text { Columbia }\end{array}$ & $1001-05$ & $\begin{array}{l}\text { County Governing Body } \\
\text { \& Local Election } \\
\text { Official }\end{array}$ & Every 5 years & $\begin{array}{l}\text { Boundaries defined by } \\
\text { Census; at least } 350 \\
\text { voters per precinct }\end{array}$ & Not Specified \\
\hline Florida & $100-101$ & $\begin{array}{l}\text { County Governing Body } \\
\text { \& Local Election } \\
\text { Official }\end{array}$ & Not Specified & $\begin{array}{l}\text { Boundaries defined by } \\
\text { Census; Not specified }\end{array}$ & Secretary of State \\
\hline Georgia & $\begin{array}{l}21-2-60 \text { to } \\
21-2-63\end{array}$ & County Governing Body & $\begin{array}{l}\text { less than } 60 \text { days } \\
\text { before an election; } \\
30 \text { days before a } \\
\text { special election }\end{array}$ & $\begin{array}{l}\text { Boundaries defined by } \\
\text { Census; less than } 200 \\
\text { voters \& no more than } \\
2,000 \text { voters }\end{array}$ & Secretary of State \\
\hline Hawaii & $11-0092$ & $\begin{array}{l}\text { Chief Election Officer of } \\
\text { the State }\end{array}$ & $\begin{array}{l}\text { Less than } 90 \text { days } \\
\text { before an election }\end{array}$ & Not Specified & $\begin{array}{l}\text { Not Specified (but } \\
\text { reprecincting is } \\
\text { conducted by the } \\
\text { CEO) }\end{array}$ \\
\hline Idaho & $34-3-01$ & County Governing Body & $\begin{array}{l}\text { No Later than } \\
\text { January 15th of an } \\
\text { election year }\end{array}$ & $\begin{array}{l}\text { No county shall have } \\
\text { less than } 2 \text { precincts }\end{array}$ & Secretary of State \\
\hline Illinois & $11-0003$ & Local Election Official & $\begin{array}{l}\text { Within } 90 \text { days after } \\
\text { an election }\end{array}$ & $\begin{array}{l}\text { Boundaries defined by } \\
\text { Census; No more than } \\
600 \text { actual voters }\end{array}$ & Not Specified \\
\hline Indiana & $3-11-0001$ & County Governing Body & Not Specified & $\begin{array}{l}\text { Boundaries defined by } \\
\text { Census; No more than } \\
2,300 \text { voters }\end{array}$ & Not Specified \\
\hline Iowa & $\begin{array}{l}49-3,49-7 \\
\&, 49-8\end{array}$ & County Governing Body & $\begin{array}{l}\text { If done following } \\
\text { the census, less than } \\
90 \text { days or October } \\
15 \text { th of the } \\
\text { following year; If } \\
\text { done in the years not } \\
\text { following census, } \\
\text { than } 99 \text { days before } \\
\text { an election }\end{array}$ & $\begin{array}{l}\text { Boundaries defined by } \\
\text { Census; No more than } \\
3,500 \text { voters }\end{array}$ & $\begin{array}{l}\text { State Election } \\
\text { Commissioner }\end{array}$ \\
\hline Kansas & $\begin{array}{l}26-A-01 \text { to } \\
26-A-05\end{array}$ & Local Election Official & $\begin{array}{l}\text { No later than four } \\
\text { months prior to } \\
\text { Primary Election } \\
\text { and the succeeding } \\
\text { General Election }\end{array}$ & $\begin{array}{l}\text { Boundaries defined by } \\
\text { Census; Not Specified }\end{array}$ & Secretary of State \\
\hline Kentucky & $\begin{array}{l}117.0551, \\
117.0552, \& \\
117.0553\end{array}$ & Local Election Official & Not Specified & $\begin{array}{l}\text { Boundaries defined by } \\
\text { Census; Not Specified }\end{array}$ & $\begin{array}{l}\text { State Board of } \\
\text { Elections }\end{array}$ \\
\hline Louisiana & $532 \& 532.1$ & $\begin{array}{l}\text { Parish Governing } \\
\text { Authority }\end{array}$ & $\begin{array}{l}\text { No later than } \\
\text { December thirty- } \\
\text { first of any year of } \\
\text { which the last digit } \\
\text { is nine and January } \\
\text { first of any year of } \\
\text { which the last digit } \\
\text { is three }\end{array}$ & $\begin{array}{l}\text { Boundaries defined by } \\
\text { Census; No more than } \\
2,200 \text { voters and no less } \\
\text { than } 300 \text { voters }\end{array}$ & Secretary of State \\
\hline Maine & 631 & $\begin{array}{l}\text { Municipal Governing } \\
\text { Authority }\end{array}$ & $\begin{array}{l}\text { At least } 90 \text { days } \\
\text { before an election }\end{array}$ & Not Specified & Secretary of State \\
\hline Maryland & $2-303$ & County Governing Body & $\begin{array}{l}\text { At least } 13 \text { weeks } \\
\text { prior to the primary } \\
\text { election }\end{array}$ & $\begin{array}{l}\text { Boundaries defined by } \\
\text { Census; Not Specified }\end{array}$ & $\begin{array}{l}\text { State Election } \\
\text { Board }\end{array}$ \\
\hline
\end{tabular}




\begin{tabular}{|c|c|c|c|c|c|}
\hline Massachusetts & $54-6$ & $\begin{array}{l}\text { Township Governing } \\
\text { Body }\end{array}$ & $\begin{array}{l}\text { No later than the } \\
\text { June } 15 \text { th following } \\
\text { a census year }\end{array}$ & $\begin{array}{l}\text { Boundaries defined by } \\
\text { Census; No more than } \\
4,000 \text { voters }\end{array}$ & Secretary of State \\
\hline Michigan & 168.658 & Local Election Official & $\begin{array}{l}\text { No later than } 60 \\
\text { days before a } \\
\text { primary or general } \\
\text { election }\end{array}$ & $\begin{array}{l}\text { Boundaries defined by } \\
\text { Census; No more than } \\
5,000 \text { active voters }\end{array}$ & Not Specified \\
\hline Minnesota & 204B.14. & County Governing Body & $\begin{array}{l}\text { At least } 10 \text { weeks } \\
\text { before the date of } \\
\text { the next election }\end{array}$ & $\begin{array}{l}\text { Boundaries defined by } \\
\text { Census; Not Specified }\end{array}$ & Secretary of State \\
\hline Mississippi & $23-15-283$ & County Governing Body & $\begin{array}{l}\text { No later than the last } \\
\text { day of September of } \\
\text { the year ending in } \\
\text { eight }\end{array}$ & $\begin{array}{l}\text { Boundaries defined by } \\
\text { Census; not specified }\end{array}$ & Secretary of State \\
\hline Missouri & 115.113 & Local Election Official & Not Specified & $\begin{array}{l}\text { Boundaries defined by } \\
\text { Census; not specified }\end{array}$ & Not Specified \\
\hline Montana & $13-3-102$ & County Governing Body & $\begin{array}{l}\text { Not within } 100 \text { days } \\
\text { before any primary } \\
\text { or between a general } \\
\text { and the primary for } \\
\text { that election }\end{array}$ & $\begin{array}{l}\text { Boundaries defined by } \\
\text { Census; not specified }\end{array}$ & $\begin{array}{l}\text { State Election } \\
\text { Official }\end{array}$ \\
\hline Nebraska & $32-903$ & Local Election Official & Not Specified & $\begin{array}{l}\text { Boundaries defined by } \\
\text { Census; Not less than } 75 \\
\text { nor more than } 1,750 \\
\text { registered voters }\end{array}$ & Not Specified \\
\hline Nevada & 293.205 & Local Election Official & $\begin{array}{l}\text { No later than the } \\
\text { third Wednesday in } \\
\text { March of every } \\
\text { even-numbered year }\end{array}$ & $\begin{array}{l}\text { Boundaries defined by } \\
\text { the Census; Not } \\
\text { Specified }\end{array}$ & Not Specified \\
\hline New Hampshire & $662 \mathrm{~A}-4$ & Local Election Official & Not Specified & $\begin{array}{l}\text { Boundaries defined by } \\
\text { the Census; Not } \\
\text { Specified }\end{array}$ & Secretary of State \\
\hline New Jersey & $19: 4-3$ & County Governing Body & $\begin{array}{l}\text { No later than } 75 \\
\text { days before the } \\
\text { primary for the } \\
\text { general election }\end{array}$ & $\begin{array}{l}\text { Boundaries defined by } \\
\text { the Census; No more } \\
\text { than } 750 \text { and no less than } \\
250 \text { registered voters }\end{array}$ & Secretary of State \\
\hline New Mexico & 1.3 .5 & County Governing Body & $\begin{array}{l}\text { No later than } 4 \\
\text { months prior to a } \\
\text { statewide election }\end{array}$ & $\begin{array}{l}\text { Boundaries defined by } \\
\text { the Census; No more } \\
\text { than } 750 \text { voters and less } \\
\text { than } 100 \text { voters in last } \\
\text { general election }\end{array}$ & Secretary of State \\
\hline New York & $4-100$ & Local Election Official & $\begin{array}{l}\text { No later than } \\
\text { February 15th of a } \\
\text { calendar year }\end{array}$ & $\begin{array}{l}\text { Boundaries defined by } \\
\text { the Census; No more } \\
\text { than } 950 \text { (or with special } \\
\text { permission } 1150 \text { ) }\end{array}$ & $\begin{array}{l}\text { State Board of } \\
\text { Elections }\end{array}$ \\
\hline North Carolina & $163 \mathrm{~A}-1045$ & Local Election Official & $\begin{array}{l}\text { No later than } 45 \\
\text { days prior to } \\
\text { primary election }\end{array}$ & $\begin{array}{l}\text { Boundaries defined by } \\
\text { the Census }\end{array}$ & $\begin{array}{l}\text { State Board of } \\
\text { Elections }\end{array}$ \\
\hline
\end{tabular}




\begin{tabular}{|c|c|c|c|c|c|}
\hline North Dakota & $16.1-04-01$ & County Governing Body & $\begin{array}{l}\text { No later than } \\
\text { December thirty- } \\
\text { first of the year } \\
\text { immediately } \\
\text { preceding an } \\
\text { election and not later } \\
\text { than } 70 \text { days before } \\
\text { a special election }\end{array}$ & $\begin{array}{l}\text { Boundaries defined by } \\
\text { the Census; Not } \\
\text { Specified }\end{array}$ & Not Specified \\
\hline Ohio & $2.1 .04 \mathrm{~B}$ & Local Election Official & $\begin{array}{l}\text { No later than } 25 \\
\text { days before the } \\
\text { primary or general } \\
\text { election }\end{array}$ & $\begin{array}{l}\text { Boundaries defined by } \\
\text { the census; No more } \\
\text { than } 1,400 \text { registered } \\
\text { voters }\end{array}$ & Secretary of State \\
\hline Oklahoma & $\begin{array}{l}3-115,3-116, \\
\& 3-118\end{array}$ & Local Election Official & $\begin{array}{l}\text { Not permitted } \\
\text { between January } 1 \\
\text { of any year which } \\
\text { last digit is nine and } \\
\text { December } 31 \text { of any } \\
\text { year which last digit } \\
\text { is zero. }\end{array}$ & $\begin{array}{l}\text { Boundaries defined by } \\
\text { the Census; Not } \\
\text { Specified }\end{array}$ & $\begin{array}{l}\text { State Board of } \\
\text { Elections }\end{array}$ \\
\hline Oregon & 545.171 & $\begin{array}{l}\text { County Board of } \\
\text { Directors }\end{array}$ & Not Specified & Not Specified & Not Specified \\
\hline Pennsylvania & $\begin{array}{l}5.501,5.502, \\
\& 5.506\end{array}$ & County Governing Body & Not Specified & $\begin{array}{l}\text { Boundaries defined by } \\
\text { the Census; No more } \\
\text { than } 1,200 \text { and no less } \\
\text { than } 100 \text { registered } \\
\text { voters }\end{array}$ & Not Specified \\
\hline Rhode Island & $17-11-01$ & County Governing Body & $\begin{array}{l}\text { No later than the } \\
60 \text { th day preceding } \\
\text { an election }\end{array}$ & $\begin{array}{l}\text { Boundaries defined by } \\
\text { the Census; No more } \\
\text { than } 3,000 \text { and no less } \\
\text { than } 500 \text { voters }\end{array}$ & $\begin{array}{l}\text { State Board of } \\
\text { Elections }\end{array}$ \\
\hline South Carolina & $7-7-710$ & $\begin{array}{l}\text { Local Election Official } \\
\text { \& County Governing } \\
\text { Body }\end{array}$ & Not Specified & $\begin{array}{l}\text { Not Specified; No more } \\
\text { than } 750 \text { voters per } \\
\text { precinct }\end{array}$ & $\begin{array}{l}\text { State Election } \\
\text { Commission }\end{array}$ \\
\hline South Dakota & $\begin{array}{l}12-14-1 \& \\
12-14-4\end{array}$ & County Governing Body & Not Specified & Not Specified & Not Specified \\
\hline Tennessee & $\begin{array}{l}2-3-102,2-3- \\
103, \& 2-3- \\
104\end{array}$ & Local Election Official & Not Specified & $\begin{array}{l}\text { Boundaries defined by } \\
\text { Census; No more than } \\
6,000 \text { registered voters }\end{array}$ & $\begin{array}{l}\text { Local Governing } \\
\text { Authority }\end{array}$ \\
\hline Texas & $\begin{array}{l}\text { 4-42-01 to 4- } \\
42-010\end{array}$ & County Governing Body & $\begin{array}{l}\text { No later than May } \\
1 \text { st of an even } \\
\text { numbered year }\end{array}$ & $\begin{array}{l}\text { Boundaries defined by } \\
\text { Census; No more than } \\
5,000 \text { and no less than } \\
100 \text { registered voters }\end{array}$ & Secretary of State \\
\hline Utah & $20 a-5-303$ & County Governing Body & $\begin{array}{l}\text { No later than } \\
\text { January } 1 \text { of a } \\
\text { general election year }\end{array}$ & $\begin{array}{l}\text { Boundaries defined by } \\
\text { Census; No more than } \\
1,250 \text { registered voters }\end{array}$ & Not Specified \\
\hline Vermont & 2501 & County Governing Body & $\begin{array}{l}\text { No later than } 40 \\
\text { days before an } \\
\text { election }\end{array}$ & Not Specified & Not Specified \\
\hline Virginia & $\begin{array}{l}24.2-305 \& \text { \& } \\
24.2-307\end{array}$ & County Governing Body & $\begin{array}{l}\text { No later than } 60 \\
\text { days before the } \\
\text { general election }\end{array}$ & $\begin{array}{l}\text { Boundaries defined by } \\
\text { Census; No more than } \\
5,000 \text { and no less than } \\
100 \text { (for counties) and } \\
500 \text { (for cities) registered } \\
\text { voters }\end{array}$ & $\begin{array}{l}\text { State Board of } \\
\text { Elections }\end{array}$ \\
\hline Washington & 29A.16.040 & County Governing Body & no precinct changes & $\begin{array}{l}\text { The number may be less } \\
\text { than the number }\end{array}$ & N/A \\
\hline
\end{tabular}




\begin{tabular}{|c|c|c|c|c|c|}
\hline & & & $\begin{array}{l}\text { may be made during } \\
\text { the period starting } \\
\text { fourteen days prior } \\
\text { to } \\
\text { the first day for } \\
\text { candidates to file for } \\
\text { the primary election } \\
\text { and } \\
\text { ending with the day } \\
\text { of the general } \\
\text { election }\end{array}$ & $\begin{array}{l}\text { established by law, but } \\
\text { in no case may the } \\
\text { number exceed one } \\
\text { thousand five hundred } \\
\text { active registered voters }\end{array}$ & \\
\hline West Virginia & $\begin{array}{l}3-1-5 \& 3-1- \\
7\end{array}$ & County Governing Body & $\begin{array}{l}\text { No later than } 90 \\
\text { days before an } \\
\text { election }\end{array}$ & $\begin{array}{l}\text { Boundaries defined by } \\
\text { Census; Any urban } \\
\text { precinct shall contain not } \\
\text { less than three hundred } \\
\text { nor more than one } \\
\text { thousand five hundred } \\
\text { registered voters. Any } \\
\text { rural or less thickly } \\
\text { settled area shall contain } \\
\text { not less than two } \\
\text { hundred nor more than } \\
\text { seven hundred registered } \\
\text { voters. }\end{array}$ & Secretary of State \\
\hline Wisconsin & $5.15-01$ & $\begin{array}{l}\text { Township Governing } \\
\text { Authority }\end{array}$ & $\begin{array}{l}\text { No later than April } \\
\text { 1st following a } \\
\text { Census year }\end{array}$ & $\begin{array}{l}\text { Boundaries defined by } \\
\text { census }\end{array}$ & Not Specified \\
\hline Wyoming & $\begin{array}{l}22-7-101 \text { to } \\
22-7-105\end{array}$ & County Governing Body & $\begin{array}{l}\text { No later than May of } \\
\text { an election year }\end{array}$ & $\begin{array}{l}\text { Not Specified; No more } \\
\text { than } 30 \text { precincts in the } \\
\text { whole state }\end{array}$ & Secretary of State \\
\hline
\end{tabular}




\begin{tabular}{|l|r|r|r|r|r|}
\hline \multicolumn{7}{|l|}{ Table B. Small-N Sample Statistics: Georgia Counties } \\
\hline $\begin{array}{l}\text { Top 9 Largest } \\
\begin{array}{l}\text { White Populations } \\
\text { in GA }\end{array}\end{array}$ & \% White & PCVPP & $\begin{array}{l}\text { Election } \\
\text { Budget '12 }\end{array}$ & $\begin{array}{l}\text { Election } \\
\text { Budget '16 }\end{array}$ & $\begin{array}{l}\text { ludget } \\
\text { Difference }\end{array}$ \\
\hline Towns County & 0.94623 & $7 \%$ & 75,000 & 96,000 & $28 \%$ \\
\hline Dade County & 0.94089 & $18 \%$ & 123,600 & 186,200 & $51 \%$ \\
\hline Union County & 0.940857 & $5 \%$ & 158,240 & 155,774 & $-2 \%$ \\
\hline Pickens County & 0.937394 & $4 \%$ & 265,288 & 337,269 & $27 \%$ \\
\hline Dawson County & 0.925976 & $5 \%$ & 236,504 & 266,279 & $13 \%$ \\
\hline White County & 0.925316 & $4 \%$ & 50,593 & 34,064 & $-33 \%$ \\
\hline Haralson County & 0.913077 & $1 \%$ & 55,000 & 126,717 & $130 \%$ \\
\hline Walker County & 0.911679 & $1 \%$ & 304,104 & 403,580 & $33 \%$ \\
\hline Lumpkin County & 0.908133 & $100 \%$ & 181,075 & 192,069 & $6 \%$ \\
\hline
\end{tabular}

\begin{tabular}{|l|r|r|r|r|r|}
\hline $\begin{array}{l}\text { Top 9 Largest } \\
\text { Black Populations } \\
\text { in GA }\end{array}$ & \% Black & \multicolumn{1}{|c|}{ PCVPP } & $\begin{array}{l}\text { Election } \\
\text { Budget '12 }\end{array}$ & $\begin{array}{l}\text { Election } \\
\text { Budget '16 }\end{array}$ & $\begin{array}{l}\text { Budget } \\
\text { Difference }\end{array}$ \\
\hline Dougherty County & 0.70752 & $-2 \%$ & 363,170 & 369,385 & $2 \%$ \\
\hline Calhoun County & 0.626356 & $0 \%$ & 35,000 & 34,905 & $0 \%$ \\
\hline Randolph County & 0.621803 & $4 \%$ & 82,578 & 106,945 & $30 \%$ \\
\hline Clay County & 0.611647 & $100 \%$ & 31,646 & 35,095 & $11 \%$ \\
\hline Terrell County & 0.611443 & $-2 \%$ & 90,000 & 100,503 & $12 \%$ \\
\hline Macon County & 0.609883 & $0 \%$ & 75,719 & 93,756 & $24 \%$ \\
\hline Taliaferro County & 0.58473 & $15 \%$ & 45,867 & 51,665 & $13 \%$ \\
\hline Richmond County & 0.582137 & $80 \%$ & 549,750 & 499,860 & $-9 \%$ \\
\hline Bibb County & 0.559438 & $32 \%$ & 758,000 & 845,700 & $12 \%$ \\
\hline
\end{tabular}




\begin{tabular}{|c|c|c|c|}
\hline \multicolumn{4}{|c|}{ Table C. Regression Results: VPP on County Turnout in $2008,2012, \& 201$} \\
\hline & 2008 & 2012 & 2016 \\
\hline$\underline{\mathrm{VPP}}$ & $\frac{-0.001^{* * *}}{(0.001)}$ & $\frac{-0.001^{* * *}}{(0.001)}$ & $\frac{-0.001^{* * *}}{(0.001)}$ \\
\hline$\%$ Black & $\underline{0.003}$ & $\begin{array}{l}0.014 \\
(0.063)\end{array}$ & $\frac{-0.011}{(0.018)}$ \\
\hline \% Black x Prec. & $\frac{0.137^{*}}{(0.057)}$ & $\underline{0.184^{* * *}}$ & $\underline{0.094}$ \\
\hline \% Hispanic & $\frac{-0.254^{* * * * *}}{(0.045)}$ & $\frac{-0.297^{* * * *}}{(0.043)}$ & $\frac{-0.300^{* * * * *}}{(0.021)}$ \\
\hline \% Hisp. x Prec. & $\frac{0.107}{(0.064)}$ & $\underline{0.173^{*}}$ & $\frac{0.203^{* * * *}}{(0.046)}$ \\
\hline Preclearance & $\frac{-2.238}{(1.733)}$ & $\frac{-3.015}{(1.611)}$ & $\frac{-1.127}{(1.481)}$ \\
\hline$\% 65$ or Older & $\frac{0.690^{* * * *}}{(0.076)}$ & $\frac{0.841^{\text {**** }}}{(0.088)}$ & $\frac{0.808^{* * * * *}}{(0.083)}$ \\
\hline Pop. Density & $\frac{-1.433^{* * * *}}{(0.254)}$ & $\frac{-1.279^{* * * * *}}{(0.347)}$ & $\frac{-0.934^{* * *}}{(0.313)}$ \\
\hline Median Income & $\frac{0.310^{* * * *}}{(0.049)}$ & $\frac{0.347^{* * * *}}{(0.055)}$ & $\frac{0.328^{* * * * *}}{(0.049)}$ \\
\hline$\%$ Bachelors & $\frac{0.599^{* * * * *}}{(0.059)}$ & $\frac{0.508^{* * * * * *}}{(0.061)}$ & $\frac{0.397^{\text {******* }}}{(0.069)}$ \\
\hline \% GOP Support & $\frac{-0.062}{(0.032)}$ & $\frac{-0.049}{(0.045)}$ & $\frac{-0.017}{(0.410)}$ \\
\hline In-Person Early & $\frac{-3.650}{(1.835)}$ & $\frac{-4.893}{(2.786)}$ & $\frac{-3.834}{(2.111)}$ \\
\hline No-Exc. Absent & $\underline{1.791}$ & $\frac{3.598}{(2.163)}$ & $\frac{4.095^{*}}{(1.877)}$ \\
\hline Strict ID & $\frac{-0.819}{(2.483)}$ & $\frac{-1.038}{(1.714)}$ & $\frac{-2.211}{(1.456)}$ \\
\hline Voting Centers & $\frac{-1.237}{(1.163)}$ & $\frac{-0.276}{(1.796)}$ & $\frac{-0.444}{(1.473)}$ \\
\hline Constant & $\frac{32.873^{* * * *}}{(3.497)}$ & $\frac{26.986^{* * * *}}{(3.555)}$ & $\frac{26.919^{* * * * *}}{(3.198)}$ \\
\hline$\underline{N}$ & 2274 & 2270 & 2270 \\
\hline
\end{tabular}




\begin{tabular}{|c|c|c|c|c|}
\hline & $2008-12$ & $2008-12$ & $2012-16$ & $2012-16$ \\
\hline & Non-Preclearance & Preclearance & Non-Preclearance & Preclearance \\
\hline PCVPP & $\begin{array}{l}-0.005 \\
(0.002) \\
\end{array}$ & $\begin{array}{c}-0.001 \\
(0.001) \\
\end{array}$ & $\begin{array}{c}-0.002 \\
(0.002) \\
\end{array}$ & $\begin{array}{c}-0.002 \\
(0.001) \\
\end{array}$ \\
\hline$\%$ Black & $\begin{array}{l}0.021^{*} \\
(0.009) \\
\end{array}$ & $\begin{array}{c}0.034 \\
(0.018) \\
\end{array}$ & $\begin{array}{l}-0.054^{* * *} \\
(0.009)\end{array}$ & $\begin{array}{l}-0.143^{* * * *} \\
(0.024)\end{array}$ \\
\hline \% Hispanic & $\begin{array}{c}-0.017^{*} \\
(0.00760) \\
\end{array}$ & $\begin{array}{c}-0.010 \\
(0.0159) \\
\end{array}$ & $\begin{array}{c}0.002 \\
(0.009) \\
\end{array}$ & $\begin{array}{l}-0.011 \\
(0.019) \\
\end{array}$ \\
\hline$\%$ Old & $\begin{array}{c}0.136^{* * * *} \\
(0.019)\end{array}$ & $\begin{array}{l}0.145^{* * *} \\
(0.032) \\
\end{array}$ & $\begin{array}{l}0.063^{* *} \\
(0.019) \\
\end{array}$ & $\begin{array}{c}0.050 \\
(0.040) \\
\end{array}$ \\
\hline Pop. Density & $\begin{array}{c}0.001 \\
(0.001)\end{array}$ & $\begin{array}{l}-0.001 \\
(0.001)\end{array}$ & $\begin{array}{l}0.001^{* * *} \\
(0.001)\end{array}$ & $\begin{array}{l}0.001^{*} \\
(0.001)\end{array}$ \\
\hline Median Inc. & $\begin{array}{c}0.001 \\
(0.001)\end{array}$ & $\begin{array}{c}0.001 \\
(0.001)\end{array}$ & $\begin{array}{c}0.001 \\
(0.001) \\
\end{array}$ & $\begin{array}{c}0.001 \\
(0.001) \\
\end{array}$ \\
\hline$\%$ Bachelors & $\begin{array}{l}-0.039 \\
(0.021) \\
\end{array}$ & $\begin{array}{l}-0.010^{*} \\
(0.040)\end{array}$ & $\begin{array}{c}-0.072^{* * * *} \\
(0.020)\end{array}$ & $\begin{array}{c}0.032 \\
(0.051)\end{array}$ \\
\hline$\%$ GOP & $\begin{array}{l}0.027^{* * *} \\
(0.008)\end{array}$ & $\begin{array}{l}-0.020 \\
(0.019)\end{array}$ & $\begin{array}{c}0.012 \\
(0.008)\end{array}$ & $\begin{array}{l}-0.027 \\
(0.025)\end{array}$ \\
\hline$\Delta$ Early & $\begin{array}{l}-0.821 \\
(0.399)\end{array}$ & $\begin{array}{l}-0.102 \\
(0.301)\end{array}$ & $\begin{array}{l}-0.423 \\
(0.532) \\
\end{array}$ & ------- \\
\hline$\Delta$ No-Exc. Abs. & $\begin{array}{c}0.122 \\
(0.322)\end{array}$ & ------- & $\begin{array}{l}-1.782^{* *} \\
(0.587)\end{array}$ & ------- \\
\hline$\Delta$ Strict ID & $\begin{array}{c}-1.462^{* * *} \\
(0.112) \\
\end{array}$ & $\begin{array}{l}1.567^{*} \\
(0.822) \\
\end{array}$ & $\begin{array}{l}-2.322^{* * *} \\
(0.522)\end{array}$ & $\begin{array}{l}-0.876^{* *} \\
(0.322) \\
\end{array}$ \\
\hline$\Delta$ Vote Cent. & $\begin{array}{l}-2.645^{* * *} \\
(0.401) \\
\end{array}$ & $\begin{array}{l}-0.986^{*} \\
(0.432) \\
\end{array}$ & $\begin{array}{l}-0.987^{*} \\
(0.511) \\
\end{array}$ & ------- \\
\hline Constant & $\begin{array}{c}-0.080^{* * * *} \\
(0.010)\end{array}$ & $\begin{array}{l}-0.033 \\
(0.022) \\
\end{array}$ & $\begin{array}{c}0.006 \\
(0.011) \\
\end{array}$ & $\begin{array}{c}0.058 \\
(0.030) \\
\end{array}$ \\
\hline$N$ & 1656 & 606 & 1656 & 606 \\
\hline$R^{2}$ & 0.118 & 0.225 & 0.444 & 0.362 \\
\hline
\end{tabular}

